\author{
UNIVERSIDADE DE SÃO PAULO - USP \\ FACULDADE DE MEDICINA DE RIBEIRÃO PRETO - FMRP \\ PROGRAMA DE PÓS-GRADUAÇÃO \\ EM IMUNOLOGIA BÁSICA E APLICADA
}

ANNIE ROCIO PIÑEROS ALVAREZ

Avaliação dos mecanismos imunológicos envolvidos na proteção contra tuberculose no modelo de coinflamação tuberculose-alergia

Versão corrigida

Ribeirão Preto

2013 
ANNIE ROCIO PINEROS ALVAREZ

\section{Avaliação dos mecanismos imunológicos envolvidos na proteção contra tuberculose no modelo de coinflamação tuberculose-alergia}

Dissertação apresentada à Faculdade de Medicina de Ribeirão Preto da Universidade de São Paulo para obtenção do Título de Mestre em Ciências, área de Concentração: Imunologia Básica e Aplicada.

Orientadora: Prof ${ }^{\mathrm{a}}$. Dr ${ }^{\mathrm{a}}$. Vânia Luiza Deperon Bonato

Ribeirão Preto 
Autorizo a reprodução e divulgação total ou parcial deste trabalho, por qualquer meio convencional ou eletrônico, para fins de estudo e pesquisa, desde que citada a fonte.

Annie Rocio Piñeros Alvarez

\section{FICHA CATALOGRÁFICA}

Piñeros, Annie Rocio.

Avaliação dos mecanismos imunológicos envolvidos na proteção contra tuberculose no modelo de coinflamação tuberculose-alergia / Annie Rocio Piñeros Alvarez; orientadora Vânia Luiza Deperon Bonato. - São Paulo, 2013.107 f.: il.

Tese (Mestrado) - Faculdade de Medicina de Ribeirão Preto/Universidade de São Paulo. Área de concentração Imunologia Básica e Aplicada. 2013

1. Tuberculose. 2. Alergia. 3. Coinflamação. 4. Linfócitos $C D 8^{+}$. 5. Macrófagos M1 e M2. 6. Leucotrienos. 


\section{APOIO E SUPORTE FINANCIERO}

Este trabalho foi realizado no Laboratório de Modulação da Resposta Imune, localizado no Departamento de Bioquímica e Imunologia da Faculdade de Medicina de Ribeirão Preto da Universidade de São Paulo com o apoio financeiro das seguintes agências de fomento e instituições:

1. Fundação de Amparo à Pesquisa do Estado de São Paulo (FAPESP)

2. Coordenação de Aperfeiçoamento de Pessoal de Nível Superior (CAPES)

3. Fundação de Apoio ao Ensino, Pesquisa e Assistência do Hospital das Clinicas da Faculdade de Medicina de Ribeirão Preto (FAEPA).

4. Faculdade de Medicina de Ribeirão Preto 
Dedicatoria..

A Deus pelas oportunidades que me brinda, por me cuidar e me ajudar a alcançar os objetivos almejados.

Aos meus pais, Juan Ignácio Piñeros e Ana Isabel Alvarez, a quem devo tudo o que eu sou, por me apojar, pelo amor e a entrega incondicional.

Aos meus sobrinhos, pela ternura e o amor que me inspiram cada dia.

Aos meus irmãos pela confiança, o carinho e pelo exemplo de honestidade e dedicação.

E a todas as pessoas que fizeram parte deste meu caminho, dedico este trabalho... 


\section{Agradecimentos}

Gostaria agradecer a minha orientadora $\operatorname{Prof}^{\mathrm{a}}$ Dr $^{\mathrm{a}}$ Vânia Luiza Deperon Bonato por abrir as portas de seu laboratório, por me ensinar com paciência, por seus conselhos, sua supervisão e por me permitir crescer no seu laboratório e contribuir em minha formação profissional durante dois excelentes anos.

Ao Prof. Dr. João Santana da Silva pela oportunidade e pela confiança brindada.

Aos professores membros da banca avaliadora da dissertação pela disponibilidade e sugestões.

A meu colega de laboratório Rafael de Queiroz Prado por sua paciência, sua dedicação, pelas aulas de português, pelas discussões que contribuíram no meu trabalho e na minha formação profissional, e pelo carinho e a amizade oferecida.

A Thaís Bertolini e a Ana Flávia Gembre pelo auxílio em todos os experimentos realizados e pelo entusiasmo com que sempre me ajudaram. E principalmente pela sua amizade, confiança e carinho.

A Dr ${ }^{\mathrm{a}}$ Denise Morais da Fonseca pelos aportes e discussões científicas que fizeram possível a realização deste trabalho.

A meus colegas de laboratório, Marinaldo Pacífico Neto, Cássia Alves e Alexandre Ignácio Souza porque colaboraram em diversas atividades durante o desenvolvimento de meu trabalho. E pela amizade e o carinho brindado.

A Wendy Rios, José Seminate, Izaira T. Brandão, e Ana Paula Massom pelo apoio técnico e principalmente pela amizade.

Aos colegas do laboratório da Prof ${ }^{\mathrm{a}}$ Arlete, Everton Padilha, Thiago Malardo e Isabela Cardoso pelo auxilio recebido, pelo companheirismo e amizade.

À Prof ${ }^{a}$ Dr $^{\text {a }}$ Lucia Helena Faciolli pelo fornecimento da droga MK-886. Aos colegas do laboratório da Dr $^{\mathrm{a}}$ Lucia Faciolli por todo o auxilio recebido. Ao Dr. Carlos Sorgi pelo apoio técnico na técnica de tetróxido de ósmio. 
À Prof ${ }^{\mathrm{a}}$ Dr $^{\mathrm{a}}$ Simone Gusmão Ramos pelo auxílio com a análise histopatológica. À técnica Elaine Medeiros Floriano pela preparação das lâminas histológicas.

Aos secretários Ana Cristine S. Ferreira e Ronaldo S. Campanini pelo auxilio e atenção ao nosso programa de pós-graduação.

A Faculdade de Medicina de Ribeirão Preto (FMRP) pela infraestrutura utilizada.

Aos funcionários Júlio Anselmo Siqueira, Dener Salviano dos Reis e a Cristina do Centro de Criação de Camundongos Especiais e do Biotério de Animais Isogênicos da Faculdade de Medicina de Ribeirão Preto pela disponibilização de animais.

À FAPESP, FAEPA e CAPES pelo auxilio financeiro.

"Zema mente que se abre para uma nova ideia, jamais retornará ao seu tamanho original".

Albert Einstein 
Epigrafe

"A busca da verdade e da beleza é uma esfera de atividade em que nos é permitido permanecer criangas para toda a vida"

Albert Q Einstein 


\section{RESUMO}

PINEROS, A. R. Avaliação dos mecanismos imunológicos envolvidos na proteção contra tuberculose no modelo de coinflamação tuberculose-alergia. 2013, 107F. Dissertação (Mestrado) - Faculdade de Medicina de Ribeirão Preto, Universidade de São Paulo, Ribeirão Preto, 2013.

Utilizando modelo de coinflamação tuberculose e alergia (TB/OVA), nosso grupo mostrou que camundongos BALB/c coinflamados apresentaram diminuição significativa no número de bacilos, associada com diminuição no infiltrado granulomatoso no pulmão, aumento na produção de leucotrieno $\mathrm{B}_{4}$ e no número de células $\mathrm{CD}^{+}$, quando comparados ao grupo infectado com Mycobacterium tuberculosis (TB). No presente estudo, nosso objetivo foi avaliar os mecanismos envolvidos na restrição ao crescimento dos bacilos nos animais do grupo TB/OVA. Quatro estratégias foram usadas: I) Para avaliar o papel dos linfócitos $\mathrm{CD}^{+}$no modelo TB/OVA, foram utilizados camundongos deficientes para a molécula CD8 (CD8KO). Foi observado que não houve diferenças significativas no crescimento do bacilo no pulmão dos animais CD8KO-TB/OVA e WT-TB/OVA. No entanto, nos pulmões dos animais WT-TB/OVA houve maior crescimento de bacilos em relação aos animais WT-TB, diferente do previamente observado com os animais TB/OVA da linhagem BALB/c. Para avaliar o papel dos leucotrienos foram usadas as seguintes estratégias: II). Camundongos da linhagem $129 \mathrm{~Sv}$ tratados com MK886, inibidor da enzima 5-lipoxigenase (5LO), envolvida na síntese de mediadores lipídicos; III) animais $129 \mathrm{~Sv}$, deficientes para a expressão da 5LO (5LOKO). Foi observado que o tratamento com MK886 não afetou o número de bacilos no pulmão do grupo coinflamado TB/OVA quando comparado ao grupo TB/OVA. Além disso, diferente do que foi previamente observado em animais BALB/c, os animais $129 \mathrm{~Sv}$ coinflamados foram mais susceptíveis que os animais $129 \mathrm{~Sv}$ infectados. Do contrário, animais 5LOKO-TB/OVA foram mais resistentes que os camundongos WT-TB/OVA.

Para avaliar se alterações no infiltrado granulomatoso estavam relacionadas com o infiltrado de macrófagos no pulmão, usamos a quarta estratégia: IV) quantificação das populações de macrófagos M1 e M2. Foi observado que os animais TB/OVA apresentaram aumento da população de macrófagos M2 no pulmão, enquanto a população de macrófagos M1 manteve-se inalterada comparado-se ao grupo apenas infectado. A diminuição no crescimento de bacilos nos animais TB/OVA foi dependente dos macrófagos M2, pois animais deficientes para a expressão do receptor de IL-33 submetidos ao protocolo de coinflamação tiveram diminuição da população de macrófagos M2, e foram susceptíveis à infecção. Esses resultados mostram que a diminuição no crescimento de bacilos nos animais coinflamados TB/OVA é dependente do aumento da população de macrófagos M2. 


\begin{abstract}
PINEROS, A. R. Evaluating of immunologic mechanisms involved in protection against tuberculosis in coinfected model tuberculosis - allergy. 2013, $107 \mathrm{~F}$. Dissertation (Master) - Faculdade de Medicina de Ribeirão Preto, Universidade de São Paulo, Ribeirão Preto, 2013.
\end{abstract}

Using model of coinfection allergy and tuberculosis (TB / OVA), our group showed that coinfected BALB/c showed a significant decrease in the number of bacilli, associated with a decrease in granulomatous infiltrate the lung, increased production of leukotriene $\mathrm{B}_{4}$ and the number of cells $\mathrm{CD}^{+}$, compared to the group infected with Mycobacterium tuberculosis (TB). To evaluate the mechanisms involved in reducing the growth of bacilli in group TB/OVA, were used four strategies: I) To assess the role of $\mathrm{CD}^{+}$ lymphocytes in model TB/OVA, we used mice deficient for the molecule CD8 (CD8KO).We was observed that the number of bacilli in the lungs of animals in the group CD8KO-TB/OVA and WT-TB/OVA was similar. However, the lungs of animals WT-TB/OVA growth of bacillus was higher compared to WT animals, TB, unlike what was previously observed with background genetic BALB/c. To evaluate the role of leukotrienes, we use the following strategies: II) strain 129Sv mice treated with MK886, an inhibitor of the enzyme 5-lipoxygenase (5LO), involved in the synthesis of lipid mediators, III) $129 \mathrm{~Sv}$ animals deficient for the expression of $5 \mathrm{LO}$ (5LOKO). We observed that treatment with MK886 did not affect the number of bacilli in the lung of the coinfected group TB/OVA. Moreover, unlike what was previously observed in animals BALB/c mice, coinfected 129Sv were more susceptible than the animals infected $129 \mathrm{~Sv}$. On the contrary, 5LOKO-TB/OVA animals were more resistant than mice WT-TB/OVA.

To assess whether changes in granulomatous infiltrates were related to macrophages, we use the fourth strategy: IV) quantification of macrophage populations M1 and M2. We observed that M2 population in animals TB/OVA showed increased lung. The decrease in bacilli growth of animals TB/OVA was dependent on macrophage M2, since animals deficient for the expression of IL-33 protocol submitted to coinfected protocol had decreased macrophage population $\mathrm{M} 2$, and were susceptible to infection. These results show that the reduction in growth of bacilli in coinfected animals TB/OVA is dependent increase in macrophage population M2. 


\section{LISTA DE FIGURAS}

Figura 1. Resultados prévios - Modulação da resposta imunológica no modelo de coinflamação tuberculose e alergia. $\quad 32$

Figura 2. Delineamento experimental tuberculose e asma (TB/OVA). 36

Figura 3. Protocolo de indução de coinflamação e tratamento com MK886. 37

Figura 4. Número de células CD8+e contagem do número de UFC no pulmão de camundongos submetidos ao protocolo TB/OVA. 48

Figura 5. Avaliação histológica do pulmão de animais CD8KO-TB/OVA e CD8KO-TB.

Figura 6. Quantificação de genes associados com macrófagos M1 e M2 no pulmão de animais TB/OVA.

Figura 7. Análise representativa para quantificação de macrófagos M2 no pulmão de animais TB/OVA.

Figura 8. Frequência e número de células $C D 11 c^{+} A F^{+}$e células $C D 11 c^{+} A F^{+} C D 206^{+}$ no pulmão de animais TB/OVA.

Figura 9. Deteç̧ão de citocinas em homogenato de pulmão de camundongos coinflamados..

Figura 10. Detecção de fibrose no pulmão de camundongos coinflamados, TB/OVA. 59

Figura 11. Frequência e número de células $C D 11 c^{+} C D 11 b^{+} C D 317^{+}$no pulmão de animais TB/OVA.

Figura 12. Expressão de genes de macrófagos M1 e M2 no pulmão de camundongos ST2KO coinflamados.

Figura 13. Quantificação do número de UFC no pulmão de camundongos ST2KO coinflamados.

Figura 14. Frequência e número de células $C D 11 c^{+} C^{2} 11 b^{+} C D 317^{+}$no pulmão de animais ST2KO coinflamados. $\quad 67$

Figura 15. Detecção de corpúsculos lipídicos no LBA de animais coinflamados. 69

Figura 16. Avaliação do número de UFC no pulmão de animais coinflamados, tratados com MK886.

Figura 17. Detecção de citocinas em homogenato de pulmão de camundongos TB/OVA.

Figura 18. Avaliação histológica do pulmão de animais coinflamados tratados com MK886.

Figura 19. Avaliação do número de UFC no pulmão de animais $5 L O K O$ coinflamados.

Figura 20. Expressão de genes associados com macrófagos M1 e M2 no pulmão de camundongos 5 LOKO coinflamados.. 


\section{LISTA DE TABELAS}

Tabela 1. Anticorpos monoclonais utilizados para análise do fenótipo celular por citometria de fluxo ...40

Tabela 2. Sequência de primers utilizados para quantificação de genes por PCR em tempo real ............. 43

Tabela 3. Kits utilizados para a detecção de citocinas no homogenato de pulmão ...................................44 


\section{LISTA DE ABREVIATURAS E SIGLAS}

AA- Ácido Araquidônico

5LO- 5-lipoxigenase

Arg1- Arginase 1

BCG- Bacilo de Calmette-Guerín

CT- Grupo controle: não infectado, não alérgico

DC- do inglês Dendritic cells

DC-SIGN- do inglês Dendritic Cell-Specific Intercellular adhesion molecule-3-Grabbing Nonintegrin

ELISA- do inglês Enzyme linked Immuno Sorbent Assay

Fizz1- do inglês Found in inflammatory zone

FLAP- do inglês 5-lipoxygenase activating protein

HE- Hematoxilina \& Eosina

HIV- Vírus da Imunodeficiência Humana

IFN- $\boldsymbol{\gamma}$ - Interferon gamma

iNOS2- Óxido Nitrico Sintase Inducível 2

KO- do inglês knockout

LBA- Lavado Broncoalveolar

LT- Leucotrieno

LTA $_{4}$ H- Leucotrieno $\mathrm{A}_{4}$ hidrolase

MR- do inglês Manose Receptor

NOD- do inglês Nucleodide-binding Oligomerization Domain

OMS- Organização Mundial da Saúde

OVA - Ovalbumida do ovo de galinha

PAS- do inglês Periodic Acide-Schiff

pDC- do inglês plasmacytoid dendritic cell

RT-PCR- do inglês Real time PCR, PCR em tempo real

ST2- Receptor da IL-33

TB- Tuberculose

TB/OVA - Coinflamação (Tuberculose e alergia)

UFC- Unidades Formadoras de Colônia

WT- do inglês Wild Type

Ym1- Proteína secretória como quitinase 


\section{SUMÁRIO}

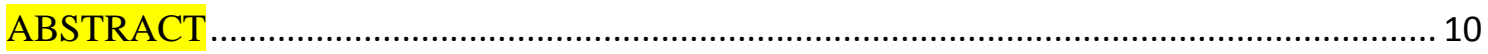

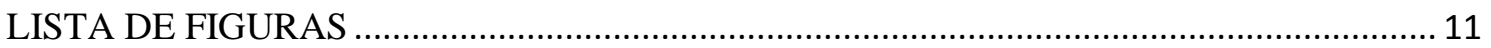

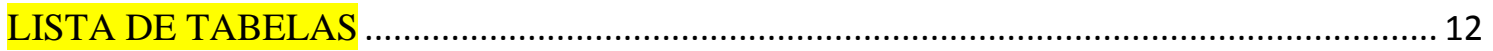

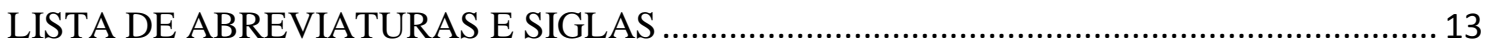

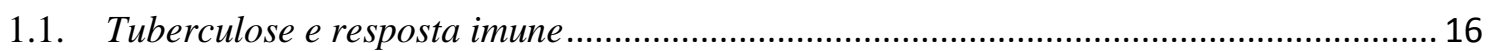

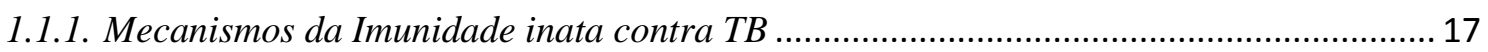

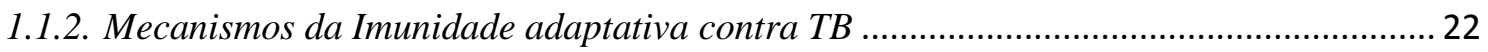

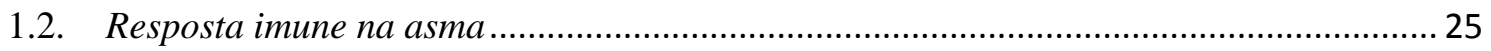

1.3. TB e asma: duas doenças pulmonares de padrões de resposta opostos ..............................28

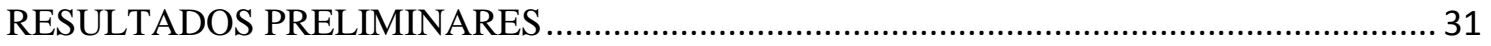

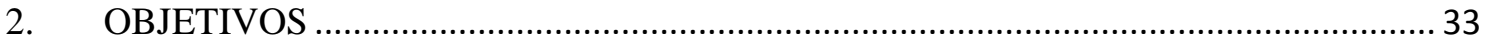

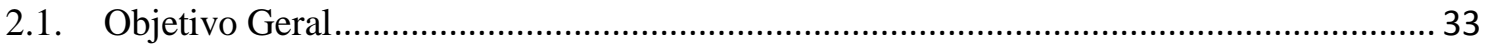

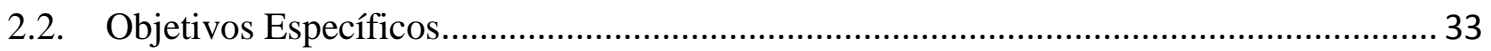

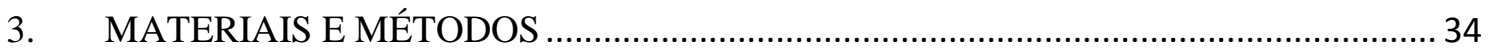

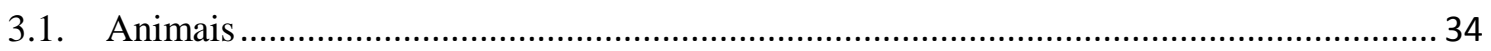

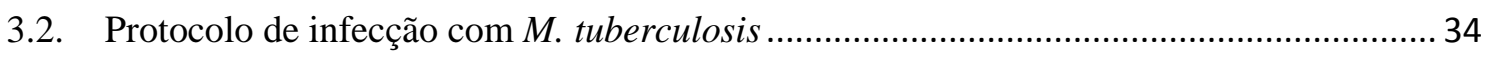

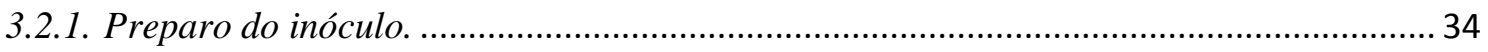

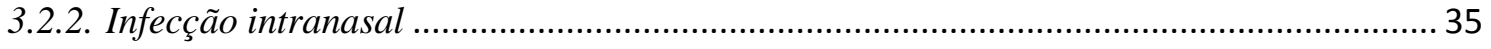

3.3. Delineamento experimental para indução de coinflamação TB/OVA................................ 35

3.4. Delineamento experimental para avaliação dos mediadores lipídicos utilizando o tratamento com MK886 nos animais coinflamados (TB/OVA)................................................ 36

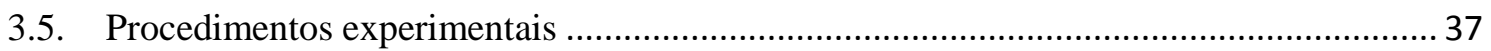

3.5.1. Obtenção e processamento do Lavado Broncoalveolar (LBA).......................................... 37

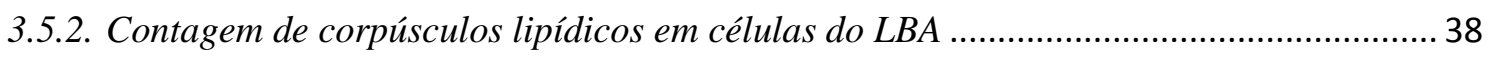

3.5.3. Contagem de Unidades Formadoras de Colônia (UFC) no pulmão ............................... 38

3.5.4. Quantificação de populações celulares por citometria de fluxo ....................................... 39

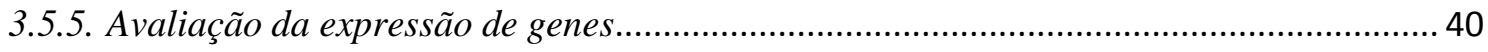

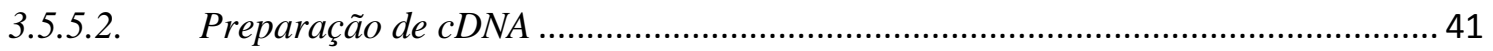

3.5.5.3. Quantificação da expressão de genes por PCR em tempo real (RT-PCR) .............. 42

3.5.6. Ensaio imunoenzimático de ELISA para a detecção de citocinas. .................................... 43

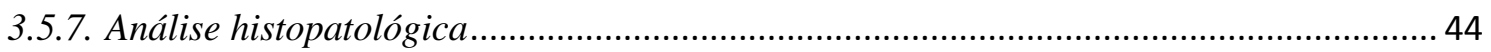

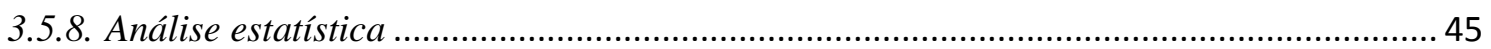

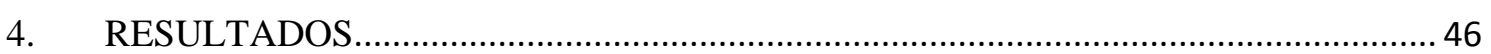


4.1. Papel dos linfócitos $\mathrm{T} \mathrm{CD8}^{+}$na diminuição no crescimento de $\mathrm{M}$. tuberculosis nos animais coinflamados, TB/OVA

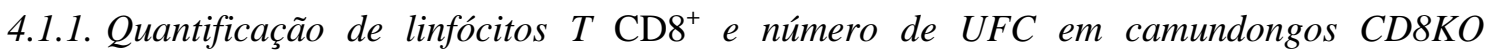

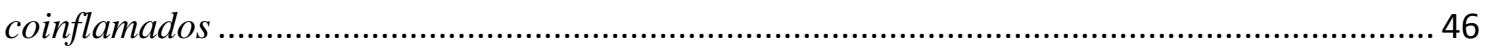

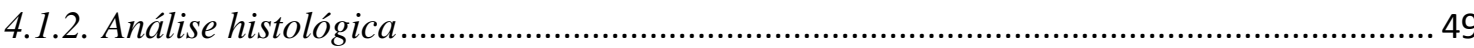

4.2. Avaliação do infiltrado de macrófagos M1 e M2 no pulmão de camundongos coinflamados 52

4.2.1. Expressão de genes característicos de macrófagos M1 e M2 ………............................. 52

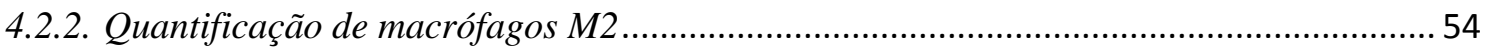

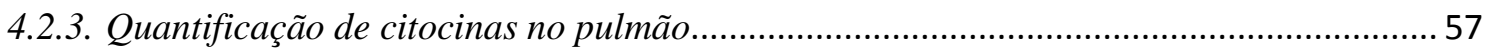

4.2.4. Quantificação de fibras colágenas nos animais coinflamados .......................................... 58

4.2.5. Quantificação de células dendríticas plasmocitóides por citometria de fluxo ...................60 60

4.2.6. Avaliação do papel dos macrófagos M2 no crescimento de bacilos nos animais

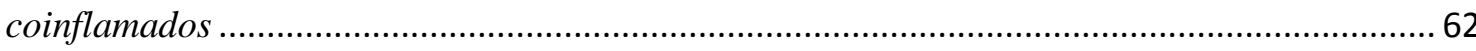

4.2.6.2. Quantificação do número de UFC no pulmão de animais ST2KO coinflamados... 65

4.2.6.3. Quantificação de células dendríticas plasmocitóides ............................................. 67

4.3. Avaliação do papel dos leucotrienos na diminuição do número de bacilos no

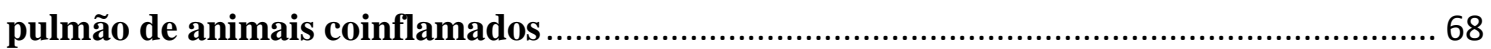

4.3.1. Quantificação de corpúsculos lipídicos em células do LBA ............................................. 68

4.3.2. DELINEAMENTO EXPERIMENTAL I. Tratamento com inibidor da enzima 5-LO,

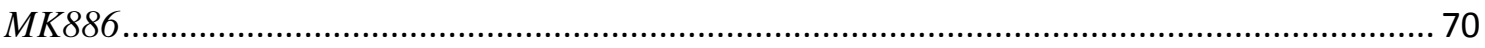

4.3.2.1. Quantificação de UFC em camundongos 129 Sv ........................................................ 70

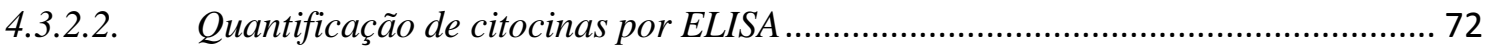

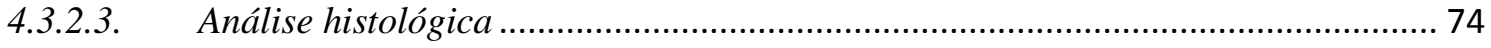

4.3.3. DELINEAMENTO EXPERIMENTAL II. Avaliação do papel da enzima 5-LO na

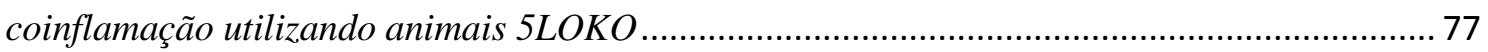

4.3.3.1. Quantificação do número de UFC em camundongos 5LOKO ................................ 77

4.3.3.2. Quantificação de macrófagos M1 e M2 em camundongos 5LOKO-TB/OVA......... 79

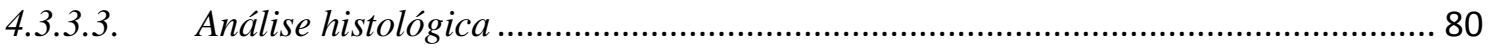

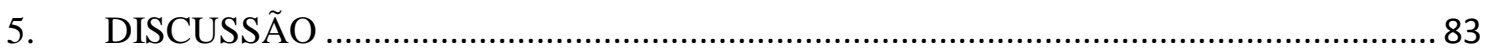

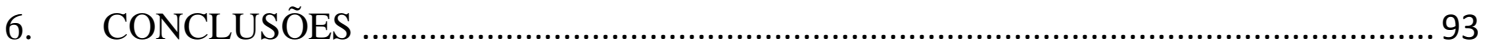

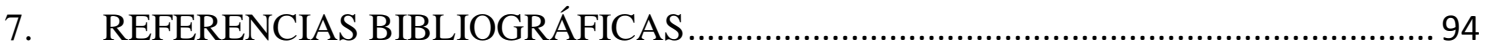

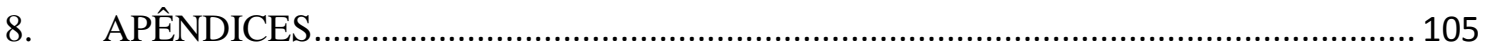

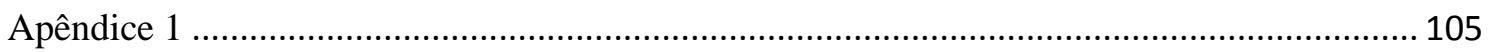

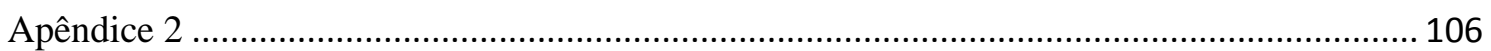

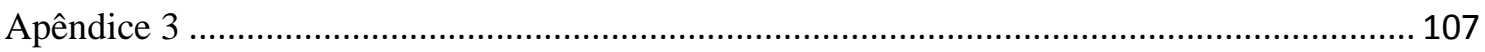




\section{INTRODUÇÃO}

\subsection{Tuberculose e resposta imune}

A tuberculose (TB) é uma doença pulmonar causada pela bactéria Mycobacterium tuberculosis, um bacilo intracelular de crescimento lento que é adquirido por via aérea (Hernandez-Pando, Orozco et al. 2009). M. tuberculosis, descrita pelo pesquisador Robert Koch, caracteriza-se por ser um microorganismo gram positivo e ácido - álcool resistente (Meena and Rajni 2010). Em 2011, a Organização Mundial de Saúde (OMS) notificou 8.7 milhões de casos de TB, com 1.7 milhões de mortes reportadas por ano (WHO 2012). Atualmente, a TB é declarada pela OMS como problema de saúde pública, sendo a prevalência no Brasil de 87 casos para cada 100.000 habitantes (WHO 2012).

Estudos epidemiológicos mostram que a cada 5 pessoas com TB, submetidas a tratamento, uma mostra resistência aos medicamentos de primeira linha (isoniazida e rifampicina). A resistência a uma droga de primeira linha é descrita como tuberculose multidroga-resistente (TB-MDR, do inglês Tuberculosis - Multi Drug Resistant). A OMS reportou que os gastos anuais no tratamento e o controle da doença alcança 2 bilhões de dólares ao ano, pois o custo do tratamento de uma pessoa com TB está na faixa de 100 a 500 dólares. Entretanto, o suporte financeiro real é de 0.6 bilhões de dólares por ano (WHO 2012). O tratamento contra TB compreende 6 meses de poliquimioterapia, e nos casos de TB-MDR, o tratamento demora 20 meses. Recentemente, foram descritas cepas de M. tuberculosis extensivamente resistentes a drogas (XDR, do inglês Extensively Drug-Resistant). Essas cepas são resistentes a drogas injetáveis de segunda geração, como amicacina, e ao menos um caso foi reportado no Brasil em 2011 (WHO 2012). Considerando que o tratamento para TB é longo e gera efeitos colaterais, a necessidade de investigações que contribuam no tratamento da doença é fundamental para manter o controle da mesma, principalmente porque existe o aumento de casos de coinfecção com HIV (do inglês Human Immunodeficiency Virus) (WHO 2012).

A transmissão da TB acontece de pessoa para pessoa, quando o indivíduo infectado espirra, tosse ou fala, gerando, desse modo, gotículas contendo bacilos. Inicialmente, as pessoas saudáveis, e que eventualmente são infectadas, não apresentam os sintomas característicos da doença. A infecção pode permanecer latente por anos. 
Sabe-se que de $90-95 \%$ de pessoas com a forma latente da infecção, apenas $5-10 \%$ podem reativar a doença por diferentes fatores como: infecção por HIV, desnutrição, tabagismo, coinfecção com helmintos ou comprometimento do sistema imunológico (Dheda, Schwander et al. 2010). Um dos motivos de preocupação frente à TB é que, embora exista a vacina BCG (Bacilo de Calmette-Guerin), sua eficácia é muito variável, e depende de vários fatores, como idade, região geográfica, área endêmica e cepa de BCG (Tyagi, Nangpal et al. 2011). Em consequência, é importante conhecer os mecanismos usados pelo sistema imunológico para controlar a infecção e dessa forma, encontrar alvos terapêuticos e profiláticos.

\subsubsection{Mecanismos da Imunidade inata contra TB}

O bacilo M. tuberculosis é inalado e depositado nos alvéolos, local onde entra em contacto com macrófagos alveolares (van Crevel, Ottenhoff et al. 2002; Philips and Ernst 2012) e células epiteliais pulmonares (Hernandez-Pando, Orozco et al. 2009). No entanto, outras células do sistema inato, como as células dendríticas (DC, do inglês Dendritic Cell), neutrófilos e macrófagos derivados de monócitos, são recrutadas durante o desenvolvimento da resposta inata frente ao bacilo (Philips and Ernst 2012).

Vários receptores expressos nas células fagocíticas permitem que $M$. tuberculosis seja reconhecida e fagocitada. Alguns desses receptores são as proteínas surfactantes (Gaynor, McCormack et al. 1995), os receptores Fc (do inglês fragment crystalline). (Maglione, Xu et al. 2008), os receptores do complemento, como o CR3 (CR, do inglês Complement Receptor) (Cywes, Hoppe et al. 1997), as lectinas do tipo C (Torrelles, Azad et al. 2006), os receptores de Manose (MR, do inglês Mannose Receptor) (Kang, Azad et al. 2005) e o receptor DC-SIGN expresso em células dendríticas (DC-SIGN, do inglês Dendritic Cell-Specific Intercellular adhesion molecule-3-Grabbing Non-integrin) (Maeda, Nigou et al. 2003; Dorhoi, Reece et al. 2011).

A fagocitose da bactéria e a ativação do receptor Fc são fenômenos associados à produção de espécies reativas do oxigênio (ROS, do inglês Reactive Oxigen Species) (Hernandez-Pando, Orozco et al. 2009) e a produção de citocinas proinflamatórias (van Crevel, Ottenhoff et al. 2002). Um estudo com camundongos infectados com $M$. tuberculosis mostrou que na ausência desse receptor, os camundongos foram mais susceptíveis à infecção (Maglione, Xu et al. 2008). Outros receptores, como MR, DC- 
SIGN e os receptores de varredura (do inglês Scavanger Receptors) contribuem no processo de fixação de $M$. tuberculosis pelas células fagociticas. No entanto, a ausência desses receptores não induziu maior susceptibilidade frente à infecção (Palecanda, Paulauskis et al. 1999; Court, Vasseur et al. 2010; Philips and Ernst 2012).

Os receptores do tipo Toll, como TLR2 (TLR, do inglês Toll Like Receptor), também são ativados durante a infecção por $M$. tuberculosis. A ativação desses

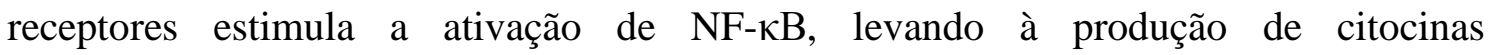
proinflamatórias (Means, Wang et al. 1999). Um estudo de Nicolle e colaboradores com macrófagos deficientes para a expressão de TLR2 (TLR2 ${ }^{--}$), infectados com BCG ou estimulados com antígenos micobacterianos, mostrou que essas células produziram menores concentrações de óxido nítrico (NO, do inglês Nitric Oxide) e de citocinas proinflamatórias, como o TNF quando comparados aos macrófagos de animais WT (do inglês Wild Type) (Nicolle, Fremond et al. 2004). O TLR9 também está envolvido no reconhecimento de $M$. tuberculosis. Um estudo realizado por Bafica e colaboradores mostrou que camundongos TLR9 $^{-/-}$infectados apresentaram crescimento significativo de bacilos no pulmão associado com diminuição na produção de IFN- $\gamma$ por células $\mathrm{T}$ $\mathrm{CD}^{+}$quando comparados aos animais WT (Bafica, Scanga et al. 2005).

M. tuberculosis pode escapar do fagossomo para o citosol (van der Wel, Hava et al. 2007), onde receptores de reconhecimento de padrões citoplasmáticos podem ser ativados. O receptor NOD2 (do inglês Nucleotide-binding and Oligomerization Domain), por exemplo, é um receptor citoplasmático que medeia a resposta a peptidoglicanos da parede celular de bactérias (Philips and Ernst 2012). Sua expressão em indivíduos com tuberculose não é diferente daquela observada em indivíduos saudáveis (Lala, Dheda et al. 2007). No entanto, utilizando macrófagos murinos deficientes de NOD2 (NOD2 ${ }^{--}$), Divangahi e colaboradores, mostraram que macrófagos de animais NOD2 $2^{--}$infectados tiveram diminuição na produção de IL12p70 e TNF- $\alpha$, quando comparados aos macrófagos de animais WT (Divangahi, Mostowy et al. 2008).

Os macrófagos são células importantes para o controle do crescimento de $M$. tuberculosis (Müller, Cobbold et al. 1987). Estas células fagocíticas são classificadas em: macrófagos M1 ou classicamente ativados e macrófagos M2 ou alternativamente ativados (Biswas and Mantovani 2010; Nakanishi, Nakatsuji et al. 2011). A ativação de macrófagos M1 acontece nas respostas mediadas por células Th1, como é o caso da infecção por micobactérias (Hesse, Modolell et al. 2001). Entretanto, a ativação de macrófagos do tipo M2 acontece na resposta de perfil Th2 (Martinez, Helming et al. 
2009). Uma das maiores diferenças entre os macrófagos M1 e M2 é o metabolismo da L-arginina. Assim, os macrófagos M1 metabolizam a L-arginina utilizando a enzima iNOS (do inglês Nitric Oxide Synthase inducible), para gerar NO (Munder, Eichmann et al. 1998), enquanto os macrófagos M2 utilizam a enzima arginase 1 (Arg1) para metabolizar o mesmo composto e gerar poliaminas e ornitinas (Mantovani, Muzio et al. 2001; Mantovani, Sica et al. 2004). A expressão dos genes iNOS e Argl é utilizada para a quantificação diferencial de ambas as populações de macrófagos, M1 e M2, respectivamente.

Os macrófagos M1 são polarizados pela citocina IFN- $\gamma$ (associada com respostas Th1) e por TNF (Mosser 2003). Esses macrófagos tem alta capacidade para apresentar antígenos e ativar a expressão da enzima iNOS e a subsequente produção NO em resposta a patógenos intracelulares (Mosser 2003; Mantovani, Sica et al. 2004; Biswas and Mantovani 2010). Um estudo realizado por MacMicking e colaboradores mostraram que camundongos $\mathrm{NOS}^{-/-}$foram mais susceptíveis à infecção por $M$. tuberculosis, se comparados aos animais WT (MacMicking, North et al. 1997). Embora, o mecanismo microbicida de produção de NO e acidificação do compartimento fagosomal seja o mecanismo utilizado pelos macrófagos para a destruição de microorganismos intracelulares, $M$. tuberculosis também possui estratégias de evasão que lhe permitem sobreviver dentro da célula. A expressão de genes, o escape do fagossomo (van der Wel, Hava et al. 2007) e a inibição da maturação do fagossomo (Armstrong and Hart 1975) são mecanismos utilizados por M. tuberculosis para evitar a ação microbicida dos macrófagos.

Além da atividade microbicida, os macrófagos também são importantes na secreção de citocinas como IL-12, citocina indutora de resposta Th1, por conseguinte, estas células são também indutoras deste tipo de resposta imune (Mantovani, Sica et al. 2004). Os macrófagos M1 são potentes células efetoras e tem a capacidade de destruir patógenos intracelulares, por meio da produção de ROS e NO (Fairweather and Cihakova ; MacMicking, North et al. 1997). No entanto, a infecção com M. tuberculosis também induz o aumento na expressão de Argl, ao mesmo tempo em que induz aumento da expressão de iNOS (El Kasmi, Qualls et al. 2008). O aumento na expressão da enzima Arg1 é associado com maior susceptibilidade à infecção (El Kasmi, Qualls et al. 2008). Em adição, também foi descrito que o aumento na expressão de Argl ocorre tanto na fase aguda como crônica da infecção (Redente, Higgins et al. 2010). 
A ativação dos receptores dos leucócitos da imunidade inata, além de envolver a indução da fagocitose e a ativação da atividade microbicida do macrófago, estimula a expressão e secreção de citocinas. Várias das citocinas do sistema inato, como IL-12, IL-1, IL-10, IL-6 e TNF são produzidas durante a infecção por $M$. tuberculosis (Cooper, Mayer-Barber et al. 2011), além de quimiocinas e mediadores lipídicos, como os leucotrienos e as prostaglandinas (Muñoz, Hernández-Pando et al. 2003; Chen, Divangahi et al. 2008; Divangahi, Chen et al. 2009; Divangahi, Desjardins et al. 2010).

Os leucotrienos são produzidos por células da linhagem mieloide, como: eosinófilos, neutrófilos, mastócitos, monócitos e macrófagos, e células dendríticas (Laidlaw and Boyce 2012) assim como da linhagem linfóide (linfócitos B) (Devillier, Baccard et al. 1999). Em particular, o $\mathrm{LTB}_{4}$ é produzido pelas células epiteliais e leucócitos polimorfonucleares (El Gazzar, El Mezayen et al. 2006). A produção de mediadores lipídicos envolve a ativação de várias enzimas, no entanto uma das enzimas fundamentais na síntese desses compostos é a enzima 5-lipoxigenase (5-LO), cujo substrato é o ácido araquidônico (AA) (Devillier, Baccard et al. 1999).

Além de seu papel na alergia, os estudos mostram que os leucotrienos são importantes durante as infecções bacterianas. Por exemplo, pesquisas realizadas em camundongos deficientes para 5-LO (5LO-KO) que foram infectados com Klebsiella pneumoniae, mostraram que esses animais apresentaram aumento no número de bactérias no pulmão e diminuição na sobrevivência. A função dos leucotrienos nas infecções bacterianas também tem sido associada com aumento na fagocitose e na atividade microbicida de macrófagos (Bailie, Standiford et al. 1996; Coffey, Phare et al. 2004; Serezani, Aronoff et al. 2005). O aumento das propriedades microbicidas e fagocíticas em macrófagos pela presença de leucotrienos tem sido associado, principalmente ao $\mathrm{LTB}_{4}$ (Canetti, Hu et al. 2003) (Serezani, Aronoff et al. 2005).

Interessantemente, $\mathrm{o} \mathrm{LTC}_{4}$ produzido durante a indução de alergia em ratos, gera um aumento na capacidade fagocítica e microbicida dos macrófagos alveolares, quando infectados com K. pneumoniae (Silva, Landgraf et al. 2010). Em adição, outras investigações com infecções virais tem mostrado que o $\mathrm{LTB}_{4}$ aumenta a capacidade de neutrófilos de produzir peptídeos antimicrobianos, como as $\beta$-defensinas (Gaudreault and Gosselin 2008).

O papel dos leucotrienos na infecção por $M$. tuberculosis ainda não está bem estabelecido, uma vez que, dois estudos, utilizando ferramentas diferentes mostraram funções opostas dos leucotrienos durante a infecção por M. tuberculosis. Assim, Bafica 
e colaboradores mostraram que camundongos deficientes da enzima 5-LO, quando infectados com $M$. tuberculosis, foram menos susceptíveis à infecção que os camundongos WT (Bafica, Scanga et al. 2005). No entanto, outros estudos mostraram que camundongos tratados com o composto MK-886, (inibidor da síntese de mediadores lipídicos pela via da 5-LO), foram mais susceptíveis à infecção por $M$. tuberculosis, se comparados com os animais não tratados (Peres, de Paula et al. 2007; Franco, Paula et al. 2010).

Além da produção de mediadores lipídicos, a ativação dos receptores dos leucócitos da imunidade inata, envolve a expressão e secreção de citocinas. A IL-10, por exemplo, é uma citocina produzida por macrófagos ou células dendríticas depois da fagocitose de M. tuberculosis (van Crevel, Ottenhoff et al. 2002). Estudos com amostras de sangue periférico de pacientes com TB mostraram aumento na expressão de IFN- $\gamma$ e IL12p70 por células mononucleares quando as culturas foram tratadas com anticorpos contra IL-10 (Zhang, Gong et al. 1994; Boussiotis, Tsai et al. 2000). Outra citocina produzida durante a infecção por $M$. tuberculosis é IL-6. Camundongos deficientes para a expressão de IL-6 foram menos resistentes à infecção por $M$. tuberculosis que os animais WT, sendo a susceptibilidade associada com diminuição na produção de IFN- $\gamma$ (Ladel, Blum et al. 1997).

A IL-12 é uma citocina proinflamatória, produzida por macrófagos e células dendríticas. A importância da IL-12 durante a infecção com M. tuberculosis foi descrita inicialmente em 1997, por Cooper e colaboradores. Os autores mostraram que camundongos deficientes para a expressão de IL-12 eram mais susceptíveis à infecção por M. tuberculosis. Em adição, esses animais apresentavam menor produção de IFN- $\gamma$ e TNF (Cooper, Magram et al. 1997). A IL-23, que compartilha a subunidade p40 com a IL-12, também é induzida durante a resposta imune contra M. tuberculosis (Khader, Pearl et al. 2005; Cooper, Mayer-Barber et al. 2011) e um estudo realizado por Cooper e colaboradores mostrou que animais IL12p40-/- (deficientes de IL-12 e IL-23) foram mais susceptíveis frente à infecção por M. tuberculosis, quando comparados com os animais IL-12p35-/- (deficientes da IL-12) (Cooper, Kipnis et al. 2002).

Outra citocina proinflamatória produzida durante a infecção com M. tuberculosis é IL-1. Pacientes infectados com M. tuberculosis mostraram aumento na expressão desta citocina (Law, Weiden et al. 1996) e um estudo com modelo murino mostrou que camundongos deficientes de IL- $1 \alpha$ e IL- $1 \beta$ apresentaram maior crescimento dos bacilos comparando-se aos camundongos WT (van Crevel, Ottenhoff et al. 2002). O TNF 
também é uma citocina importante na indução da produção de óxido nítrico durante a resposta a micobactérias (Flynn, Goldstein et al. 1995; Bekker, Freeman et al. 2001), assim como no controle do crescimento de M. tuberculosis e na contenção da infecção por participar diretamente da formação de granulomas (Ehlers 2003). O bloqueio de TNF com anticorpo neutralizante diminuiu significativamente a sobrevivência dos camundongos infectados com M tuberculosis (Flynn, Goldstein et al. 1995).

Portanto, pelo que foi descrito até o momento, as citocinas IL-12, TNF, IL-1, IL6, IL-23, secretadas por leucócitos da imunidade inata, residentes ou recrutados para o local da infecção, são importantes para a geração de resposta imune associada com o controle da replicação de $M$. tuberculosis. Do contrário, a produção exacerbada de IL10 pode comprometer a eficácia tanto da resposta inata como da resposta adaptativa, a ser descrita posteriormente.

Além dos fagócitos, o reconhecimento de $M$. tuberculosis pelo sistema inato também envolve a participação de células da linhagem linfóide. As células Natural Killer (NK), por exemplo, são importantes durante a infecção por M. tuberculosis, porque são a principal fonte de produção de IFN- $\gamma$ em camundongos deficientes de células T e que foram infectados com M. tuberculosis (Feng, Kaviratne et al. 2006). Além disso, parece que as células NK representam a fonte inicial de síntese de IFN- $\gamma$, quando a resposta adaptativa ainda não foi ativada. As células Natural Killer T (NKT), como as NK, também produzem IFN- $\gamma$ em resposta a lipídeos de origem micobacteriana (Sada-Ovalle, Chiba et al. 2008). A produção de IFN- $\gamma$ por NK e NKT, além de ativar a resposta microbicida dos macrófagos frente a $M$. tuberculosis, induz a polarização de linfócitos T imaturos para o perfil Th1. Por conseguinte, a ativação desses linfócitos durante a infecção por micobactérias contribui na indução da resposta adaptativa.

Outras células iniciadoras da resposta imune adaptativa são as DC, que uma vez ativadas, tem a capacidade de migrar para o linfonodo e ativar a resposta imune celular (Cooper 2009). No entanto, a infecção com M. tuberculosis atrasa a migração de DC para os linfonodos e, portanto, a capacidade de ativar a resposta imune adaptativa (Marino, Pawar et al. 2004; Wolf, Linas et al. 2007).

\subsubsection{Mecanismos da Imunidade adaptativa contra $T B$}

O mecanismo adaptativo de contenção de $M$. tuberculosis pelo sistema imune caracteriza-se principalmente pela ativação da resposta imune celular de padrão Th1. 
Essa resposta é caracterizada pela produção de citocinas como o IFN- $\gamma$ (Surcel, TroyeBlomberg et al. 1994). A resposta Th1 permite a ativação dos macrófagos via IFN- $\gamma$ (Hernandez-Pando, Orozcoe et al. 1996), favorecendo a produção de ROS (Shiloh and Nathan 2000) e de NO, que permitem a destruição da bactéria (MacMicking, North et al. 1997).

O IFN- $\gamma$ é uma das citocinas mais importantes na infecção com M. tuberculosis. Além de induzir a produção de ROS por macrófagos infectados, também regula positivamente a expressão de moléculas de MHC de classe II (Hernandez-Pando, Orozcoe et al. 1996; Singh, LeMaire et al. 2011). A ausência dessa citocina potencializa a necrose do pulmão e favorece o crescimento dos bacilos (Cooper, Dalton et al. 1993; Flynn, Chan et al. 1993). As principais células produtoras de IFN- $\gamma$ são os linfócitos T $\mathrm{CD}^{+}$(Hernandez-Pando, Orozcoe et al. 1996; Mogues, Goodrich et al. 2001) e os linfócitos T CD8 ${ }^{+}$(Sousa, Mazzaccaro et al. 2000).

Embora a resposta Th1 seja um componente fundamental durante a resposta frente à infecção por $M$. tuberculosis, outras populações de células $\mathrm{T} \mathrm{CD}^{+}$são ativadas durante a infecção pelo bacilo. Estudos em pacientes infectados com M. tuberculosis mostraram diminuição no número de células $\mathrm{T} \mathrm{CD}^{+}$produtoras de $\mathrm{IL}-17$ em sangue periférico desses pacientes quando comparados com os indivíduos saudáveis (Scriba, Kalsdorf et al. 2008). Um estudo em modelo animal mostrou que camundongos vacinados com BCG e desafiados com $M$. tuberculosis apresentaram aumento na produção de IL-17 antígeno específica, sendo esse aumento associado com maior dano tecidual e maior resposta inflamatória (Cruz, Fraga et al. 2010). Porém, Khader e colaboradores, também empregando esquema de imunização, mostraram que camundongos vacinados contra tuberculose, na presença de células Th17 apresentaram maior migração de células T produtoras de IFN- $\gamma$ (Khader, Bell et al. 2007). Nesse sentido, nota-se que ainda são necessários estudos que permitam entender melhor a função das células Th17 na TB. Porém, parece que o papel protetor ou deletério da IL17 está relacionado com a magnitude de produção dessa citocina, sendo as concentrações elevadas associadas com dano tecidual.

As células T reguladoras (Treg) são um conjunto de células $\mathrm{T}$ conhecidas por sua capacidade de controlar a resposta inflamatória por diferentes mecanismos, dentre eles, a produção de citocinas anti-inflamatórias, como IL-10 e TGF- $\beta$ (Cooper 2009). Pacientes com a infecção ativa por $M$. tuberculosis mostraram aumento na população de células Treg $\mathrm{CD}^{+} \mathrm{CD} 25^{+}$ou $\mathrm{CD}^{+}{ }^{+}$oxp $^{+}{ }^{+}$(Guyot-Revol, Innes et al. 2006; Ribeiro- 
Rodrigues, Resende Co et al. 2006). Mas qual seria a função dessa população de leucócitos na TB? Um estudo realizado por Scott-Browne e colaboradores mostrou que a depleção de células Treg em camundongos infectados com M. tuberculosis induziu diminuição no crescimento dos bacilos no pulmão desses animais (Scott-Browne, Shafiani et al. 2007). Em adição, o mesmo grupo mostrou que as células Treg atrasam a migração de células efetoras $\mathrm{CD}^{+}$e $\mathrm{CD}^{+}$para o pulmão de animais infectados (Shafiani, Tucker-Heard et al. 2010). Nosso grupo mostrou previamente que quanto maior o inóculo usado para promover infecção com M. tuberculosis, maior o número de células Treg quantificadas no pulmão, sendo a resposta imune nesses animais caracterizada como perfil de resposta mista, com presença de IFN- $\gamma$ e de IL-5 (Morais Fonseca, Rosada et al. 2010). Outro estudo realizado por nosso grupo mostrou que as células Treg de animais BALB/c eram mais supressoras que as células Treg de animais C57BL/6, sendo esses últimos capazes de controlar melhor a infecção e de produzir concentrações significativamente maiores de IFN- $\gamma$ e IL-17 (Paula, Fonseca et al. 2011). Recentemente, nosso grupo testou a eficácia vacinal de três preparações vacinais e comparou com número e frequência de células Treg no baço e pulmão. Nesse estudo foi observado que quanto maior o número de células Treg, menor a eficácia da preparação vacinal (Fedatto, Sérgio et al. 2012). Assim, embora as células Treg sejam importantes para controlar o excesso de resposta inflamatória, nossos resultados e os dados da literatura mostram que o aumento dessas células está associado com progressão da infecção.

A resposta Th2, além de colaborar para intensificar a magnitude da resposta humoral mediada por anticorpos, e ativar eosinófilos, também modula negativamente a resposta de perfil Th1. Um estudo realizado por Buccheri e colaboradores mostrou que durante a infecção com $M$. tuberculosis, camundongos tratados com anticorpo contra IL-4 apresentaram diminuição no crescimento de bacilos no pulmão, em relação aos animais não tratados e infectados com M. tuberculosis (Buccheri, Reljic et al. 2007). Além disso, pacientes com formas mais graves da doença caracterizam-se por aumento na produção de IL-4 (Rook 2007). Um estudo realizado por nosso grupo mostrou que a IL-4 interferia na capacidade protetora de vacina constituída por proteínas secretadas por $M$. tuberculosis em presença do adjuvante $\mathrm{CpG}$ e ao modificar o esquema de vacinação, gerando menor produção de IL-4, foi observada uma maior eficácia da vacina (Fonseca, Silva et al. 2007; da Fonseca, Silva et al. 2009). Nesse contexto, 
parece que a resposta Th2 está relacionada com susceptibilidade e progressão da infecção por M. tuberculosis.

Em resumo, a infecção com $M$. tuberculosis induz forte resposta Th1, caracterizada pela produção da citocina IFN- $\gamma$, e a ativação de macrófagos proinflamatórios com fenótipo M1, que exercem função microbicida durante a infecção. Porém, células Treg e células Th2 também são induzidas e podem regular negativamente a resposta imune associada com proteção.

\subsection{Resposta imune na asma}

A asma alérgica é uma doença crônica pulmonar que é comum em crianças, e caracteriza-se pela falta de ar, tosse, broncoconstrição e produção de escarro (Hammad and Lambrecht 2008). Segundo a OMS, aproximadamente 300 mil pessoas no mundo tem asma, com uma prevalência superior a $10 \%$ nos países desenvolvidos (WHO 2007). O Brasil sendo um país com economia emergente apresenta uma prevalência de casos de asma superior ao 10\% (WHO 2007).

A asma alérgica caracteriza-se como resposta de hipersensibilidade do tipo I, cursa com intensa resposta do tipo Th2 (Tai, Tam et al. 2006; Hammad and Lambrecht 2008; Paul and Zhu 2010) que envolve inflamação eosinofílica, elevada secreção de IL4, IL-5 e IL-13 no pulmão, além de produção aumentada de IgE no soro (Finn and Bigby 2009). Atribui-se às células epiteliais importante papel na síntese de citocinas que contribuem para a diferenciação da resposta Th2, típica das doenças alérgicas (Allakhverdi, Comeau et al. 2007). Dentre as citocinas que contribuem para a geração e diferenciação da resposta Th2 na asma estão TSLP, IL-25 e IL-33.

A linfopoietina estromal tímica (TSLP, do inglês Thymic stromal lymphopoietin), produzida por células epiteliais e por basófilos, estimula a produção de citocinas características da resposta alérgica, como IL-5 e IL-13 (Paul and Zhu 2010), em resposta a RNA de dupla fita, às citocinas inflamatórias ou peptidoglicanos (Allakhverdi, Comeau et al. 2007). A participação da TSLP durante a resposta imune na asma foi confirmada quando biópsias de células epiteliais do pulmão de pacientes asmáticos mostraram aumento na expressão desta citocina (Ying, O’Connor et al. 2005). Posteriormente, esse aumento na expressão foi também observado em camundongos submetidos a indução de asma experimental (Zhou, Comeau et al. 2005). 
IL-25 é uma citocina produzida por eosinófilos, basófilos e células epiteliais (Kim, DeKruyff et al. 2010), que atua na polarização de células T para o fenótipo Th2 (Saenz, Noti et al. 2010). Em modelo murino, estudos mostraram aumento na expressão de IL-25 durante o desenvolvimento de asma alérgica (Angkasekwinai, Park et al. 2007), sendo a neutralização dessa citocina relacionada com diminuição da eosinofilia e do recrutamento de linfócitos $\mathrm{T} \mathrm{CD}^{+}$para o pulmão (Tamachi, Maezawa et al. 2006).

A IL-33 é uma citocina da família da IL-1 que se liga no receptor ST2. A expressão desta citocina induz aumento na síntese de IgE, eosinofilia (Schmitz, Owyang et al. 2005) e o aumento na sobrevivência de eosinófilos (Cherry, Yoon et al. 2008). Os níveis de IL-33 estão aumentados em pacientes atópicos (Pushparaj, Tay et al. 2009). Já em modelo animal, foi observado que o tratamento com anticorpo contra ST2 induziu diminuição na hiper-responsividade brônquica e na produção de muco no pulmão de camundongos alérgicos (Kearley, Buckland et al. 2009). Outras funções da IL-33 estão associadas com a indução da degranulação de mastócitos durante o desenvolvimento da asma. Além disso, a IL-33 está associada com a polarização de macrófagos para o fenótipo M2 ou macrófagos alternativamente ativados (Kurowska-Stolarska, Stolarski et al. 2009). Os estudos realizados por Kurowska e colaboradores mostraram que camundongos deficientes para a expressão de IL-33 apresentavam diminuição na resposta alérgica, associada com redução de macrófagos M2 no pulmão (KurowskaStolarska, Stolarski et al. 2009).

Além da produção de citocinas associadas com a resposta inata, outros mediadores inflamatórios como os mediadores lipídicos são produzidos durante a resposta frente à asma. Pacientes com asma, por exemplo, apresentam aumento na produção de $\mathrm{LTC}_{4}$ durante a exposição ao LPS, se comparados com pacientes não asmáticos que são expostos ao LPS (Bhavsar, Levy et al. 2010). Na alergia, a liberação de leucotrienos e outros mediadores são importantes na manutenção da resposta inflamatória no pulmão (El Gazzar, El Mezayen et al. 2006). Especificamente, os leucotrienos são alvos de intensa pesquisa nas doenças alérgicas, devido a sua função como quimioatraentes de eosinófilos, macrófagos, neutrófilos e mastócitos (FordHutchinson, Gresser et al. 1994; El Gazzar, El Mezayen et al. 2006). Os cisteinil leucotrienos são conhecidos por sua potente capacidade como broncoconstritores (Dahlén, Hansson et al. 1983; Makker, Lau et al. 1993), vasoconstrictores (Dahlén, Björk et al. 1981) indutores de fibrose (Beller, Friend et al. 2004) e do recrutamento de células T para as vias aéreas (Goodarzi, Goodarzi et al. 2003; Luster and Tager 2004). 
Além disso, estudos realizados em pacientes asmáticos mostraram aumento na produção de $\mathrm{LTB}_{4}$ e de $\mathrm{LTC}_{4}$ em células de sangue periférico desses pacientes se comparados com indivíduos saudáveis (Sampson, Thomas et al. 1992).

Como mencionado, a resposta alérgica também envolve a produção das citocinas IL-4 e IL-13, que estimulam a produção de IgE (Ngoc, Gold et al. 2005; Munitz, Brandt et al. 2008; Paul and Zhu 2010), e a polarização de macrófagos para o fenótipo M2 (Locksley 2010). A IL-13 também está envolvida no aumento da expressão de ST2, o receptor da IL-33 (Kurowska-Stolarska, Stolarski et al. 2009), a produção de muco pelas células caliciformes e a contração do músculo, associada com hiperresponsividade (Locksley 2010). Esses efeitos são observados em uma via independente da presença de IL-4 (Grünig, Warnock et al. 1998). Por outro lado, a IL-5 (Cho, Miller et al. 2004) e a IL-9 estimulam o recrutamento de eosinófilos e de mastócitos, respectivamente (Paul and Zhu 2010).

Além dos linfócitos Th2, mastócitos, eosinófilos, basófilos, DC e macrófagos M2 também desempenham importante papel na manutenção e magnitude das respostas alérgicas. Dentre esses leucócitos, os eosinófilos atuam de modo significativo. Eles constituem 50\% do infiltrado celular no pulmão de pacientes asmáticos (Larche, Akdis et al. 2006). Quando ativados, os eosinófilos produzem leucotrienos e citocinas, como IL-4, IL-5, IL-10 e IL-13 (Kim, DeKruyff et al. 2010), envolvidas na resposta Th2. Em modelos experimentais, a quantificação de eosinófilos constitui-se um dos parâmetros primordiais para se avaliar a indução de resposta alérgica. Outras células ativadas após a exposição ao alérgeno são os mastócitos, que quando ativados, liberam leucotrienos e outros mediadores inflamatórios, como a histamina (Bischoff 2007; Kim, DeKruyff et al. 2010).

Como mencionado anteriormente, os macrófagos M2 encontram-se em número aumentado na asma pelo fato de sofrerem diferenciação em microambiente rico em IL-4 e IL-13. Entretanto, o papel dessa população de macrófagos ainda é pouco explorado na asma. As células dendríticas também são importantes para a diferenciação da resposta Th2 na asma, pois na ausência de DC, houve diminuição na ativação de células T CD4 ${ }^{+}$, na produção de IgG1 (Kool, Soullié et al. 2008) e do recrutamento de eosinófilos no pulmão (Lambrecht, Salomon et al. 1998). Visto que os basófilos são células produtoras de IL-4 (Paul and Zhu 2010), eles também se constituem como indutores da resposta Th2 (Sokol, Chu et al. 2009). 
Além da resposta de tipo Th2, as células Th17, também estão envolvidas nas doenças alérgicas. Estudos realizados em pacientes asmáticos mostraram aumento na expressão de IL-17A no escarro de pacientes comprando-se às amostras de escarro de indivíduos saudáveis (Bullens, Truyen et al. 2006). Por outra parte, Kudo e colaboradores, mostraram que a produção de IL17A está associada ao aumento da hiper-responsividade brônquica em camundongos alérgicos (Kudo, Melton et al. 2012).

As células $\mathrm{T}$ reguladoras também exercem papel na resposta alérgica e estudos realizados em pacientes alérgicos mostraram diminuição nas populações de Treg. Porém, a transferência adotiva de células Treg em camundongos sensibilizados com OVA induziu diminuição em parâmetros característicos da alergia como: diminuição na produção de muco, na hiper-resposividade brônquica e na eosinofilia (Xu, Lan et al. 2012).

\subsection{TB e asma: duas doenças pulmonares de padrões de resposta opostos}

A TB e a alergia são doenças que acometem o pulmão. A TB é endêmica em países em desenvolvimento. Do contrário os casos de alergia tem maior prevalência em países desenvolvidos (Ngoc, Gold et al. 2005; Devereux 2006). No entanto, ambas as doenças coexistem em países, como o Brasil. Os padrões de resposta que caracterizam cada uma dessas doenças são distintos. Assim, a resposta Th1 induzida na infecção por M. tuberculosis é regulada negativamente pela resposta Th2 gerada na asma, e a resposta Th2 na asma é regulada negativamente pela resposta Th1. A teoria da Higiene que postula que o contato com micro-organismos contribuiria para prevenir a prevalência de doenças alérgicas baseia-se na capacidade de modulação da resposta imune exercida pelas respostas Th1 e Th2 (Strachan 2000).

Um estudo com crianças que moram em ambientes rurais ou urbanos mostrou que aqueles que moram em um ambiente agrícola tem menos sintomas de asma, febre e são menos sensíveis ao pólen que aqueles indivíduos que moram em ambientes urbanos (Eder, Klimecki et al. 2006). Assim, o contato com micro-organismos no início da vida parece conferir proteção frente a doenças alérgicas. Isso foi mostrado por vários estudos epidemiológicos, nos quais crianças positivas para Helicobacter pylori tiveram teste negativo para o diagnóstico de asma ou para testes de sensibilidade ao pólen e mofo (Chen and Blaser 2007; Chen and Blaser 2008). Estes estudos também foram realizados em uma população de indivíduos adultos, observando-se novamente essa relação 
inversa entre a positividade a $H$. pylori e a presença de asma (Reibman, Marmor et al. 2008).

Modelos experimentais também confirmaram os dados epidemiológicos. Camundongos submetidos ao protocolo de indução de alergia quando infectados com Acinetobacter baumanni, apresentaram diminuição de parâmetros característicos da resposta alérgica, como redução da eosinofilia, da produção de muco e de citocinas associadas ao padrão Th2 (Qiu, KuoLee et al. 2011).

Há também estudos epidemiológicos que mostram relação entre o contacto com bactérias patogênicas e a incidência de asma. Por exemplo, um estudo realizado por Obihara e colaboradores mostrou que crianças localizadas em áreas endêmicas para TB e que apresentavam rinite alérgica, foram negativas para o teste de tuberculina (prova que revela se a pessoa foi alguma vez exposta a $M$. tuberculosis). Pelo contrário, crianças que não mostraram sintomas de rinite alérgica, foram positivas para o teste de tuberculina (Obihara, Beyers et al. 2005).

Vários estudos em modelos experimentais confirmaram que a infecção com micobactérias (BCG, M. vaccae), ou a estimulação com antígenos de micobactérias é capaz de reduzir a eosinofilia, a produção de muco, a secreção de IL-4, IL-5, e mesmo a hiper-reatividade brônquica (Bilenki, Gao et al. 2010; Fonseca, Paula et al. 2011; Fonseca, Wowk et al. 2012). Todos esses estudos mostraram que a alergia é modulada negativamente pela resposta a infecções geradas por bactérias ou produtos bacterianos, tanto de micro-organismos patogênicos ou não. Entretanto, será que há modulação na resposta contra M. tuberculosis, em decorrência da resposta alérgica?

Considerando que o Brasil apresenta porcentagem alta de casos de asma e, além disso, o número de casos de TB ainda continua elevado, existe a probabilidade de que indivíduos infectados com M. tuberculosis, também sejam alérgicos. Em suma a asma modularia a resposta imunológica na TB? Em uma região endêmica para Onchocerca volvulus (um helminto que gera um padrão de resposta Th2) e para M. tuberculosis, foi realizada uma pesquisa em crianças, para avaliar o efeito da infecção por helmintos sobre a resposta a $M$. tuberculosis. Neste estudo, os autores mostraram que a proteção da vacina BCG diminui em regiões onde as infecções por helmintos são endêmicas (Stewart, Boussinesq et al. 1999; Elias, Britton et al. 2008). Outras pesquisas mostraram que as células de indivíduos que tem infecção crônica por parasitas intestinais apresentaram diminuição na proliferação de células específicas para PPD (do inglês Purified Protein Derivative) e diminuição na produção de IFN- $\gamma$. Quando os indivíduos 
foram tratados com albendazole (medicamento que elimina ou reduz vermes intestinais), houve um aumento na resposta de células antígeno-específicas para a bactéria e na produção de IFN- $\gamma$ (Elias, Wolday et al. 2001). Resultados similares foram obtidos por Elias e colaboradores, ao mostrarem que camundongos infectados com Schistosoma mansoni, vacinados com BCG, e posteriormente, infectados com $M$. tuberculosis tiveram aumento no crescimento de bacilos no pulmão, quando comparados com os animais que foram somente infectados com M. tuberculosis (Elias, Akuffo et al. 2005). Esses resultados foram associados com diminuição na produção de IFN- $\gamma$ e de óxido nítrico (Elias, Akuffo et al. 2005).

Do mesmo modo, Potian e colaboradores observaram que camundongos coinfectados com M. tuberculosis e Nyppostrongylus brasiliensis apresentaram aumento no crescimento de bacilos no pulmão, sendo a susceptibilidade dependente da produção da IL-4 e da diferenciação de macrófagos M2 (Potian, Rafi et al. 2011).

Sendo as respostas alérgicas de mesmo perfil que as respostas induzidas em infecções por helmintos, há grande possibilidade da asma regular negativamente a resposta imunológica na infecção por $M$. tuberculosis. 


\section{RESULTADOS PRELIMINARES}

Pelo exposto previamente, dados epidemiológicos sugerem que indivíduos alérgicos ou asmáticos possam apresentar infecção latente por M. tuberculosis ou ao contrário, indivíduos que desenvolvem tuberculose podem ser asmáticos. Nós nos questionamos sobre o que aconteceria com a resposta imunológica desses indivíduos, sendo o pulmão o órgão alvo de ambas as doenças, que se caracterizam por perfis de resposta opostos. Para tentar responder essa questão, estabelecemos um modelo, descrito como coinflamação. Nesse modelo de coinflamação, camundongos BALB/c foram infectados com M. tuberculosis e após 30 dias, foram submetidos ao protocolo de indução de alergia com OVA (TB-OVA). Os resultados mostraram que os camundongos coinflamados ou TB/OVA apresentaram diminuição no número de bacilos no pulmão quando comparados com os animais apenas infectados (grupo TB) (Figura 1A), sendo a diminuição independente da produção de IFN- $\gamma$ (Figura 1B).

Além disso, nós observamos que os camundongos coinflamados apresentaram aumento de linfócitos $\mathrm{T} \mathrm{CD}^{+}$, em relação aos camundongos apenas infectados com $M$. tuberculosis (grupo TB) (Figura 1C). Também foi observado que os animais TB/OVA apresentaram diminuição significativa do infiltrado granulomatoso (Figura 1D) e maior produção de $\mathrm{LTB}_{4}(\mathrm{p}<0.05)$ (Figura 1E), se comparados com os animais TB.

Diante desses resultados, o objetivo desse estudo foi avaliar os diferentes mecanismos imunológicos que podem estar envolvidos na diminuição da carga bacilar no pulmão dos animais coinflamados. Nossa hipótese inicial é que o aumento da produção do $\mathrm{LTB}_{4}$ pode estar envolvido na proteção frente à infecção por $M$. tuberculosis nos animais TB/OVA de duas maneiras: 1- Aumentando o recrutamento de células $\mathrm{T} \mathrm{CD} 8^{+}$para o pulmão e 2 - Induzindo maior atividade fagocítica e microbicida nas células do pulmão. Em adição, células $\mathrm{T} \mathrm{CD}^{+}$contribuiriam na diminuição no crescimento do bacilo através da ativação da sua função citolítica. 
A)

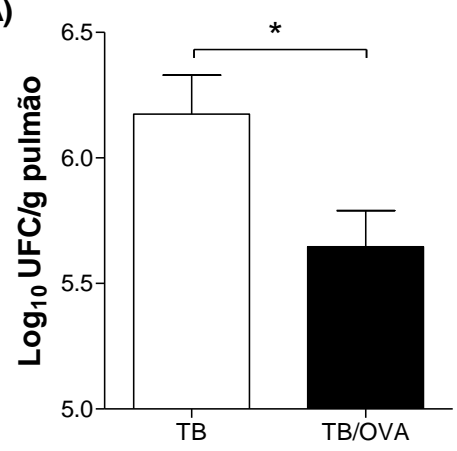

B)

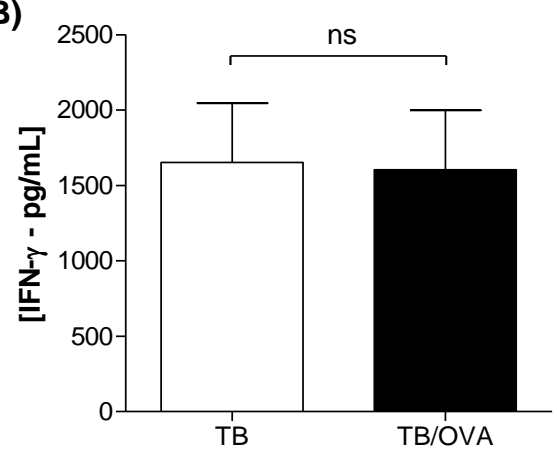

C)

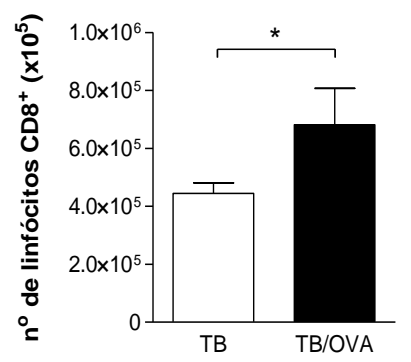

D)

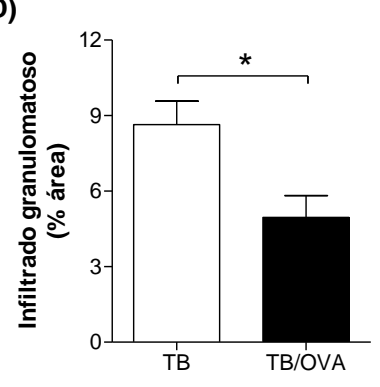

E)

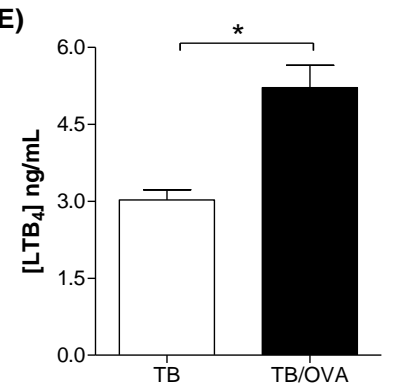

Figura 1. Resultados prévios - Modulação da resposta imunológica no modelo de coinflamação tuberculose e alergia. Carga bacilar (A), produção de IFN- $\gamma$ (B), número de linfócitos $\mathrm{T} \mathrm{CD}^{+}(\mathbf{C})$, quantificação de infiltrado granulomatoso por análise histológica (D) e produção de $\mathrm{LTB}_{4}(\mathbf{E})$ no pulmão de camundongos coinflamados. * $\mathrm{p}$ $<0,05$; ns: não significativo. 


\section{OBJETIVOS}

\subsection{Objetivo Geral}

Avaliar possíveis mecanismos envolvidos na diminuição do crescimento de bacilos no pulmão de animais infectados e alérgicos comparando aos animais apenas infectados.

\subsection{Objetivos Específicos}

2.2.1. Avaliar o papel das células $\mathrm{CD}^{+}$na redução do crescimento de bacilos no pulmão de animais infectados e alérgicos;

2.2.2. Avaliar as populações de macrófagos M1 e M2 no pulmão de animais infectados e alérgicos;

2.2.3. Avaliar o papel do $\mathrm{LTB}_{4}$ na diminuição do crescimento de bacilos nos animais infectados e alérgicos, usando como ferramenta a inibição ou deficiência da enzima 5-lipoxigenase. 


\section{MATERIAIS E MÉTODOS}

\subsection{Animais}

Foram utilizados camundongos fêmeas 129Sv (Wyld Type, WT), deficientes para a expressão da enzima 5 lipoxigenase (5-LOKO, linhagem 129Sv), deficientes para a expressão da molécula CD8 (CD8KO, linhagem C57BL/6) e deficientes para o receptor da IL-33 (ST2KO, linhagem BALB/c), com 6 a 8 semanas de idade. Os animais foram fornecidos pelo Centro de Criação de Camundongos Especiais da Faculdade de Medicina de Ribeirão Preto (FMRP-USP). Também foram utilizados camundongos fêmeas C57BL/6 e BALB/c com 6 a 8 semanas de idade, fornecidos pelo Biotério de Animais Isogênicos da Faculdade de Medicina de Ribeirão Preto. Os animais infectados com $M$. tuberculosis e submetidos ao protocolo de indução de alergia foram mantidos em isoladores no laboratório de biossegurança nível III, adequado para a manipulação de animais infectados com $M$. tuberculosis, com acesso à água estéril e ração ad libitum. Todos os procedimentos realizados foram aprovados pelo Comitê de Ética em Experimentação Animal local (Protocolo $n^{0}$ 133-2012)

\subsection{Protocolo de infecção com M. tuberculosis}

\subsubsection{Preparo do inóculo.}

A preparação do inoculo de M. tuberculosis H37Rv (ATCC 27294) para infecção foi realizada a partir de uma alíquota de micobactérias congelada à $-70^{\circ} \mathrm{C}$ (com viabilidade superior a $85 \%$ ). Mil microlitros $(\mu \mathrm{L})$ dessa alíquota foram distribuídos em $2.5 \mathrm{~mL}$ de meio Middlebrook 7H9 (BD Bioscience, Franklin Lakes, NJ, USA) enriquecido com OADC (BD Biosciences, Spark, USA), seguindo-se incubação por 10 dias, a $37^{\circ} \mathrm{C}$. A suspensão de micobactérias obtida foi centrifugada a 3220 x g por 20 minutos. O sedimento foi ressuspenso em $2 \mathrm{~mL}$ de PBS estéril/livre de endotoxinas e agitado vigorosamente por 1 minuto em tubo contendo pérolas de vidro, até adquirir aspecto homogêneo. A viabilidade da cultura foi verificada incubando-se $100 \mu \mathrm{L}$ desta suspensão de bactérias com $100 \mu \mathrm{L}$ de diacetato de fluoresceína $(2 \mu \mathrm{g} / \mathrm{mL}$ - Acros Organics, Geel, Bélgica) e $100 \mu \mathrm{L}$ de brometo de etídio $(10 \mathrm{mg} / \mathrm{mL}$ - Sigma-Aldrich, St. Louis, MO, USA) por 10 minutos a $37^{\circ} \mathrm{C}$. Após incubação, a viabilidade foi determinada com auxílio de microscópio de fluorescência modelo Aristoplan (Leica 
Microsystems GmbH, Wetzlar, Germany). As bactérias viáveis apresentavam coloração verde enquanto as bactérias mortas coravam-se com a solução de brometo e apresentavam coloração avermelhada. As suspensões celulares com viabilidade igual ou superior a $85 \%$ foram diluídas para determinar sua concentração utilizando como padrão a Escala de McFarland, como descrito previamente (Bonato, Gonçalves et al. 2004; Morais da Fonseca, Lopes Silva et al. 2007).

Para controle da concentração do inoculo, uma alíquota de $100 \mu \mathrm{L}$ da suspensão de bactérias foi utilizada para realizar diluição seriada de 100, 1000, 10.000 e 100.000 vezes. Um volume igual a $100 \mu \mathrm{L}$ de cada uma das diluições foi distribuído em meio 7H11 (DIFCO Laboratories, Detroit, MI, USA). As placas foram vedadas e incubadas por 28 dias a $37^{\circ} \mathrm{C}$. Após esse período as unidades formadoras de colônia (UFC) foram contadas com auxílio de lupa (Leica Microsystems, ZOOM 2000) e os números de colônias obtidos foram corrigidos pelo fator de diluição.

\subsubsection{Infecção intranasal}

Os camundongos foram infectados com $50 \mu \mathrm{L}$ contendo $1 \times 10^{5}$ bacilos pela via intranasal. Para esse procedimento os animais foram previamente anestesiados com 100 $\mu \mathrm{L}$ de uma solução de $20 \%$ de Ketamina (Cloridrato de Cetamina, Ketamina Agener, Embu-Guaçu, SP, Brasil) e 10\% de Xilazina (Dopazer® Laboratórios Calier S.A., Barcelona, Espanha), pela via intraperitoneal.

\subsection{Delineamento experimental para indução de coinflamação TB/OVA.}

Após 30 dias da infecção com $M$. tuberculosis, os camundongos foram submetidos ao protocolo de indução de asma experimental como descrito abaixo. Esse protocolo experimental foi denominado coinflamação.

Inicialmente, os animais foram imunizados com $100 \mu \mathrm{g}$ de albumina de ovo de galinha, OVA (Fração V, Sigma, St Louis, Mo, EUA), na presença de $1.6 \mathrm{mg}$ do adjuvante $\mathrm{Al}(\mathrm{OH})_{3}$, em um volume final de $200 \mu \mathrm{L}$ pela via subcutânea (sc). Após 14 dias, os animais foram imunizados novamente pela via intraperitoneal com $50 \mu \mathrm{g}$ de OVA diluída em $100 \mu \mathrm{L}$ de uma solução estéril e apirogênica de cloreto de sódio $0.9 \%$ (Samtec Botecnologia, Ribeirão Preto, SP, Brasil). Após 21 dias da primeira imunização, os camundongos foram desafiados com $100 \mu \mathrm{g}$ de OVA diluída em $50 \mu \mathrm{L}$ 
de solução de cloreto de sódio $0.9 \%$, pela via intranasal (in). Três dias após o desafio, os animais foram sacrificados.

Considerando que a OVA é uma proteína comumente utilizada na geração de asma experimental, quando administrada com adjuvante (de Heer, Hammad et al. 2004; Lambrecht and Hammad 2009), a partir desse momento utilizaremos a sigla TB/OVA para referirmos aos animais submetidos ao protocolo de coinflamação e OVA para referirmos aos animais submetidos somente ao protocolo de asma experimental.

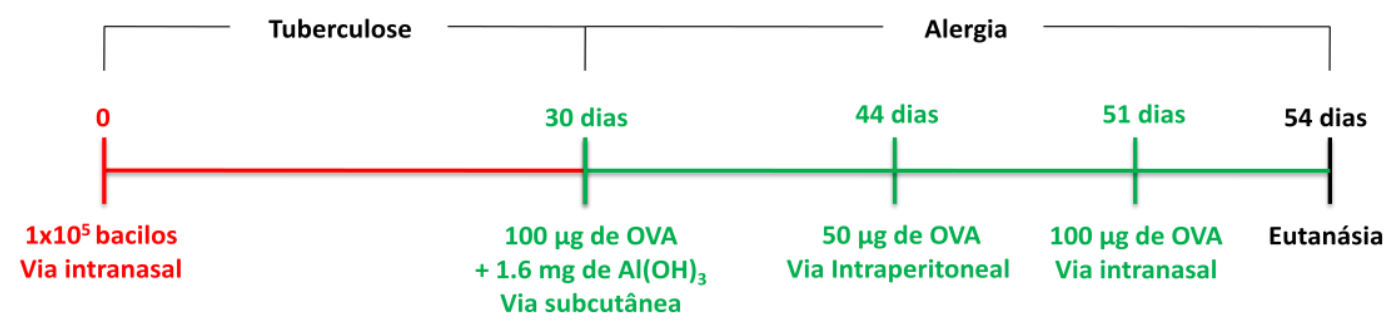

Figura 2. Delineamento experimental tuberculose e asma (TB/OVA). Trinta dias após a infecção com $M$. tuberculosis, os camundongos foram submetidos ao protocolo de indução de asma experimental.

\subsection{Delineamento experimental para avaliação dos mediadores lipídicos utilizando o tratamento com MK886 nos animais coinflamados (TB/OVA)}

Camundongos 129Sv, coinflamados (TB/OVA) foram tratados durante a fase de indução de alergia com 5 mg/Kg de MK886 (Merck Frost, Canadá), composto que inibe a síntese de mediadores lipídicos pela via da enzima 5 lipoxigenase (5-LO). O composto liga-se na FLAP (proteína ativadora de 5-lipoxigenase), impedindo a ativação da enzima 5-LO. O MK886 foi fornecido pela Prof ${ }^{\mathrm{a}}$. Dr ${ }^{\mathrm{a}}$. Lúcia Helena Faccioli (Faculdade de Ciências Farmacêuticas de Ribeirão Preto - FCFRP-USP).

O tratamento iniciou-se 1 hora antes da sensibilização com OVA e a cada $24 \mathrm{~h}$ foram administrados por gavagem $5 \mathrm{mg} / \mathrm{Kg}$ de MK886 diluído em $100 \mu \mathrm{L}$ de etanol absoluto (J.T. Baker, México) e $4.9 \mathrm{~mL}$ de água estéril para a obtenção de uma concentração de $0,4 \mathrm{mg} / \mathrm{mL}$ (Figura 3). Os animais receberam um volume final de 0.5 mL de MK886 diluído, durante 24 dias até o dia da eutanásia. 


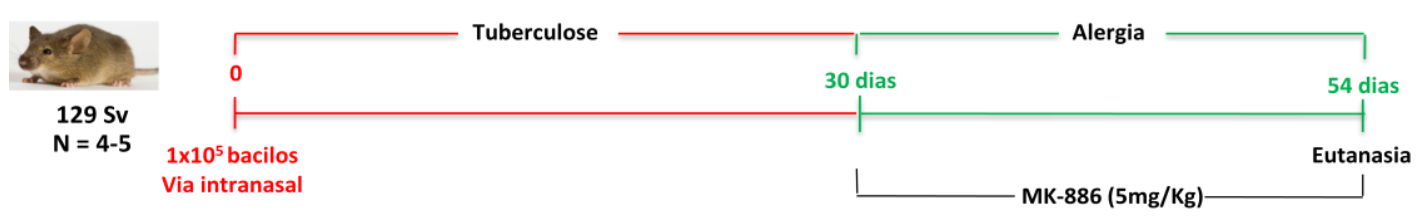

Figura 3. Protocolo de indução de coinflamação e tratamento com MK886. Camundongos $129 \mathrm{~Sv}$ foram submetidos ao protocolo de coinflamação (TB/OVA) e durante a fase de sensibilização e desafio para indução de asma experimental, os animais foram tratados diariamente com $5 \mathrm{mg} / \mathrm{Kg}$ de $\mathrm{MK} 886$ por gavagem.

\subsection{Procedimentos experimentais}

Após os 54 dias da infecção com M. tuberculosis, os camundongos foram submetidos aos seguintes procedimentos experimentais:

\subsubsection{Obtenção e processamento do Lavado Broncoalveolar (LBA)}

Após 72 horas do desafio, os animais imunizados e desafiados com OVA receberam uma dose letal de anestésico, pela via retrorbital. Para obter o LBA, os animais foram sujeitos à cirurgia para expor a traqueia, que foi perfurada utilizando um cateter estéril (BD Ind. Cirúr, Curitiba, PR, Brasil). Posteriormente, com uma seringa hipodérmica de $1 \mathrm{~mL}$ (BD Ind. Cirúr, Curitiba, PR, Brasil), foi injetado e recuperado 1 mL de meio de cultura RPMI-1640 incompleto, (Sigma-Aldrich, St Louis, MO, USA). Este procedimento foi realizado 5 vezes. Para obter as células do LBA, o meio recuperado resultante da coleta dos $5 \mathrm{~mL}$ injetados foi armazenado em tubos tipo Falcon de $15 \mathrm{~mL}$. O conteúdo foi centrifugado a $453 \mathrm{x} \mathrm{g}, 10$ minutos, a $4^{\circ} \mathrm{C}$. $\mathrm{O}$ sedimento obtido foi ressuspenso em $500 \mu \mathrm{L}$ de meio RPMI-1640 incompleto (Sigma-Aldrich, St Louis, MO, USA). A contagem total de células foi realizada utilizando câmara de Neubauer e o corante azul de tripan (Vetec Química Final, LTDA, Rio de Janeiro, RJ, Brasil) em uma diluição de 1:10. A contagem diferencial das células do LBA foi realizada com $50 \mu \mathrm{L}$ da suspensão celular por citocentrifugação a $400 \mathrm{rpm}$ (rotações por minuto), durante 3 minutos. Após a citocentrifugação, as células foram coradas com o corante Panótico Rapido (LABORCLIN, LTDA, Pinhais, PR, Brasil). As contagens de macrófagos, linfócitos, neutrófilos e eosinófilos foram realizadas de acordo com os parâmetros morfológicos observados no aumento de 1000x. Para cada animal foi quantificada o total de 100 células, em campos aleatórios. 


\subsubsection{Contagem de corpúsculos lipídicos em células do LBA}

A contagem de corpúsculos lipídicos foi realizada a partir de células obtidas do LBA como descrito acima. Foram utilizadas $100 \mu \mathrm{L}$ da suspensão de células para confecção de lâminas por citocentrifugação a $400 \mathrm{rpm}$, durante 3 minutos. Após a citocentrifugação, as células foram fixadas com 3.7\% de formol em PBS e coradas pelo método de Tetróxido de ósmio $\left(\mathrm{OsO}_{4}\right)$ descrito por (Bozza, Payne et al. 1996). Brevemente, as lâminas foram lavadas com $0.1 \mathrm{M}$ de tampão cacodilato, pH $7.4 \mathrm{e}$ coradas com $1.5 \%$ de $\mathrm{OsO}_{4}$ por 30 minutos. Posteriormente, as células foram lavadas com água destilada e submersas em uma solução de tiocarbohidrazida 1.0\%. As células foram novamente lavadas e coradas com tampão cacodilato $0.1 \mathrm{M}$ e $1.5 \%$ de $\mathrm{OsO}_{4}$ durante 3 minutos. Após esse período, as lâminas foram lavadas e incubadas a temperatura ambiente para secagem. A contagem de corpúsculos lipídicos foi realizada em microscópio óptico, utilizando o aumento de 1000x. Para cada animal foram quantificadas 100 células totais, em campos aleatórios.

\subsubsection{Contagem de Unidades Formadoras de Colônia (UFC) no pulmão}

Para quantificação do número de Unidades Formadoras de Colônia (UFC) nos pulmões dos animais, os lóbulos médio e inferior direito foram lavados com PBS estéril e cortados em fragmentos pequenos. Posteriormente, os fragmentos foram digeridos com uma solução de RPMI-1640 incompleto contendo $0,5 \mu \mathrm{g} / \mathrm{mL}$ de liberase (Liberase TM Research Grade - Roche Diagnostics GmbH, Indianapolis, IN, USA) e 0,04 $\mu \mathrm{g} / \mathrm{mL}$ de DNAse I de pâncreas de bovino (Sigma-Aldrich, Co St Louis Mo, USA). Os fragmentos de pulmão foram incubados com as enzimas a $37^{\circ} \mathrm{C}$, durante 30 minutos sob agitação constante de $250 \mathrm{rpm}$. Após a incubação, as células foram dispersas com auxílio de seringa de $10 \mathrm{~mL}$ e centrifugadas a 453 x g, 10 minutos a $4^{\circ} \mathrm{C}$. $\mathrm{O}$ sobrenadante foi descartado e as células obtidas foram ressuspensas em $1 \mathrm{~mL}$ de meio RPMI suplementado com 10\% de soro fetal bovino (SFB) (Gibco - Invitrogen, Grand Island, NY, USA), para interromper a ação da liberase e da DNAse. Uma alíquota de $100 \mu \mathrm{L}$ da suspensão celular foi utilizada para realizar as seguintes diluições seriadas: 10, 100, 1000, 10.000 e 100.000 vezes. A partir da diluição 1:100 foi plaqueado um volume igual a $100 \mu \mathrm{L}$ em meio sólido $7 \mathrm{H} 11$. As placas foram vedadas e incubadas a $37^{\circ} \mathrm{C}$ por 28 dias. Após esse tempo, o número de UFC foi contado com auxílio de lupa (Leica Microsystems, ZOOM 2000), sendo posteriormente corrigido pelo fator de diluição. 


\subsubsection{Quantificação de populações celulares por citometria de fluxo}

Após a digestão do pulmão com liberase e DNAse, como descrito acima, $4 \mathrm{~mL}$ de meio RPMI contendo $10 \%$ de soro fetal bovino (SFB) foram acrescentados às amostras. As células obtidas foram separadas dos fragmentos de pulmão utilizando um filtro de $100 \mu \mathrm{m}$ (Cell Strainer, BD Biosciences, San Jose, California), o qual, posteriormente, foi lavado com $5 \mathrm{~mL}$ de meio RPMI incompleto. O filtrado obtido foi centrifugado a $453 \mathrm{x} \mathrm{g}, 10$ minutos a $4^{\circ} \mathrm{C}$. O sedimento celular resultante foi submetido ao protocolo de lise de hemácias por 3 minutos, sendo novamente centrifugado a $453 \mathrm{x}$ g, 10 minutos a $4^{\circ} \mathrm{C}$. Em seguida, o sedimento celular foi ressuspenso em $1 \mathrm{~mL}$ de meio RPMI incompleto, e como descrito acima, as células foram quantificadas utilizando azul de tripan.

Para a realização da fenotipagem das populações de linfócitos $\mathrm{T}$, células dendríticas e macrófagos, 1 × $10^{6}$ células foram incubadas a $4^{\circ} \mathrm{C}$ por 40 minutos Block $\left(1 \mu \mathrm{g} / 1\right.$ x $10^{6}$ células; BD Bioscience, San Jose, CA, USA). células foram incubadas com os anticorpos monoclonais descritos na

Tabela 1, durante 30 minutos a $4^{\circ} \mathrm{C}$, no escuro. Os anticorpos foram diluídos em solução de fosfato tamponado contendo $2 \%$ de SFB (Tampão FACS). Após a incubação, as células foram lavadas com $2 \mathrm{~mL}$ de tampão FACS e depois fixadas com solução tamponada contendo $1 \%$ de formol. A marcação com os anticorpos foi avaliada por citometria de fluxo, utilizando o citômetro FACSCanto ${ }^{\mathrm{TM}} \mathrm{II}$ (BD, San José, CA, USA). Foram adquiridos 100.000 eventos por amostra, utilizando o programa Cell Quest. As células foram avaliadas por tamanho (FSC), granularidade (SSC) e intensidade de fluorescência. Inicialmente foi selecionada uma região para excluir as células que estavam entre si, processo conhecido como exclusão de doublets. Para isso, as células selecionadas pelos parâmetros de FSC-A (área) e FSC-H (altura). Uma vez doublets, foram utilizados os parâmetros de FSC-A e SSC-A, para selecionar a que contém as células de maior tamanho e granulosidade, esta região contém as dendríticas e os macrófagos ou a região de menor tamanho e granulosidade, esta contém os linfócitos. As células presentes nesta região foram utilizadas para expressão de diferentes moléculas utilizando os anticorpos monoclonais descritos na

Tabela 1. Os dados foram analisados utilizando-se o software FlowJoTM 7.6.1 (Tree Star, Inc. Ashland, Oregon, USA). 
Tabela 1. Anticorpos monoclonais utilizados para análise do fenótipo celular por citometria de fluxo

\begin{tabular}{|c|c|c|c|}
\hline Fenótipo & Anticorpos & Clone & Isotipo \\
\hline \multirow{4}{*}{ Linfócitos } & CD3 - FITC & $145-2 \mathrm{C} 11$ & Hamster, IgG1, $\kappa$ \\
\hline & $\mathrm{CD} 3-\mathrm{APC}$ & $145-2 \mathrm{C} 11$ & Hamster, IgG1, $\kappa$ \\
\hline & $\mathrm{CD} 8-\mathrm{PE}$ & $53-6.7$ & Rato, IgG2a, $\kappa$ \\
\hline & $\mathrm{CD} 8-\mathrm{PECy}^{\mathrm{TM}} 5$ & $53-6.7$ & Rato, IgG2a, $\kappa$ \\
\hline \multirow{3}{*}{ Células dendríticas } & CD11b - APC-CyTM 7 & $\mathrm{M} 1 / 70$ & Rato, IgG2b, $\kappa$ \\
\hline & CD11c - PECyTM 7 & HL3 & Hamster, IgG1, $\lambda 2$ \\
\hline & CD317- PE & eBio297 & Rato, IgG2b, $\kappa$ \\
\hline \multirow{3}{*}{ Macrófagos } & CD11b - APC-CyTM 7 & $\mathrm{M} 1 / 70$ & Rato, IgG2b, $\kappa$ \\
\hline & CD11c - PECyTM 7 & HL3 & Hamster, IgG1, $\lambda 2$ \\
\hline & CD206 - Alexa488 & MR5D3 & Rato, IgG2a, $\kappa$ \\
\hline
\end{tabular}

\subsubsection{Avaliação da expressão de genes}

\subsubsection{Extração de RNA}

Para a extração de RNA mensageiro (mRNA), os lóbulos direitos, inferior e mediano, ou os lóbulos esquerdos foram homogeneizados em $1 \mathrm{~mL}$ de Trizol (Invitrogen, Carlsbad, CA, USA) utilizando homogeneizador S10NG IKA® T10 basic (IKA® - Werke GMHB \& Co. KG, Staufen-Alemanha). As amostras homogeneizadas foram incubadas por 5 minutos a temperatura ambiente com Trizol. Para separar o material proteico e lipídico e obter condições adequadas para a extração de RNA, os pulmões homogeneizados foram centrifugados a $12000 \mathrm{x}$ g, 15 minutos a $4{ }^{\circ} \mathrm{C}$. $\mathrm{O}$ sobrenadante foi transferido para um tubo cônico estéril de 1,5 mL, $200 \mu \mathrm{L}$ de clorofórmio foram acrescentados (Vetec Quimica Fina, Rio de Janeiro, RJ, Brasil), seguindo-se de homogeneização por vortex. Posteriormente, as amostras foram centrifugadas a $12000 \mathrm{x} \mathrm{g}, 15$ minutos a $4^{\circ} \mathrm{C}$. Após a centrifugação, foram obtidas três fases, uma fase inferior que contém o DNA, uma fase intermediária que contém proteína, e uma fase superior, transparente, que contém RNA. Dessa última fase foram 
retirados $200 \mu \mathrm{L}$, transferidos para tubo estéril de $1,5 \mathrm{~mL}$, contendo $800 \mu \mathrm{L}$ de isopranol (LabSynth, Diadema, SP, Brasil). Para diminuir a contaminação por fenol, as amostras foram lavadas duas vezes com $1 \mathrm{~mL}$ de solução de etanol $75 \%$ em água livre de RNAses ou água contendo o agente inibidor de RNAses, dietilpirocarbonato (DEPC), (Sigma, St Louis, MO, USA). Após as lavagens, o RNA foi deixado à temperatura ambiente durante 15 minutos para secagem, e em seguida, ressuspenso em $30 \mu \mathrm{L}$ de água livre de RNAses. O RNA obtido foi quantificado utilizando Nanodrop (Thermo Fisher Scientific, Wilmington, DE, USA) e o programa ND1000V37.1. As leituras de absorbância foram realizadas no comprimento de onda $260 \mathrm{~nm}$.

\subsubsection{2. $\quad$ Preparação de cDNA}

Para preparar o DNA complementar (cDNA), $1 \mu \mathrm{g}$ do RNA extraído foi tratado com DNAse I 10x (Invitrogen by life Biotechnologies ${ }^{\mathrm{TM}}$, Carlsbad, CA, USA) durante 15 minutos a $25^{\circ} \mathrm{C}$. Posteriormente, as amostras foram incubadas com $1 \mu \mathrm{L}$ de EDTA $25 \mathrm{mM}$ (Invitrogen by life Biotechnologies ${ }^{\mathrm{TM}}$, Carlsbad, CA, USA), a $65^{\circ} \mathrm{C}$, durante 15 minutos, para interromper a ação da enzima. A fim de iniciar a síntese de cDNA, o RNA tratado com DNAse foi incubado durante 2 minutos a $42^{\circ} \mathrm{C}$, com $1 \mu \mathrm{L}$ de dNTPs $10 \mathrm{mM}$ e $1 \mu \mathrm{L}$ de OligodT $0.5 \mu \mathrm{g} / \mu \mathrm{L}$ (Invitrogen by life Biotechnologies ${ }^{\mathrm{TM}}$, Carlsbad, CA, USA), $2.5 \mu \mathrm{L}$ de Buffer $5 \mathrm{x}, 2.0 \mu \mathrm{L}$ de DTT $0.1 \mathrm{M}$ (Invitrogen by life Biotechnologies $^{\mathrm{TM}}$, Carlsbad, CA, USA), $0.5 \mu \mathrm{L}$ de $\mathrm{MgCl}_{2} 25 \mathrm{mM}$ e $2 \mu \mathrm{L}$ de água ultrapura (Invitrogen, Carlsbad, CA, USA). Em seguida, $1 \mu \mathrm{L}$ da enzima Reverse transcriptase SuperScript ${ }^{\mathrm{TM}}$ II (Invitrogen by life Biotechnologies ${ }^{\mathrm{TM}}$, Carlsbad, CA, USA) foi acrescentado às amostras, que foram incubadas durante 50 minutos a $42^{\circ} \mathrm{C}$. Posteriormente, as amostras foram incubadas a $70^{\circ} \mathrm{C}$ durante 15 minutos, seguido de uma incubação a $4{ }^{\circ} \mathrm{C}$ por 10 minutos. O cDNA obtido foi quantificado utilizando Nanodrop (Thermo Fisher Scientific, Wilmington, DE, USA) e o programa ND1000V37.1. As leituras de absorbância foram realizadas no comprimento de onda $260 \mathrm{~nm}$.

As amostras de cDNA foram diluídas em água livre de RNAses até atingir a concentração $100 \mathrm{ng} / \mu \mathrm{l}$. O cDNA diluído foi armazenado a $-70^{\circ} \mathrm{C}$ até a avaliação da expressão de genes por real time. 


\subsubsection{Quantificação da expressão de genes por PCR em tempo real (RT-} $\underline{P C R)}$

Para a quantificação genes por RT-PCR, $3 \mu \mathrm{l}$ do cDNA diluído foram acrescentados com $6.25 \mu \mathrm{l}$ de Maxima SYBR Green/ROX qPCR Master Mix (2x) (Thermo Fisher Scientific, Inc. Waltham, MA, USA), $0.5 \mu 1$ de cada par de primer (10 $\mu \mathrm{M}$ - Invitrogen by life Biotechnologies ${ }^{\mathrm{TM}}$, Carlsbad, CA, USA) e $2.75 \mu \mathrm{l}$ de água livre de nucleases. As condições para amplificação dos genes de interesse compreendem uma fase inicial de incubação do cDNA a $50{ }^{\circ} \mathrm{C}$ durante 2 minutos. Posteriormente, as amostras foram submetidas a um processo de desnaturação a $95{ }^{\circ} \mathrm{C}$ durante 10 minutos. Após esse período, as amostras passaram por 40 ciclos contendo fase de desnaturação a $95{ }^{\circ} \mathrm{C}$ durante 15 segundos, seguida de fase de anelamento a $58{ }^{\circ} \mathrm{C}$ por 30 segundos e, finalmente, uma fase de extensão da fita de DNA a $72^{\circ} \mathrm{C}$ por 30 segundos. As reações e análises foram realizadas no aparelho StepOnePlus ${ }^{\mathrm{TM}}$ Real-Time PCR Systems (Applied Biosystems, Foster City, CA, USA). Os resultados foram analisados com base no valor de CT (Cicle Threshold - ou ciclo limiar). O CT é o ponto que indica o número de ciclos onde a amplificação atinge um dado limiar que permite a análise quantitativa da expressão do fator avaliado. A fórmula utilizada para análise dos resultados foi 2$(\Delta \Delta \mathrm{Ct})$, na qual $\Delta \Delta \mathrm{Ct}=\Delta \mathrm{Ct}$ amostra $-\Delta \mathrm{Ct}$ controle e $\Delta \mathrm{Ct}=\mathrm{CT}$ gene alvo $-\mathrm{CT} \beta$ Actina (gene de referência endógeno). As sequências dos primers avaliados encontramse na Tabela 2. 
Tabela 2. Sequência de primers utilizados para quantificação de genes por PCR em tempo real

\begin{tabular}{|c|c|c|}
\hline \multirow{2}{*}{ GENE } & TIPO DE PRIMER & SEQUÊNCIA 5' --> 3' \\
\hline \multirow{2}{*}{$\beta$-Actina } & Sense & CCC TAG GCA CCA GGG TGT GA \\
\cline { 2 - 3 } & Antisense & GCC ATG TTC AAT GGG GTA CTT C \\
\hline \multirow{2}{*}{ iNOS2 } & Sense & TGC TGT TCT CAG CCC AAC AAT A \\
\cline { 2 - 3 } & Antisense & GTC CAG GGA TTC TGG AAC ATT CT \\
\hline \multirow{3}{*}{ Arginase 1 } & Sense & CAA AAG GAC AGC CTC GAG GAG \\
\cline { 2 - 3 } & Antisense & CCC GTG GTC TCT CAC GTC AT \\
\hline \multirow{2}{*}{ Fizzl } & Sense & CCT GAG ATT CTG CCC CAG GAT \\
\cline { 2 - 3 } & Antisense & TTC ACT GGG ACC ATC AGC TGG \\
\hline \multirow{2}{*}{ Ym1 } & Sense & TCA CAG GTC TGG CAA TTC TTC TG \\
\cline { 2 - 3 } & Antisense & ACT CCC TTC TAT TGG CCT GTC C \\
\hline
\end{tabular}

\subsubsection{Ensaio imunoenzimático de ELISA para a detecção de citocinas.}

Para a detecção de citocinas no homogenato pulmonar foram utilizados os kits imunoenzimáticos DuoSet ${ }^{\circledR}$ ELISA Development System (R\&D Systems, Inc. Minneapolis, MN, USA) e BD OptEIA ${ }^{T M}$ Set (BD Biosciences, San Diego, CA, USA). As referências de cada kit usado para detecção de citocinas encontram-se na Tabela 3. Os kits foram usados de acordo com as instruções dos fabricantes. 
Tabela 3. Kits utilizados para a detecção de citocinas no homogenato de pulmão

\begin{tabular}{|c|c|c|}
\hline CITOCINA & NÚMERODE CATÁLOGO & FABRICANTE \\
\hline IFN- $\gamma$ & 555138 & \multirow{2}{*}{ BD Biosciences } \\
\hline IL-5 & 555236 & \multirow{2}{*}{ R\&D Systems } \\
\hline IL-13 & DY413 & \\
\hline TGF- $\beta$ & DY1679 & \\
\hline IL-1 $\beta /$ IL-1F2 & DY401 & \\
\hline
\end{tabular}

\subsubsection{Análise histopatológica}

Após 24 ou 72 horas do desafio com OVA, os pulmões foram coletados para análise histopatológica. O lóbulo direito superior foi armazenado em tampão de fosfato, contendo $37 \%$ de formaldeído $(\mathrm{pH}=7.0)$, e posteriormente, foi realizada a inclusão em parafina e confecção das lâminas. As cortes histológicos do pulmão foram corados com Hematoxilina e Eosina (H\&E) e com Picrusirius Red. As lâminas coradas para $\mathrm{H} \& \mathrm{E}$ foram analisadas morfometricamente pela patologista $\operatorname{Prof}^{\mathrm{a}}$. $\operatorname{Dr}^{\mathrm{a}}$. Simone Gusmão Ramos (Departamento de Patologia FMRP-USP). As imagens coradas com H\&E foram capturadas utilizando aumento de 100X em microscópio Olympus BX50 acoplado à câmera Olympus DP71 (Olympus Corporation, Japan). Os cortes de pulmão corados com Picrusirius Red foram utilizados para quantificação da deposição de fibras de colágeno. Imagens dos pulmões corados foram capturadas em microscópio óptico, no aumento de 200X. A quantificação da fibrose foi determinada pela razão entre as somas das áreas do pulmão positivas para a coloração de Picrusirius Red.

A análise das imagens para quantificação de deposição de fibras de colágeno foi realizada com o software ImageJ (NIH Image Inc., Bethasda, Maryland, USA). 


\subsubsection{Análise estatística}

Para a realização da análise estatística, utilizamos o programa StatSoft, Inc. (2004) STATISTICA (data analysis software system), version 7, Tulsa, OK, USA. Para análise com dois grupos experimentais, inicialmente, foi realizado o teste de normalidade Shapiro Wilk, seguido do teste de Levene's para avaliar homogeneidade de variâncias. Os experimentos cujos dados foram positivos para ambos os testes foram analisados aplicando teste $\mathrm{t}$ não pareado (one tailed). Os dados que não passaram no teste de normalidade ou no teste de Levene's foram transformados utilizando a função $\log _{10}$ e analisados novamente. Uma vez transformados, os dados que foram negativos para um ou para os dois testes foram analisados utilizando o teste não paramétrico de Mann Whitney.

Os experimentos com mais de dois grupos, também foram submetidos ao teste de normalidade Shapiro Wilk e ao teste de Levene's de igualdade de variâncias. Os experimentos cujos dados passaram nos dois testes foram analisados utilizando análise de variância de uma via (ANOVA), aplicando o teste Tukey. Os dados que não passaram em nenhum dos testes anteriores foram transformados utilizando a função $\log _{10}$ e analisados novamente. Para os dados transformados que não passaram nos dois testes foi aplicado o teste não paramétrico Kruskall Wallis com análise de médias. Os valores com $\mathrm{p}<0.05$ foram considerados estatisticamente significativos. 


\section{RESULTADOS}

Resultados preliminares do nosso grupo mostraram que camundongos submetidos ao protocolo de coinflamação, tuberculose - alergia (Figura 2) exibiram diminuição da carga bacilar no pulmão, associada com redução no infiltrado granulomatoso, aumento no número de linfócitos $\mathrm{T} \mathrm{CD8}^{+}$e na produção de $\mathrm{LTB}_{4}$ (Figura 1). Assim, nós nos propusemos a avaliar como efetivamente cada um desses parâmetros poderia afetar a diminuição do crescimento de bacilos no pulmão dos animais infectados e alérgicos (TB/OVA).

\subsection{Papel dos linfócitos $\mathrm{T} \mathrm{CD8}^{+}$na diminuição no crescimento de $M$. tuberculosis nos animais coinflamados, TB/OVA}

Os linfócitos $\mathrm{T} \mathrm{CD}^{+}$são células importantes no controle da infecção por $M$. tuberculosis (Müller, Cobbold et al. 1987) e na produção das citocinas proinflamatórias IFN- $\gamma$ e TNF durante a infecção (Flynn, Goldstein et al. 1992). Os resultados preliminares de nosso grupo mostraram que a diminuição no crescimento do bacilo nos animais infectados com $M$. tuberculosis e alérgicos (TB/OVA) está associada com aumento no número de linfócitos $\mathrm{T} \mathrm{CD}^{+}$no pulmão desses animais (Figura 1A). Para determinar o papel dessas células na diminuição da carga bacilar, foram utilizados animais deficientes para a molécula CD8 (CD8KO). Primeiramente, foi avaliado se os animais CD8KO coinflamados (CD8KO-TB/OVA) apresentavam parâmetros característicos da alergia. Foi observado que os animais CD8KO-TB/OVA apresentavam aumento no número $(\mathrm{p}>0.05)$ e na frequência $(\mathrm{p}<0.05)$ de eosinófilos presentes no LBA quando comparados com o grupo CD8KO-TB (Apêndice 1).

4.1.1. Quantificação de linfócitos $T \mathrm{CD}^{+}$e número de UFC em camundongos CD8KO coinflamados

Inicialmente, foram avaliadas as populações de linfócitos $\mathrm{T} \quad \mathrm{CD} 8^{+} \mathrm{em}$ camundongos selvagens (Wild Type, WT) e animais CD8KO da linhagem C57BL/6, submetidos ao protocolo de coinflamação (Figura 4A). Foi observado que os animais WT coinflamados (WT-TB/OVA) apresentaram aumento significativo no número de 
linfócitos $\mathrm{T} \mathrm{CD}^{+}$, se comparados com os animais WT infectados (WT-TB). Como esperado, esse aumento não foi observado nos animais CD8KO-TB/OVA (Figura 4B). Estes resultados foram similares daqueles observados em animais da linhagem BALB/c quando submetidos ao protocolo de coinflamação (Figura 1A).

Posteriormente, quando avaliamos a carga bacilar dos animais CD8KO, observamos que tanto os animais CD8KO-TB/OVA, quanto os animais CD8KO infectados (CD8KO-TB) apresentaram números de UFC semelhantes (Figura 4C). Do mesmo modo, observamos que o crescimento de bacilos no pulmão de animais WTTB/OVA foi similar ao observado nos grupos CD8KO-TB/OVA e CD8KO-TB. Entretanto, de modo inesperado, os animais WT-TB apresentaram carga bacilar significativamente menor que os animais WT-TB/OVA $(\mathrm{p}<0.05)$ (Figura 4C). Esses resultados foram diferentes daqueles observados nos animais da linhagem BALB/c que foram submetidos ao protocolo TB/OVA, pois como representado na Figura 4D, os animais TB/OVA dessa linhagem foram mais resistentes à infecção por M. tuberculosis em relação aos animais infectados (linhagem BALB/c) $(\mathrm{p}<0.05)$.

Esses resultados sugerem que os animais CD8KO talvez não representem uma estratégia adequada para avaliar a diminuição do crescimento do bacilo nos animais TB/OVA. Além disso, os resultados sugerem que a linhagem de camundongo parece influenciar na resposta imune desses animais frente à infecção por M. tuberculosis. Em resumo, os animais TB/OVA da linhagem BALB/c apresentaram maior controle no crescimento de bacilos que o grupo TB da mesma linhagem. Entretanto, os animais TB/OVA da linhagem C57BL/6 exibiram menor controle no crescimento de bacilos quando comparados com o grupo TB da mesma linhagem. 
A)

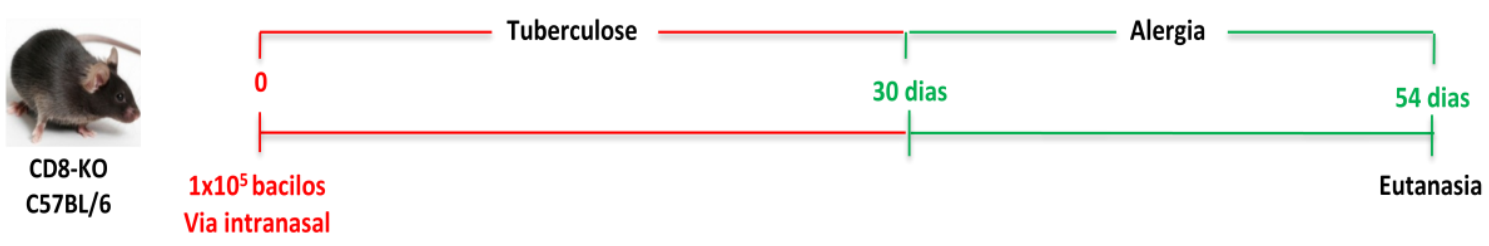

B)

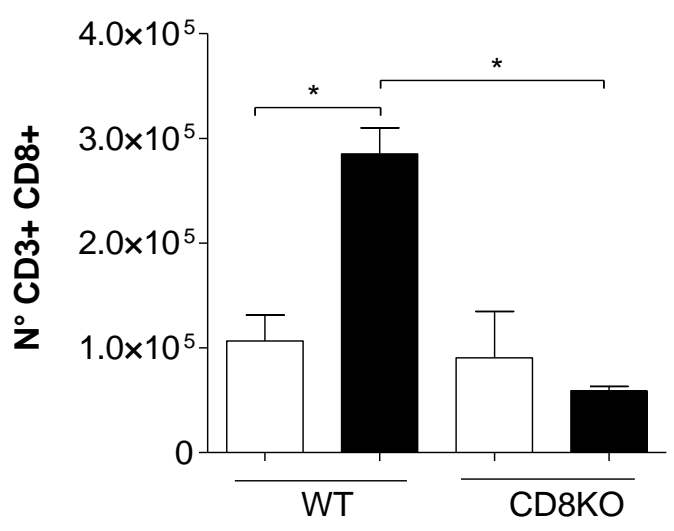

C)

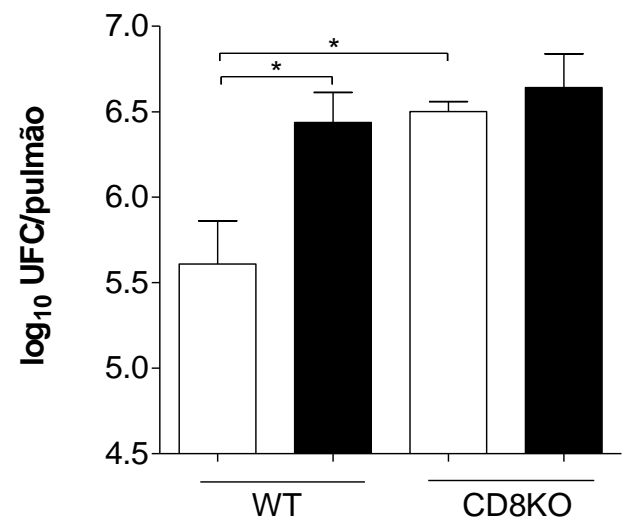

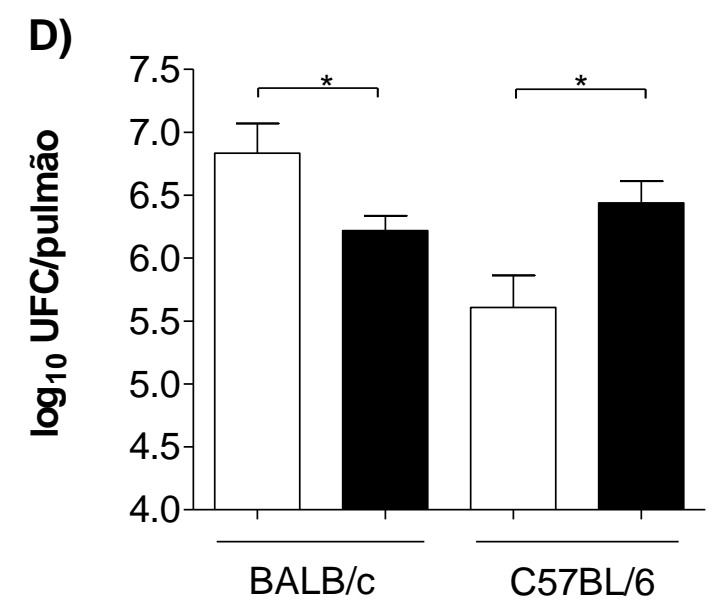

Figura 4. Número de células CD8+ e contagem do número de UFC no pulmão de camundongos submetidos ao protocolo TB/OVA. (A) Camundongos C57BL/6, CD8KO e BALB/c foram infectados com M. tuberculosis e 30 dias após a infecção foram submetidos ao protocolo de alergia descrito anteriormente. Após 72 horas do desafio com alérgeno, os pulmões foram processados para avaliar o número de células $\mathrm{CD}^{+}(\mathbf{B})$ e o número de bacilos (UFC) no pulmão (C - D). Resultados representativos de 1 a 6 experimentos independentes $(n=5-9$ animais por grupo por experimento), com valores individuais expressos como médias \pm desvio padrão. $* \mathrm{p}<0.05$.

$\mathrm{TB}=$ Grupo infectado com $M$. tuberculosis TB/OVA = Grupo infectado com $M$. tuberculosis e alérgico 


\subsubsection{Análise histológica}

Devido ao recrutamento de células no pulmão e à intensa resposta inflamatória causada pela infecção com $M$. tuberculosis, a estrutura desse órgão é afetada e um comprometimento do parênquima é evidenciado pela formação de granulomas e o surgimento de processos necróticos (Fayyazi, Eichmeyer et al. 2000). Considerando que os animais TB/OVA da linhagem C57BL/6 apresentaram maior carga bacilar comparados aos animais TB da mesma linhagem, nós avaliamos o estado do parênquima pulmonar desses animais através de análise histopatológica. A Figura 5 mostra imagens representativas do pulmão, corado com hematoxilina e eosina, dos diferentes grupos estudados. Foi observado que de modo geral, os quatro grupos experimentais mostraram comprometimento no parênquima pulmonar, infiltrado crônico e multifocal, com predomínio de macrófagos xantomatosos e hiperplasia no tecido linfóide associado aos brônquios (BALT) (Figura 5A-D). Em adição, os pulmões dos animais do grupo WT-TB/OVA apresentaram processo inflamatório maior e disperso, se comparado com o grupo WT-TB. Similarmente, observamos que os animais CD8KO-TB/OVA e o grupo CD8KO-TB, também mostraram maior processo inflamatório no parênquima pulmonar em relação aos animais WT-TB (Figura 5 A, BD).

Esses resultados sugerem que além do aumento na susceptibilidade à infecção por M. tuberculosis, os animais WT-TB/OVA (linhagem C57BL/6) também apresentaram aumento da inflamação no parênquima pulmonar. 

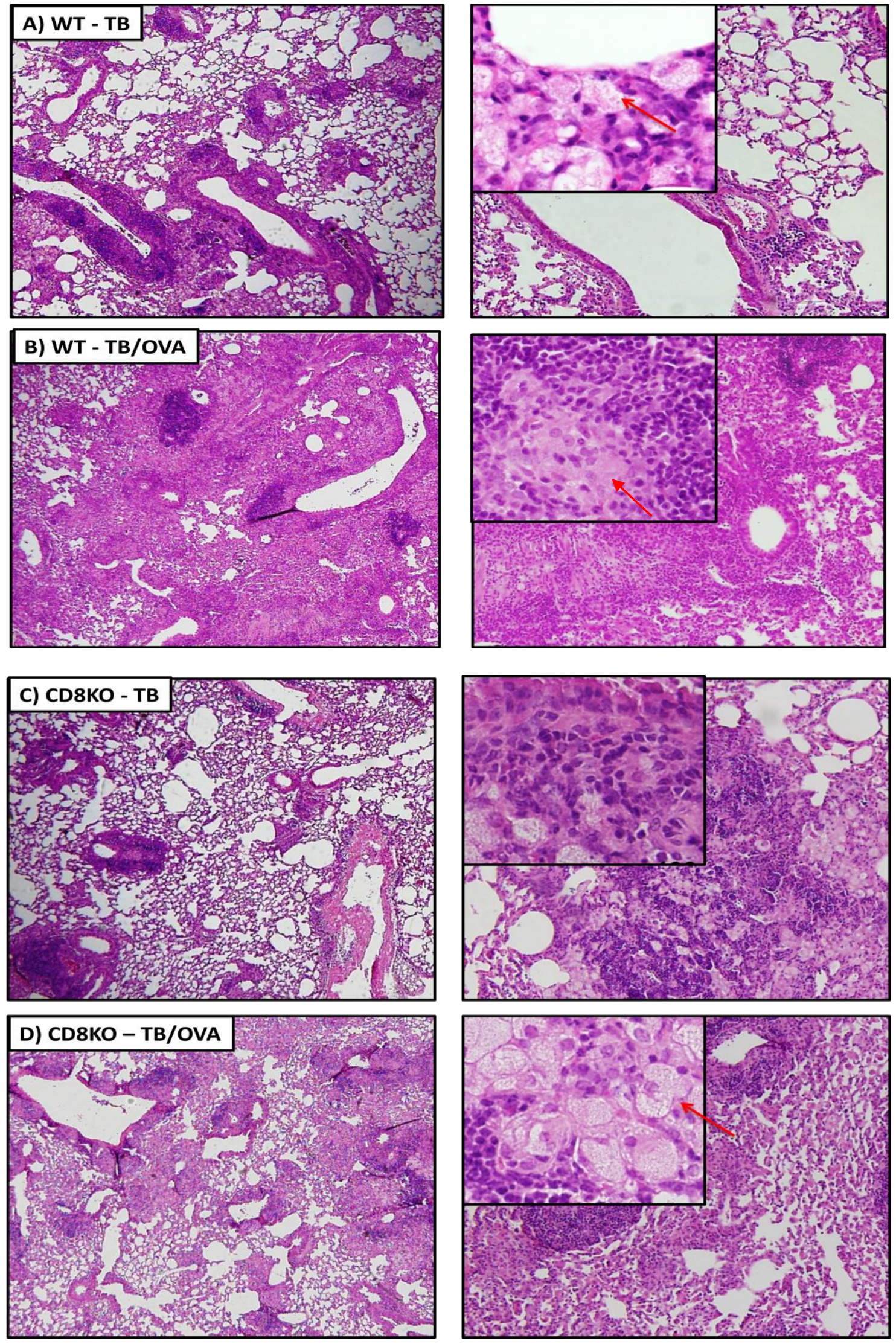

Figura 5. Avaliação histológica do pulmão de animais CD8KO-TB/OVA e CD8KO-TB. Camundongos C57BL/6 (WT) e CD8KO foram infectados com $M$. tuberculosis e 30 dias após a infecção foram submetidos ao protocolo de indução de 
asma experimental (Figura 4A). Após 72 horas do desafio com alérgeno, os pulmões foram coletados e processados para a confecção de lâminas histopatológicas. As fotomicrografias de seções de pulmão corados com Hematoxilina e Eosina são mostradas em aumento de 40X (esquerda) e 100X (direita), além de detalhes em aumento de 400X na direita. Setas vermelhas indicam um macrófago xantomatoso Resultados representativos de dois experimentos independentes $(n=4-5$ animais por grupo). 


\subsection{Avaliação do infiltrado de macrófagos M1 e M2 no pulmão de camundongos coinflamados}

Pelo fato de termos encontrado diminuição no infiltrado granulomatoso nos animais coinflamados, nós nos questionamos se a redução na replicação de bacilos no pulmão desses camundongos poderia ser decorrente da mudança no infiltrado de macrófagos nesse local. Na literatura é reportado que os macrófagos podem mudar sua função de acordo com o microambiente em que se encontram (Murray and Wynn 2011). Assim macrófagos estimulados em um ambiente com IFN- $\gamma$, apresentam fenótipo de macrófago M1 (pro-inflamatórios), enquanto em microambiente com citocinas, como IL-4 ou IL-13, o fenótipo característico é M2 (macrófagos anti-inflamatórios).

\subsubsection{Expressão de genes característicos de macrófagos M1 e M2}

Para avaliar se no pulmão dos camundongos TB/OVA havia mudança no infiltrado de macrófagos, as populações de macrófagos M1 e M2 foram quantificadas em camundongos da linhagem BALB/c, submetidos ao protocolo de tuberculose e alergia (

Figura 6A). Utilizando RT-PCR, foi avaliada a expressão de mRNA para iNOS2 (característico da população de macrófagos M1), e para Argl, Fizzl e Yml (característicos de macrófagos M2).

Observou-se aumento significativo na expressão do gene iNOS2 no grupo TB e no grupo TB/OVA quando comparados ao grupo controle não infectado, não alérgico (CT) (Figura 6B). Não houve diferença significativa na expressão relativa de iNOS2 entre os grupos TB e TB/OVA. Além disso, foi observado que os camundongos TB/OVA apresentaram aumento na expressão de Argl que não foi significativamente diferente do aumento observado nos camundongos alérgicos (OVA) (Figura 6C). Também observamos aumento significativo na expressão de RNAm para Fizzl e Yml nos camundongos TB/OVA em relação ao grupo TB (Figura 6D e E).

Esses resultados sugerem que houve mudança do padrão de infiltrado de macrófagos no pulmão dos animais TB/OVA, mais precisamente, aumento no infiltrado de macrófagos M2 em relação ao grupo TB. Contudo, a população de macrófagos M1 não foi alterada no grupo coinflamado. 
A)

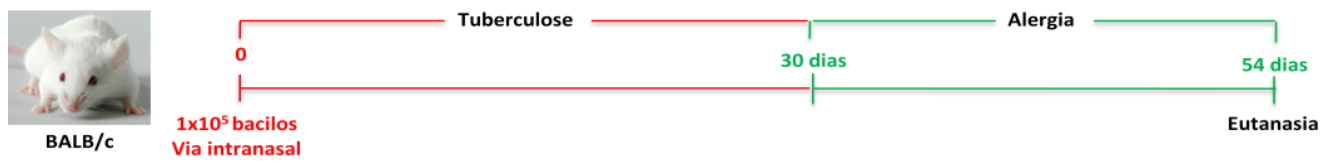

B)

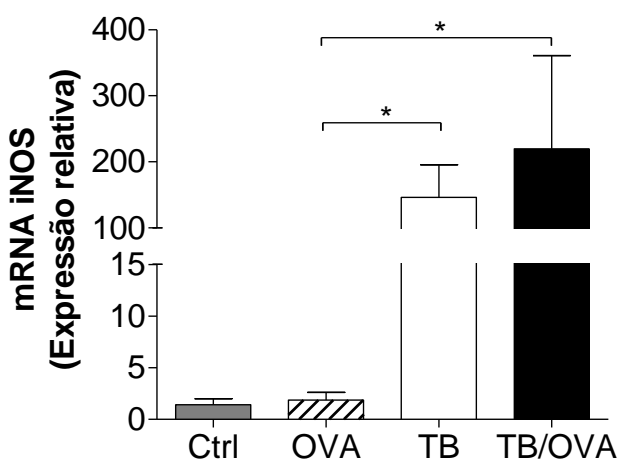

D)

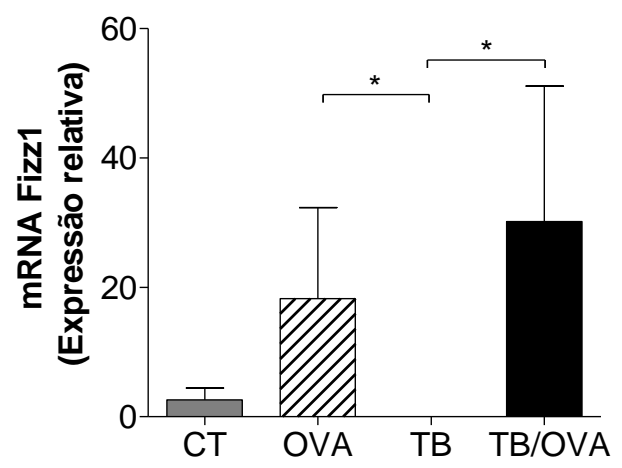

C)

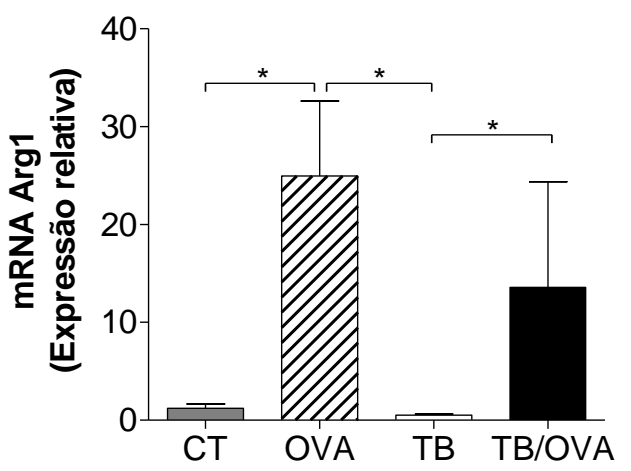

E)

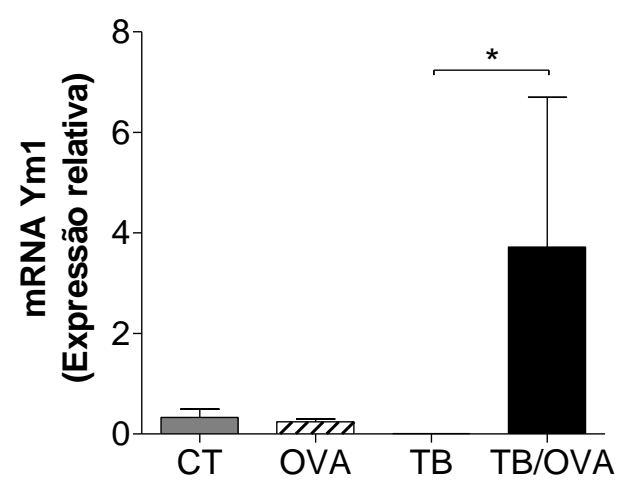

Figura 6. Quantificação de genes associados com macrófagos M1 e M2 no pulmão de animais TB/OVA. (A) Camundongos BALB/c foram infectados com $M$. tuberculosis e 30 dias após a infecção foram submetidos ao protocolo de asma experimental. Setenta duas horas após o desafio com alérgeno, os pulmões dos animais foram coletados e processados para quantificação de mRNA para iNOS2 (B), Argl (C), Fizzl (D) e $Y m l$ (E) por RT-PCR. A expressão relativa do gene de interesse foi determinada em relação à expressão do gene endógeno $\beta$-Actina $(\Delta \mathrm{Ct})$ e em relação à expressão do gene de interesse no grupo controle, não infectado, não alérgico $(\Delta \Delta \mathrm{Ct})$. Resultados representativos de quatro experimentos independentes $(n=4-5$ animais por grupo), expressos como médias \pm desvio padrão. *p $<0.05$.

$\mathrm{CT}=$ Grupo controle (Não infectado, não alérgico)

OVA = Grupo alérgico

TB $=$ Grupo infectado com $M$. tuberculosis

TB/OVA = Grupo coinflamado (infectado com M. tuberculosis e alérgico) 


\subsubsection{Quantificação de macrófagos M2}

Para confirmar as mudanças no infiltrado de macrófagos M2 no pulmão dos animais TB/OVA, essas células foram quantificadas avaliando a expressão do receptor de manose, CD206 (marcador específico de macrófagos M2). Para a análise do fenótipo da população de macrófagos M2, inicialmente, foram utilizados os parâmetros FSC-A (do inglês Forward Side Scatter-Area) e FSC-H (do inglês Forward Side ScatterHeight) para excluir as células aderidas entre si (exclusão de doublets) (Figura 7A). Após a exclusão, foram utilizados os parâmetros de FSC e SSC para selecionar a região que contém as células de maior tamanho e granulosidade, que são características das células dendríticas e macrófagos (Figura 7B). As células presentes nesta região foram utilizadas para avaliar a expressão da molécula CD11c (Figura 7C). As células que foram positivas para $\mathrm{CD} 11 \mathrm{c}^{+}$foram utilizadas para avaliar a expressão de CD206

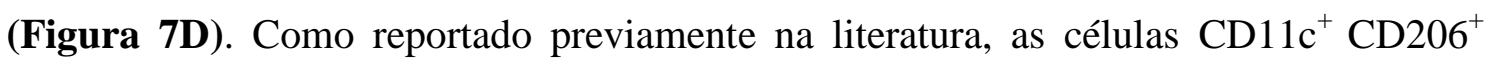
foram consideradas como macrófagos alveolares do pulmão (Potian, Rafi et al. 2011).

Utilizando a análise descrita anteriormente (Figura 7), foi determinada a frequência e o número de macrófagos nos animais TB/OVA. Inicialmente, foi observado aumento na frequência $(\mathrm{p}<00.5)$ e número total $(\mathrm{p}>0.05)$ de células $\mathrm{CD} 11 \mathrm{c}^{+}$ nos animais TB/OVA em relação ao grupo TB (Figura 8A - B). Como observado na Figura 8C e D, também houve aumento no número e na frequência de células CD11c ${ }^{+}$ $\mathrm{CD}_{206}{ }^{+}$nos animais TB/OVA em relação aos animais TB $(\mathrm{p}<0.05)$.

Esses resultados confirmam que nos camundongos TB/OVA houve mudança no infiltrado de macrófagos, uma vez que foi observado aumento na frequência e número de macrófagos com fenótipo M2 $\left(\mathrm{CD} 11 \mathrm{c}^{+} \mathrm{CD} 206^{+}\right)$no pulmão desses animais em relação ao grupo apenas infectado (TB). 
Figura 7. Análise representativa para quantificação de macrófagos M2 no pulmão de animais TB/OVA. Camundongos BALB/c foram submetidos ao delineamento experimental TB/OVA, descrito na Figura 6A. Setenta e duas horas após o desafio com OVA, os pulmões foram coletados, digeridos e processados para a marcação de células $\mathrm{CD}_{11 \mathrm{c}^{+}} \mathrm{CD}^{206^{+}}$. Foram adquiridos 100.000 eventos por amostra. (A) Inicialmente, foram selecionadas as células únicas e viáveis. (B) Posteriormente, foram selecionadas as células com maior tamanho (FSC) e maior granulosidade (SSC). (C) Dentro desta última população foram analisadas as células positivas para CD11c (R1). (D) Dentro da região R1 foram analisadas as células positivas para CD206 (R2). 
A)

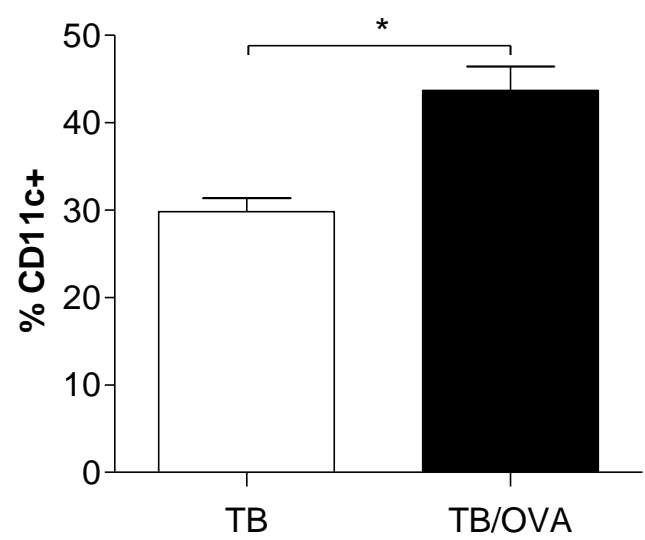

C)

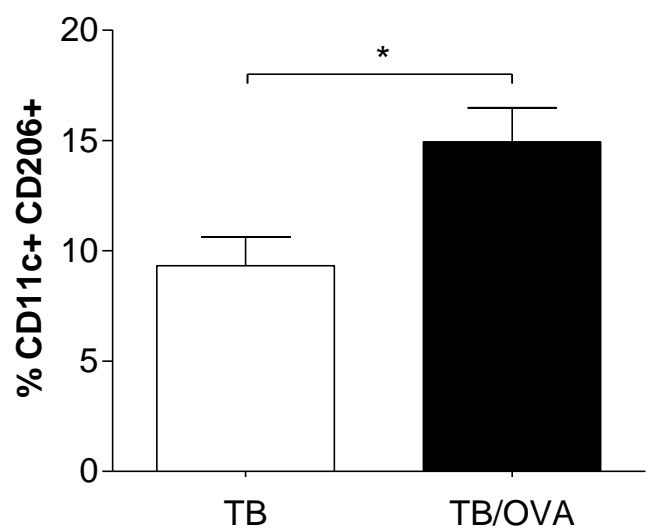

B)

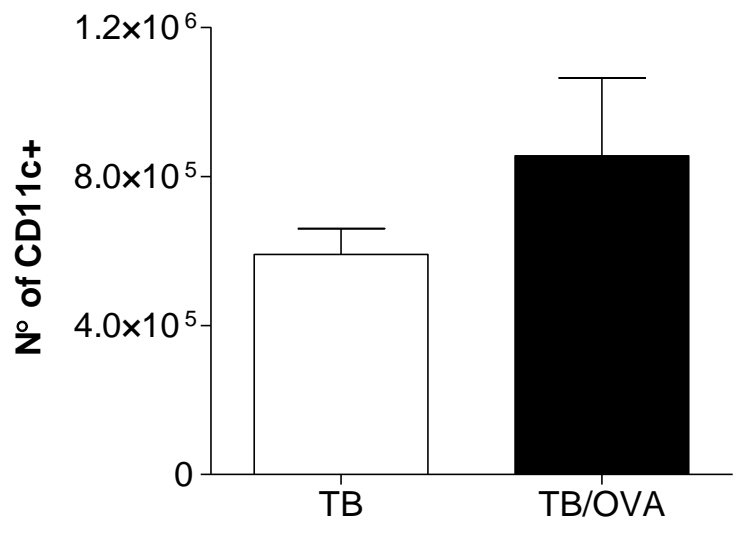

D)

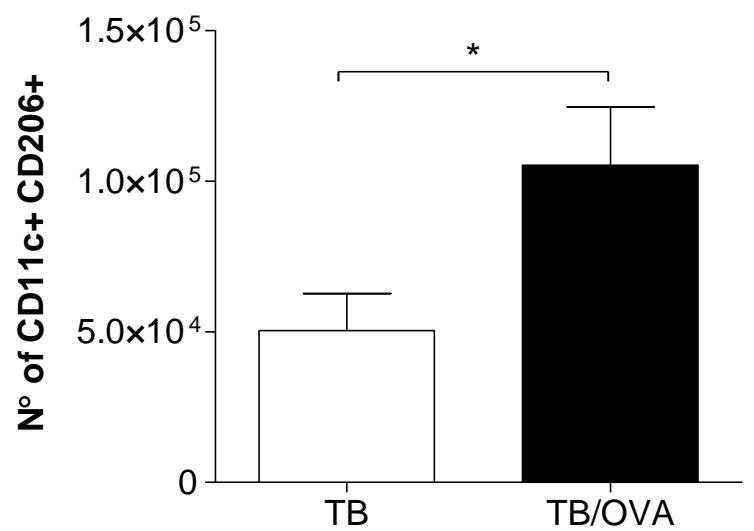

Figura 8. Frequência e número de células $\mathrm{CD} 11 c^{+}$e células $\mathrm{CD} 11 c^{+} \mathrm{CD206}^{+}$no pulmão de animais TB/OVA. Camundongos BALB/c foram submetidos ao delineamento experimental TB/OVA, conforme descrito na Figura 6A. Setenta e duas horas após o desafio com OVA, os pulmões foram coletados, digeridos e processados para a marcação de células $\mathrm{CD} 11 \mathrm{c}^{+} \mathrm{CD}_{206}{ }^{+}$. (A) Frequência e (B) número de células CD11 ${ }^{+}$no pulmão de animais TB e TB/OVA. (C) Frequência e (D) número de células $\mathrm{CD} 11 \mathrm{c}^{+} \mathrm{CD}^{206^{+}}$. Resultados representativos de um experimento ( $\mathrm{n}=7$ animais), com dados expressos como médias \pm desvio padrão. 


\subsubsection{Quantificação de citocinas no pulmão}

Em resumo, até o momento, nossos resultados mostram que a diminuição na carga bacilar nos animais BALB/c TB/OVA está associada com um aumento na população de macrófagos M2. Quando avaliamos as citocinas presentes no homogenato de pulmão desses camundongos, foi observado que não houve diferenças significativas na produção das citocinas IL-5 (Figura 9A) e IL-13 (Figura 9B) nesses animais, quando comparados com o grupo TB. Pelo contrário, houve aumento significativo na produção de IL-1 $\beta$ ( Figura 9C) e TGF- $\beta$ (Figura 9D) no grupo TB/OVA em relação ao grupo TB $(\mathrm{p}<0.05)$.

A)

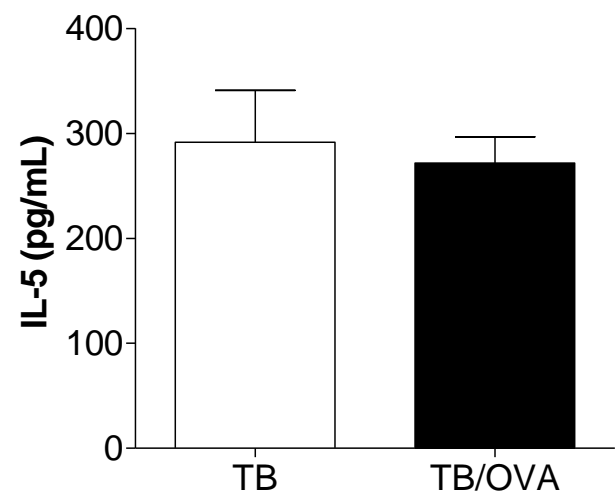

C)

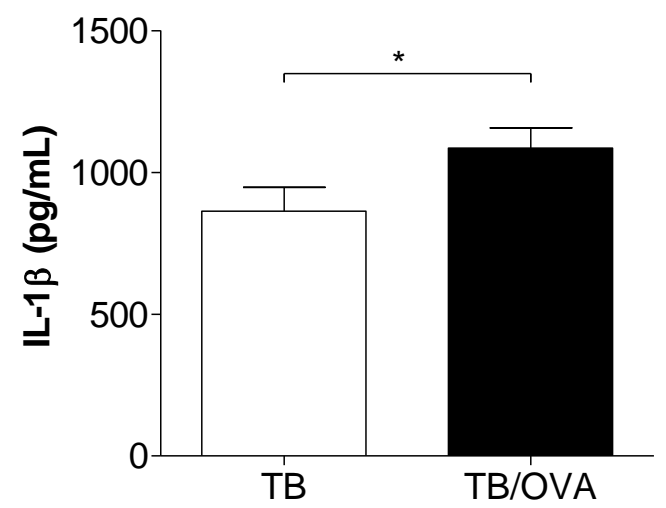

B)

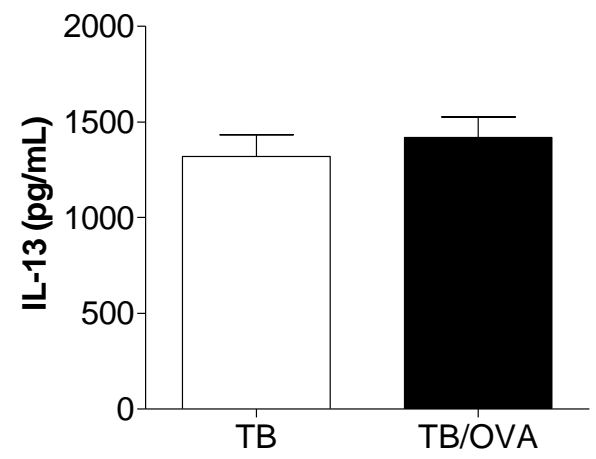

D)

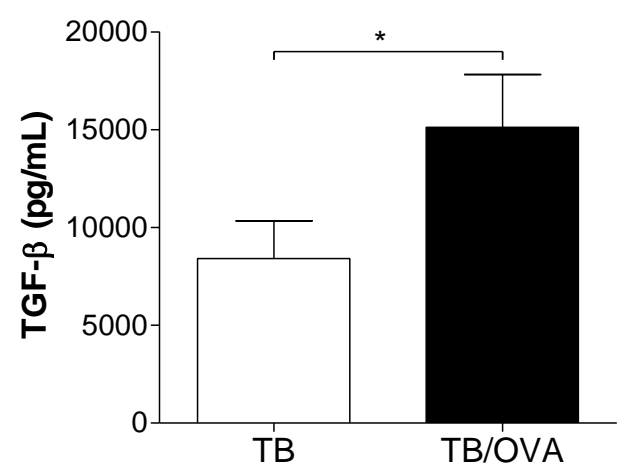

Figura 9. Detecção de citocinas em homogenato de pulmão de camundongos coinflamados. Camundongos BALB/c foram submetidos ao protocolo de coinflamação tuberculose e alergia conforme descrito na

Figura 6A. Setenta e duas horas após o desafio com OVA, os pulmões foram coletados e homogeneizados para quantificação de citocinas por ELISA. Resultados representativos de 2 experimentos independentes ( $\mathrm{n}=5-7$ animais), expressos como média \pm desvio padrão. Para TGF- $\beta$, os resultados foram obtidos de um experimento (n $=5-7$ animais). ${ }^{*} \mathrm{p}<0.05$. 


\subsubsection{Quantificação de fibras colágenas nos animais coinflamados}

Considerando que os macrófagos M2 são células associadas com reparo tecidual, e como foi observado aumento na população dessas células no pulmão de animais coinflamados, o próximo passo foi analisar o reparo tecidual através da quantificação de fibrose (Figura 10A).

A análise histológica de lâminas coradas com Picrusirius Red mostra que não houve diferença significativa na deposição de fibras de colágeno nos camundongos dos grupos TB e TB/OVA. Esse resultado mostra que embora os animais TB/OVA mostrassem aumento na população de macrófagos M2, esse aumento não parece estar associado com maior reparo tecidual no pulmão (Figura 10B ). 
A)
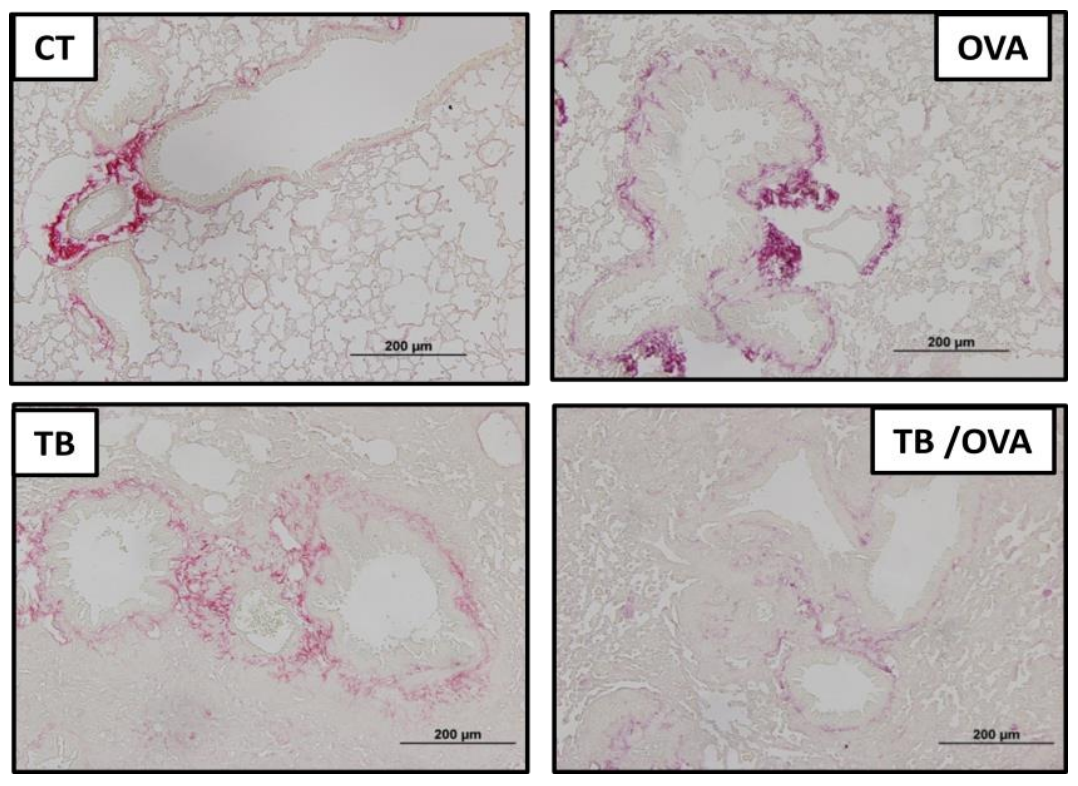

B)

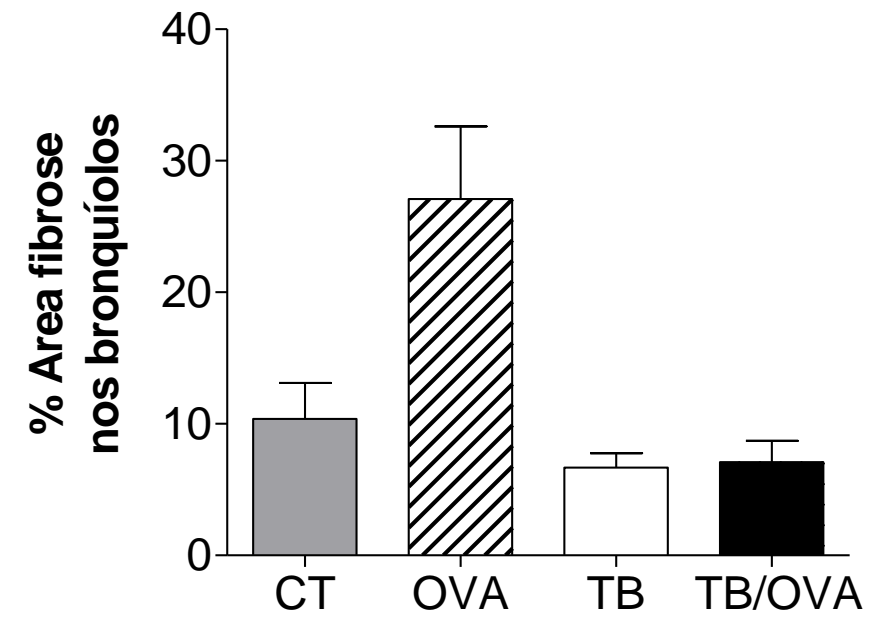

Figura 10. Detecção de fibrose no pulmão de camundongos coinflamados, TB/OVA. Camundongos BALB/c foram submetidos ao delineamento experimental TB/OVA, conforme descrito na

Figura 6A. Setenta e duas horas após o desafio com OVA, os pulmões foram coletados e armazenados em solução tamponada de fosfato contendo $37 \%$ de formol para análise histológica. (A) Fotomicrografias de cortes corados com Picrusirius Red são mostradas em aumento de 200x. (B) A deposição de fibras colágenas foi quantificada nas fotomicrografias de cortes histológicos de pulmão. A quantificação foi realizada por meio da razão entre a área positiva para a coloração de Picrusirius Red e a área total da imagem. Resultados de 1 experimento foram expressos como média \pm desvio padrão $(\mathrm{n}=6-8$ animais).

$\mathrm{CT}=$ Grupo controle (Não infectado, não alérgico)

$\mathrm{OVA}=$ Grupo alérgico

TB = Grupo infectado com M. tuberculosis

TB/OVA = Grupo coinflamado (infectado com M. tuberculosis e alérgico) 


\subsubsection{Quantificação de células dendríticas plasmocitóides por citometria de fluxo}

Considerando que foram observadas mudanças no infiltrado de células no pulmão de pulmão de animais TB/OVA, com aumento de macrófagos com fenótipo M2, nós também avaliamos a população de células dendríticas plasmocitóides (pDCs), pois como reportado na literatura, esta população está associada com homeostase no pulmão. Para avaliar se ocorria mudança na população de pDCs no pulmão de camundongos TB/OVA, essa população de células foi avaliada por citometria de fluxo. Inicialmente, foi realizada a exclusão de doublets (Figura 11

Figura 11A), como descrito anteriormente. Após a exclusão, foram utilizados os parâmetros de FSC e SSC para selecionar a região que continha as células de maior tamanho e granulosidade, onde estariam contidas as células dendríticas (Figura 11B). As células presentes nesta região foram utilizadas para avaliar a expressão da molécula CD11c (Figura 11C), sendo as células $\mathrm{CD}_{11} \mathrm{c}^{+}$utilizadas para avaliar a expressão das moléculas CD11b e CD317 (marcador de células dendríticas plasmocitóides) (Figura 11D).

Os camundongos do grupo TB/OVA foram caracterizados por aumento na

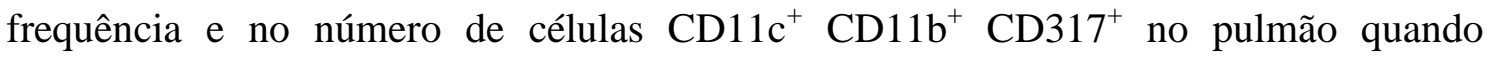
comparados com o grupo TB (Figura 11E e F). 
A)

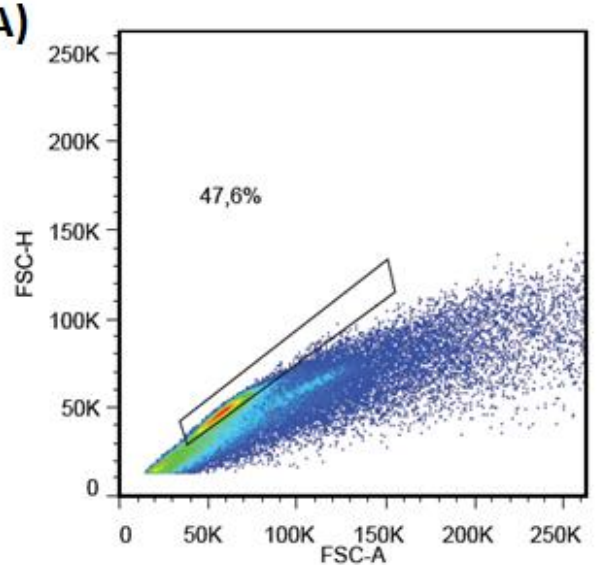

C)

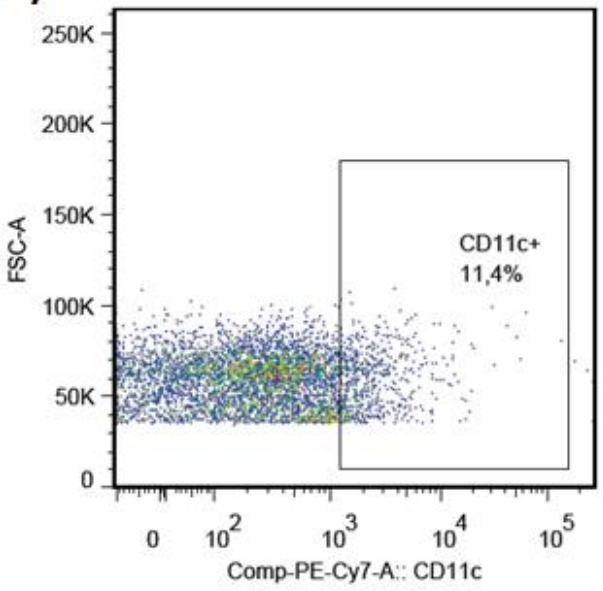

B)

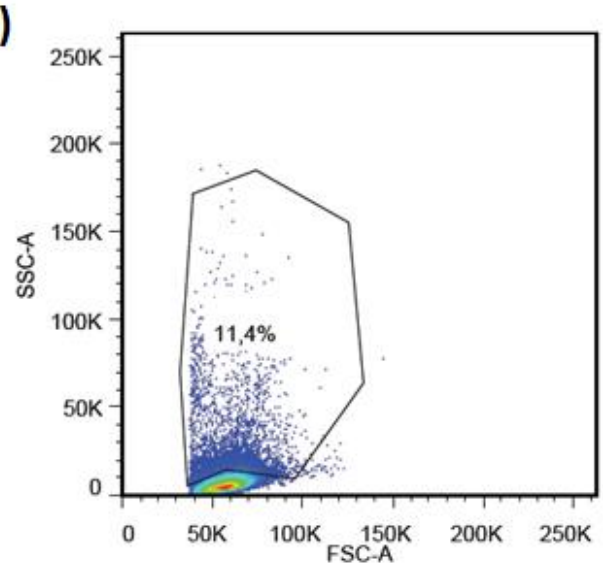

D)

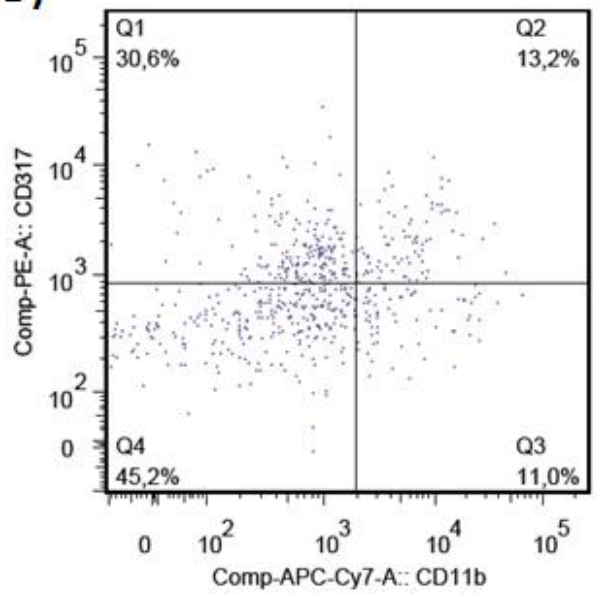

E)

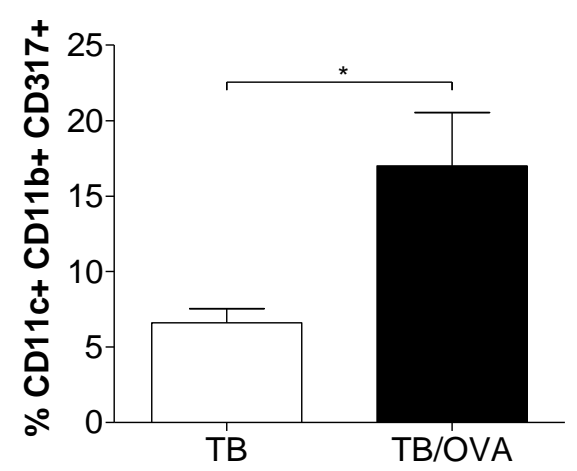

F)

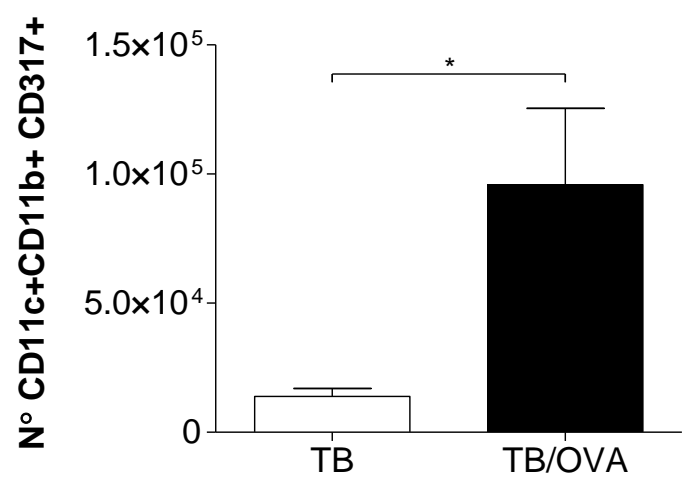

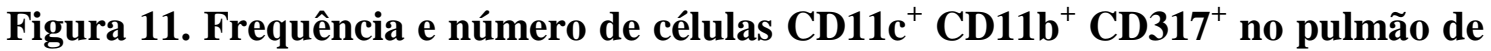
animais TB/OVA. Camundongos $\mathrm{BALB} / \mathrm{c}$ foram submetidos ao delineamento experimental TB/OVA descrito na Figura 6A. Esquema representativo da análise da população de células dendríticas plasmocitóides no pulmão de animais TB/OVA. (A) Inicialmente, foram selecionadas as células únicas e viáveis. (B) Posteriormente, foram selecionadas as células com maior tamanho (FSC) e maior granulosidade (SSC). (C) Dentro desta última população, foram analisadas as células positivas para CD11c. (D) Dentro da região de células $\mathrm{CD} 11 \mathrm{c}^{+}$, foram analisadas as células $\mathrm{CD} 11 \mathrm{~b}^{+} \mathrm{CD} 317^{+}$. (E) Frequência e (F) número de células $\mathrm{CD}_{11 \mathrm{c}^{+}} \mathrm{CD}_{11 \mathrm{~b}^{+}} \mathrm{CD} 317^{+}$. Resultados representativos de dois experimentos independentes ( $n=7-8$ animais), expressos como médias \pm desvio padrão. ${ }^{*} \mathrm{p}<0.05$ 
4.2.6. Avaliação do papel dos macrófagos M2 no crescimento de bacilos nos animais coinflamados

Até o momento, nossos resultados mostram que os camundongos do grupo TB/OVA apresentaram aumento no infiltrado de macrófagos M2 no pulmão, porém, esse aumento não estava associado com aumento no reparo tecidual nesse órgão.

A IL-33, citocina envolvida na geração de resposta Th2 que caracteriza a resposta alérgica (Oshikawa, Kuroiwa et al. 2001), está envolvida na diferenciação de macrófagos M2 (Kurowska-Stolarska, Stolarski et al. 2009; Jiang, Milovanović et al. 2012). Portanto, animais ST2KO (deficientes para a expressão dos receptores de membrana e solúvel para IL-33), também falham na diferenciação deste tipo de macrófagos (Kurowska-Stolarska, Stolarski et al. 2009). Considerando o papel da via IL-33/ST2 na diferenciação de macrófagos M2, foram utilizados camundongos deficientes do receptor da IL-33 (ST2KO) para avaliar o efeito dos macrófagos M2 na redução do crescimento de bacilos no pulmão de animais coinflamados. Considerando a importância da via de sinalização IL-33/ST2 na indução da resposta Th2, primeiramente foi avaliado se os animais ST2KO, quando submetidos ao protocolo de indução de alergia experimental com OVA (Apêndice 2A), apresentavam parâmetros característicos da alergia. Foi observado que os animais ST2KO alérgicos (ST2KOOVA) apresentavam aumento no número de células totais $(\mathrm{p}<0.05)$ e na frequência de eosinófilos $(\mathrm{p}<0.05)$ presentes no LBA quando comparados com o grupo controle (ST2KO-PBS) (Apêndice 2B-C).

\subsubsection{Quantificação das populações de macrófagos M1 e M2 em animais}

\section{$\underline{\text { ST2KO coinflamados }}$}

Inicialmente, foram avaliadas as populações de macrófagos M1 e M2 nos camundongos WT e ST2KO, com o objetivo de verificar a diminuição de macrófagos M2 no pulmão dos animais ST2KO.

Os resultados apresentados na Figura 12 mostram que na ausência de ST2, os animais coinflamados (ST2KO-TB/OVA) apresentaram menor expressão dos genes Arg1, Fizz1 e Yml (associados a macrófagos M2) quando comparados com os animais do grupo WT-TB/OVA ( $\mathrm{p}<0.05)$ (Figura 12B - D). Portanto, esses resultados confirmam que na ausência de ST2, os animais coinflamados não apresentam aumento na população de macrófagos M2. 
Em adição, foi observado que na ausência de ST2 não há diferenças significativas na significativas na expressão de iNOS2 entre os grupos ST2KO coinflamados (ST2KOTB/OVA) e ST2KO infectados (ST2KO-TB). No entanto, foi observado que em ambos os grupos, a expressão deste gene foi significativamente maior que a expressão $\begin{array}{lllllll}\text { observada nos animais WT-TB/OVA e } & \text { WT-TB } & \text { (Figura } & 12\end{array}$

A)

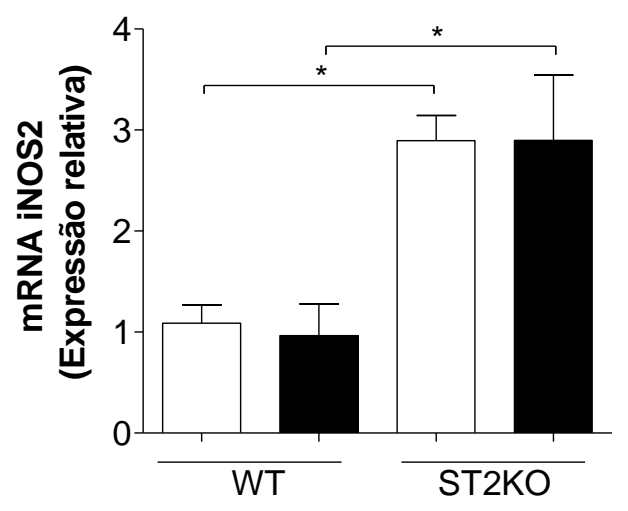

C)

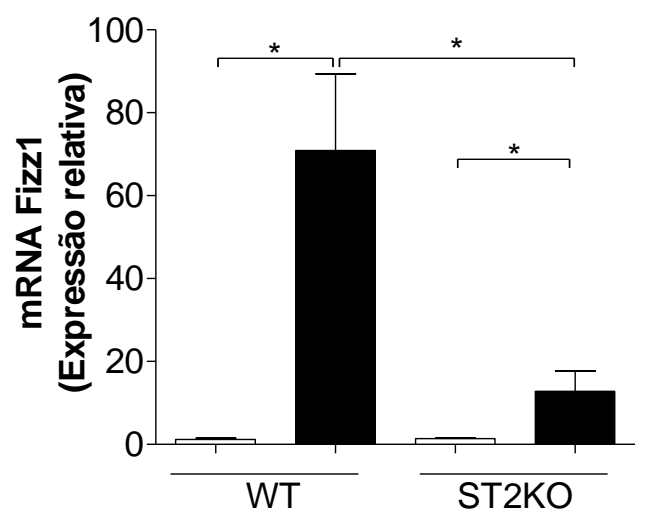

B)

TB

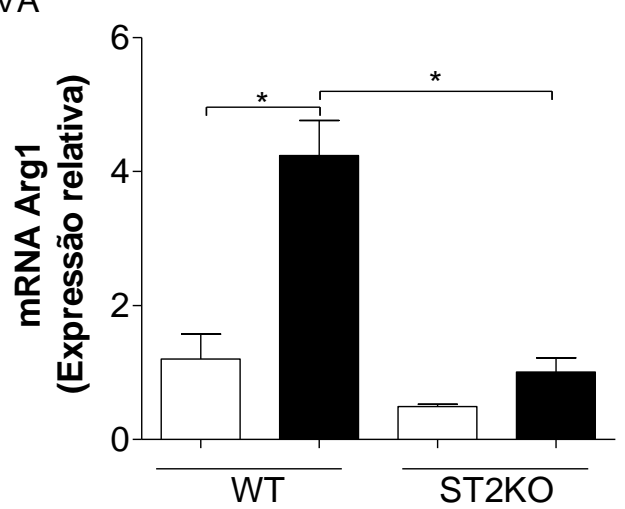

D)

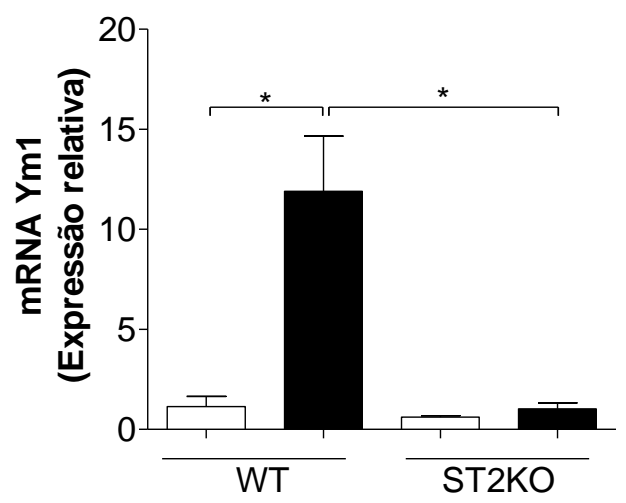

Figura 12. A). Esses resultados mostram que a ausência do receptor da IL-33 nos animais TB/OVA está associado com aumento na população de macrófagos M1 nos animais ST2-TB/OVA e ST2-TB.

Em suma, os resultados apresentados na Figura 12 mostram que a ausência do receptor da IL-33 diminui o infiltrado de macrófagos M2 no pulmão dos animais ST2KO-TB/OVA quando comparados com os animais WT-TB/OVA. Portanto, os animais ST2KO constituem uma ferramenta adequada para a avaliação do papel dos macrófagos M2 na diminuição do crescimento do bacilo no pulmão de animais TB/OVA. 
A)

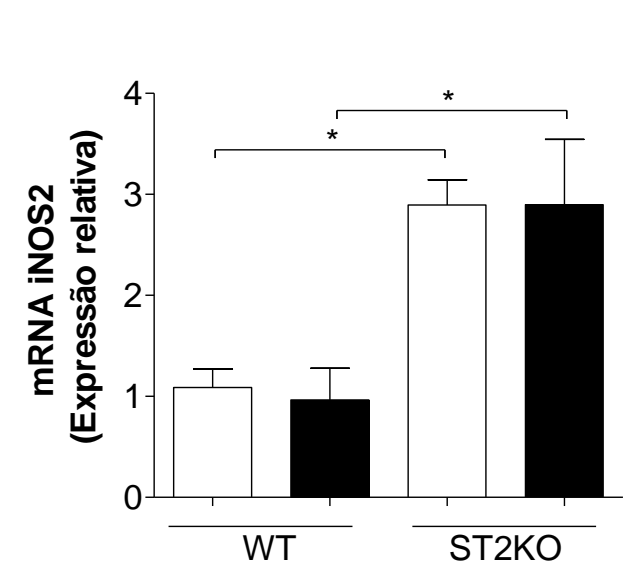

C)

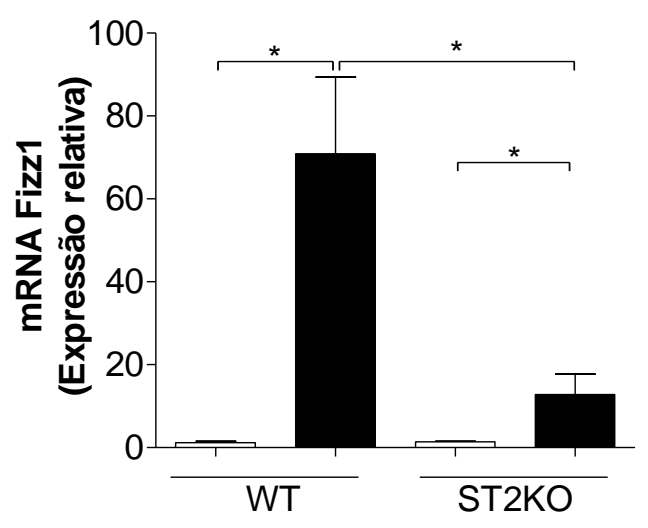

B)

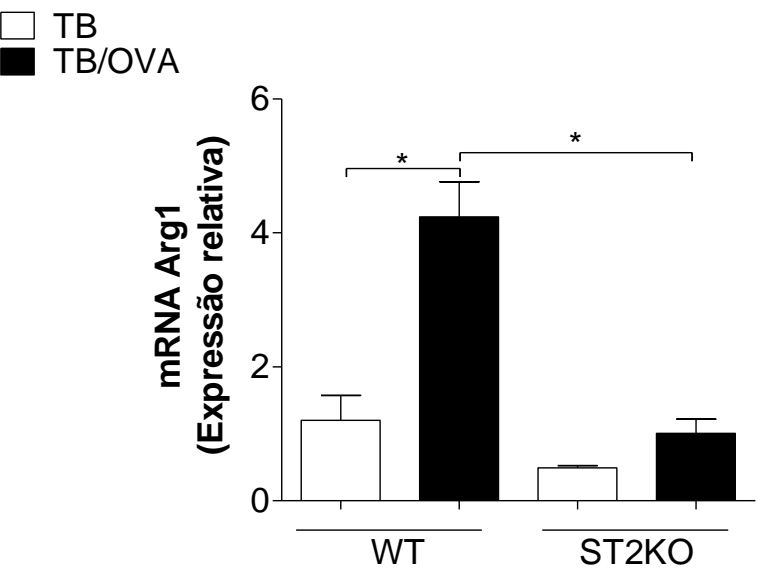

D)

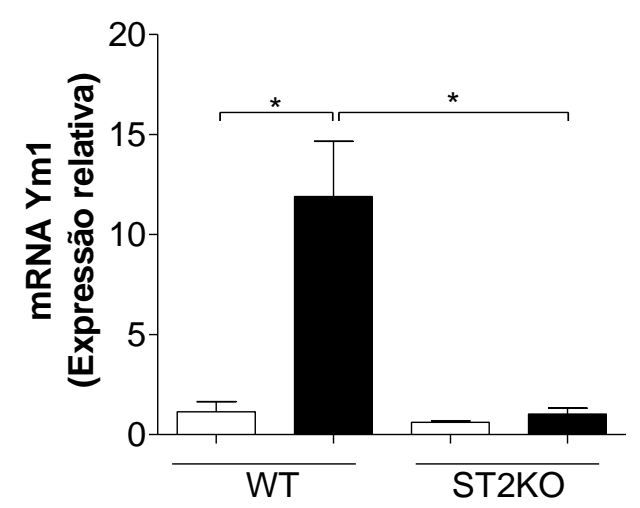

Figura 12. Expressão de genes de macrófagos M1 e M2 no pulmão de camundongos ST2KO coinflamados. Camundongos WT (BALB/c) e ST2KO foram submetidos ao delineamento experimental TB/OVA, conforme descrito na

Figura 6A. Setenta e duas horas após o desafio com OVA, o RNA total dos pulmões foi obtido e quantificado para avaliação da expressão dos genes iNOS2 (A), Argl (B), Fizzl (C) e $Y m 1$ (D) por RT-PCR. A expressão relativa do gene de interesse foi determinada em relação à expressão do gene endógeno $\beta$-Actina $(\Delta \mathrm{Ct}) \mathrm{e}$ em relação à expressão do gene de interesse no grupo WT-TB $(\Delta \Delta \mathrm{Ct})$. Resultados representativos de um experimento ( $n=6-8$ animais por grupo), expressos como médias \pm desvio padrão. *p $<0.05$. 


\subsubsection{Quantificação do número de UFC no pulmão de animais ST2KO} coinflamados

Visto que na ausência do receptor da IL-33, os animais ST2KO-TB/OVA não mostraram aumento na população de macrófagos M2, como observado no grupo WTTB/OVA, o passo seguinte foi avaliar se esses animais seriam mais susceptíveis à infecção por $M$. tuberculosis. Como observado na Figura 13, não houve diferença significativa no número de bacilos no pulmão dos animais dos grupos ST2KO-TB/OVA e ST2KO-TB. Além disso, foi observado que os animais ST2KO-TB/OVA apresentaram aumento significativo no número de UFC no pulmão quando comparados aos animais WT-TB/OVA (Figura 13). Em adição, foi observado que não houve diferença significativa na carga bacilar observada nos animais dos grupos WT-TB, ST2KO-TB e ST2KO-TB/OVA (p>0.05) (Figura 13).

Esses resultados mostram que a diminuição no número de bacilos nos animais TB/OVA depende do aumento da população de macrófagos M2 no pulmão desses animais. 
A)

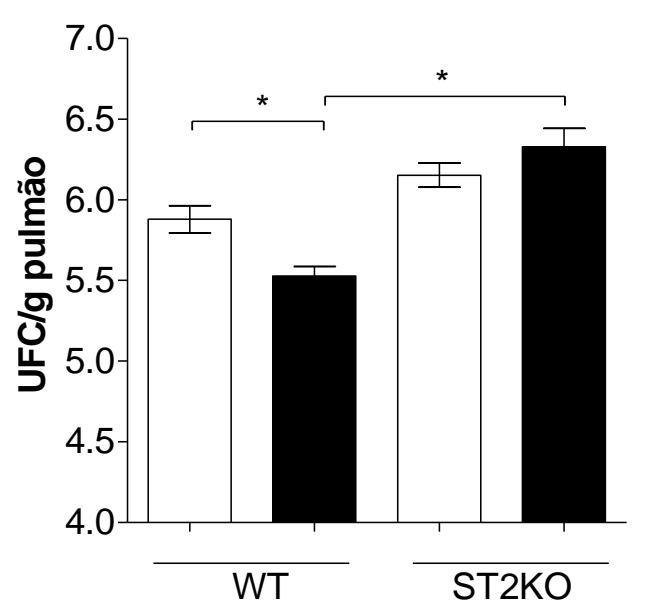

B)

TB

TB/OVA

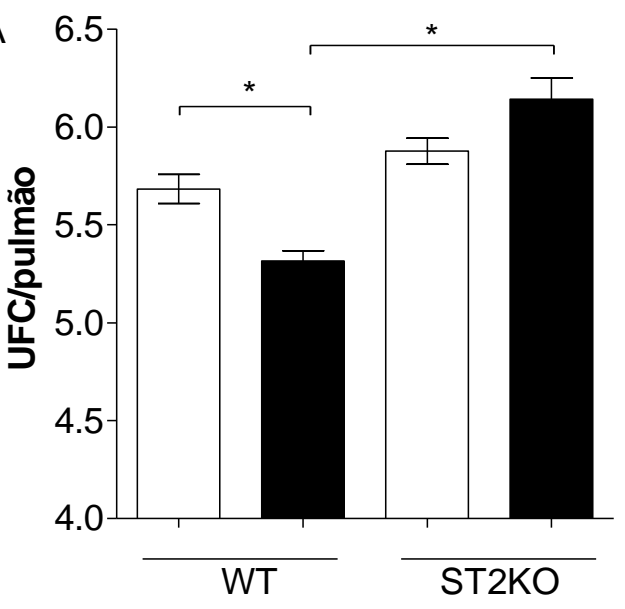

Figura 13. Quantificação do número de UFC no pulmão de camundongos coinflamados. Camundongos BALB/c (WT) e ST2KO foram infectados com $M$. tuberculosis e 30 dias após a infecção foram submetidos ao protocolo de alergia, conforme descrito na

Figura 6A. Após 72 horas do desafio com OVA, os pulmões foram processados para quantificação do número UFC. (A) UFC por grama de pulmão e (B) UFC por órgão total de animais coinflamados (TB/OVA) e infectados (TB). Resultados representativos de um experimento ( $n=6-8$ animais por grupo), expressos como médias \pm desvio padrão. ${ }^{*} p<0.05$. 


\subsubsection{Quantificação de células dendríticas plasmocitóides}

Ao avaliar a população de pDCs, observamos tanto a frequência quanto o número de pDCs não foi diferente estatisticamente entre os grupos ST2KO-TB/OVA e ST2KO-TB. Também não foram observadas diferenças significativas na frequência e no número de pDCs entre os grupos ST2KO-TB/OVA e WT-TB/OVA. Entretanto, como visto anteriormente, os animais do grupo WT-TB/OVA apresentaram aumento significativo no número e na frequência de células dendríticas plasmocitóides quando comparados com o grupo WT-TB (Figura 14A e B).

A)

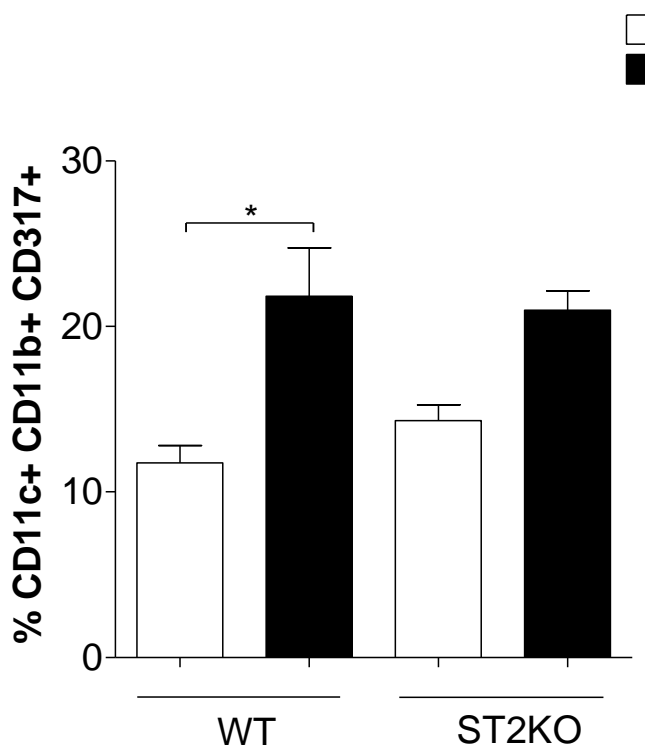

B)

TB

TB/OVA

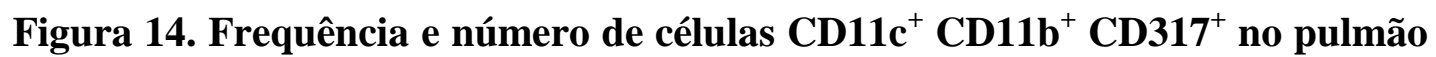
animais ST2KO coinflamados. Camundongos BALB/c (WT) e ST2KO foram submetidos ao delineamento experimental TB/OVA, conforme descrito na

Figura 6A. Setenta e duas horas após o desafio com OVA, os pulmões foram coletados, digeridos e processados para a marcação de células $\mathrm{CD}_{11 c^{+}} \mathrm{CD} 11 \mathrm{~b}^{+} \mathrm{CD} 317^{+}$. Foram adquiridos 100.000 eventos por amostra e as células foram analisadas como na Figura 7. Frequência $(\mathbf{A})$ e número $(\mathbf{B})$ de células $\mathrm{CD} 11 \mathrm{c}^{+} \mathrm{CD} 11 \mathrm{~b}^{+} \mathrm{CD} 317^{+}$. Os resultados foram expressos como média \pm desvio padrão. Resultados representativos de 1 experimento ( $n=6-8$ animais $)$. 


\subsection{Avaliação do papel dos leucotrienos na diminuição do número de bacilos no pulmão de animais coinflamados}

\subsubsection{Quantificação de corpúsculos lipídicos em células do LBA}

Conforme a infecção com $M$. tuberculosis progride é observado aumento na população de macrófagos xantomatosos (Peyron, Vaubourgeix et al. 2008), que são células que acumulam lipídeos em organelas conhecidas como corpúsculos lipídicos (Singh, Jamwal et al. 2012). Estas organelas estão envolvidas na produção de mediadores lipídicos, como $\mathrm{LTB}_{4}$ (Bozza, Pacheco et al. 2002). Considerando resultados prévios de nosso grupo mostrando que os camundongos TB/OVA têm aumento na produção de $\mathrm{LTB}_{4}$, nós avaliamos se existe relação entre os animais TB/OVA e a formação de corpúsculos lipídicos nas células do LBA desses animais.

Para quantificar a formação de corpúsculos lipídicos nas células do LBA foi utilizado o método de coloração tetróxido de ósmio. Foi observado que os animais coinflamados TB/OVA apresentaram aumento na frequência e no número de células com corpúsculos lipídicos comparados aos animais do grupo TB (Figura 15).

Esses resultados sugerem que a menor susceptibilidade dos animais TB/OVA pode estar associada com aumento na formação de corpúsculos lipídicos no pulmão desses camundongos. 
A)

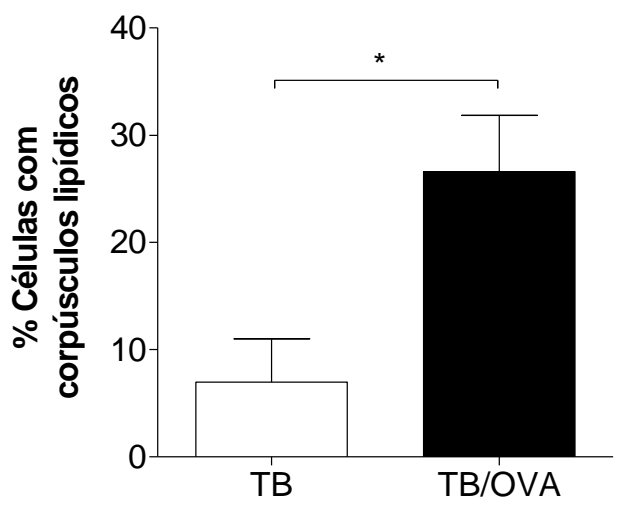

B)

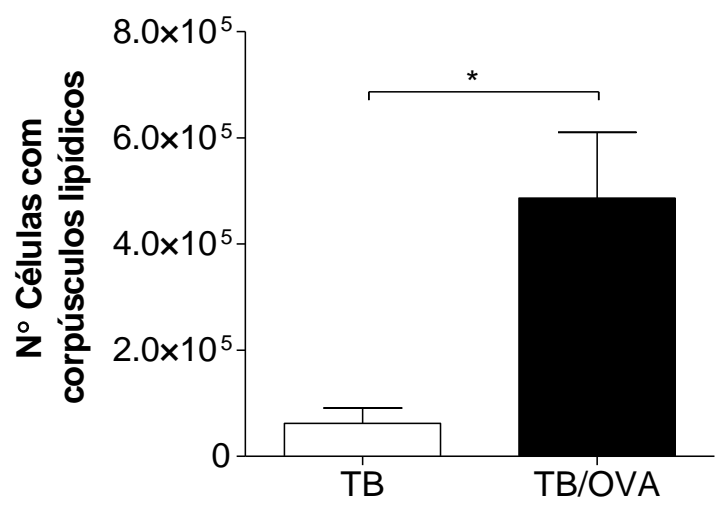

Figura 15. Detecção de corpúsculos lipídicos no LBA de animais coinflamados. Camundongos BALB/c foram submetidos ao delineamento experimental TB/OVA, conforme descrito na

Figura 6A. Setenta e duas horas após o desafio com OVA, foi coletado o LBA dos animais e as células obtidas foram utilizadas para a coloração por tetróxido de ósmio. A quantificação de células positivas para a formação de corpúsculos lipídicos foi realizada utilizando microscópio óptico no aumento de 1000x. A quantificação foi realizada em campos aleatórios e em 100 células por animal. Resultados representativos de dois experimentos independentes $(\mathrm{n}=3-5$ animais por grupo), expressos como médias \pm desvio padrão. *p $<0.05$. 


\subsubsection{DELINEAMENTO EXPERIMENTAL I. Tratamento com inibidor da enzima} 5-LO, MK886

Como observado anteriormente, os animais do grupo TB/OVA apresentaram aumento na formação de corpúsculos lipídicos. Por conseguinte, será que o aumento na produção de $\mathrm{LTB}_{4}$ e de sítios de síntese desses mediadores também é um mecanismo importante para o controle do crescimento dos bacilos no pulmão dos animais do grupo TB/OVA?

Os leucotrienos são componentes importantes na atividade microbicida dos macrófagos alveolares durante a infecção bacteriana (Serezani, Aronoff et al. 2005) e o papel desses mediadores lipídicos na tuberculose ainda não está bem definido (Bafica, Scanga et al. 2005; Peres, de Paula et al. 2007). Para avaliar o papel dos leucotrienos na diminuição do crescimento dos bacilos nos animais do grupo TB/OVA, nós utilizamos duas ferramentas: o tratamento com o inibidor da síntese de mediadores lipídicos pela via da enzima 5-lipoxigenase (o composto MK886) e animais deficientes para a expressão da enzima 5-lipoxigenase (5-LO). Os animais deficientes para expressão da enzima 5-LO (5LO-KO) são da linhagem 129Sv. Portanto, para avaliar o papel dos leucotrienos utilizando ambas as ferramentas, foram utilizados camundongos $129 \mathrm{~Sv}$ em nosso modelo experimental de coinflamação.

\subsubsection{Quantificação de UFC em camundongos 129Sv}

Inicialmente, nós usamos o protocolo TB/OVA, como descrito previamente. Em adição, durante o protocolo de indução da alergia, os camundongos foram tratados diariamente com $5 \mathrm{mg} / \mathrm{Kg}$ de MK886 (Figura 16A). Não houve diferença entre o número de UFC recuperado do pulmão de animais TB/OVA não tratados - Mock - (NTTB/OVA) e TB/OVA tratados (TR-TB/OVA), como esperávamos que houvesse. De acordo como nossa hipótese, esperávamos encontrar maior número de bacilos no pulmão dos animais do grupo TR-TB/OVA do que no pulmão do grupo NT-TB/OVA. Também não encontramos diferença na carga bacilar do grupo TR-TB/OVA e do grupo TB tratado (TR-TB) (Figura 16B). No entanto, foi observado que os animais NTTB/OVA tiveram aumento significativo na carga bacilar no pulmão quando comparados aos animais infectados e não tratados (NT-TB) (Figura 16B). Esse resultado mostra que a diminuição na carga bacilar no pulmão depende da linhagem do camundongo utilizada, visto que os animais BALB/c coinflamados foram menos susceptíveis à 
infecção por M. tuberculosis que os animais do grupo TB da mesma linhagem (Figura 16C).

Em suma, os animais TB/OVA das linhagens C57BL/6 e 129Sv foram mais susceptíveis à infecção por $M$. tuberculosis quando comparados ao grupo TB das respectivas linhagens. Do contrário, os animais TB/OVA da linhagem BALB/c foram mais resistentes à infecção quando comparados ao grupo TB (Figura 16C Erro! Fonte de referência não encontrada.).

A)

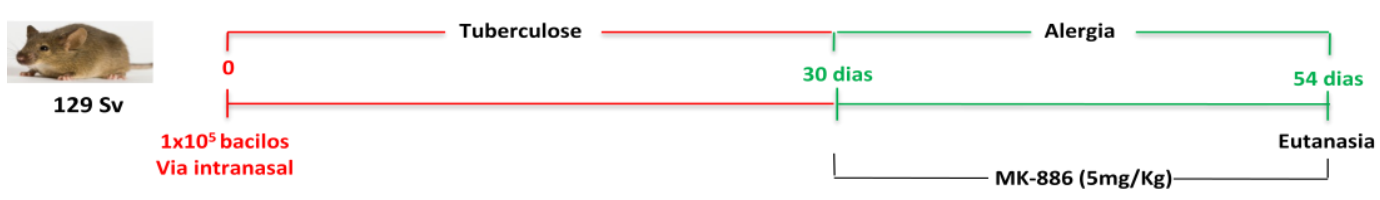

B)

C)
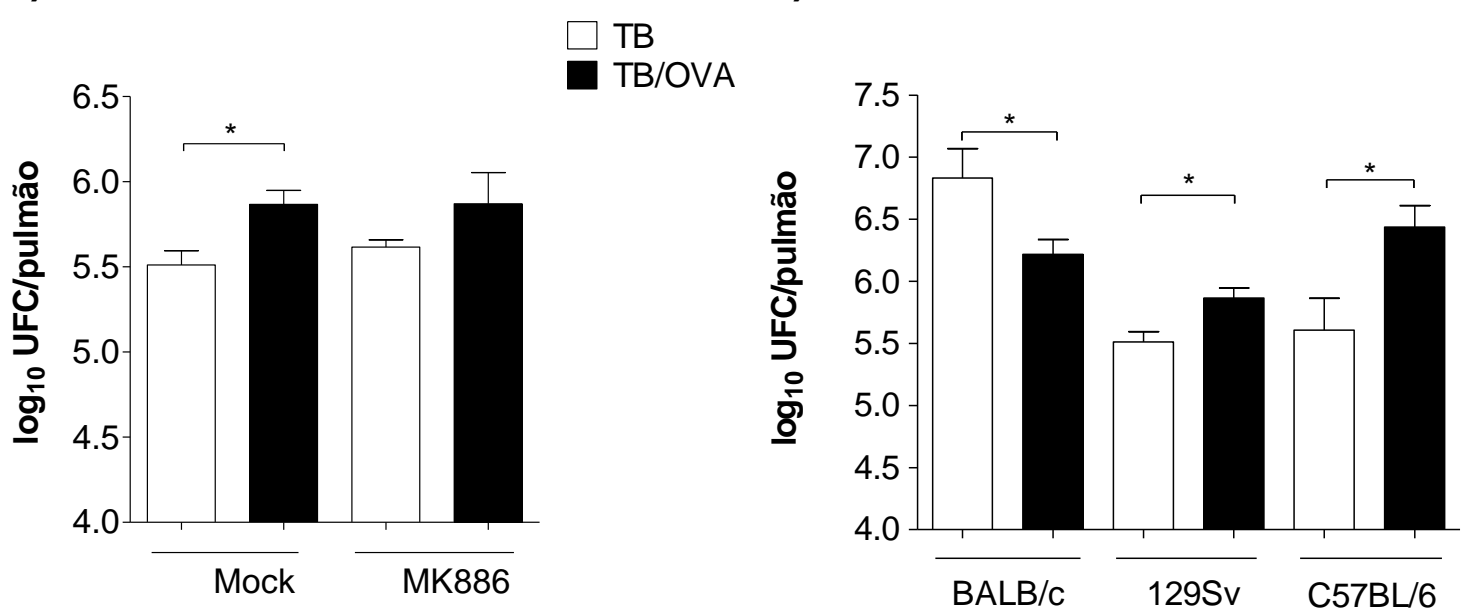

Figura 16. Avaliação do número de UFC no pulmão de animais coinflamados, tratados com MK886. Camundongos 129Sv foram infectados com M. tuberculosis e, 30 dias após a infecção, foram submetidos ao protocolo de indução de asma experimental, como descrito na Figura 2. (A) Durante a fase de indução da alergia, os animais infectados foram tratados diariamente com $5 \mathrm{mg} / \mathrm{Kg}$ de MK886 por gavagem até o dia da eutanásia. O grupo de animais apenas infectado também foi tratado com MK886. (B) Ao final do protocolo de indução da alergia, os pulmões foram coletados, processados e utilizados para a realização do ensaio de UFC. (C) Número de UFC no pulmão de animais coinflamados das linhagens BALB/c, C57BL/6 e 129Sv. Resultados representativos de um 1-6 experimentos $(\mathrm{n}=3-7)$ foram expressos como médias \pm desvio padrão. $* \mathrm{p}<0,05$. 


\subsubsection{Quantificação de citocinas por ELISA}

Quando avaliamos as citocinas presentes no homogenato de pulmão de camundongos TR-TB/OVA, foi observado que houve diminuição significativa na produção de IFN- $\gamma$ e IL-1 $\beta$, se comparados com os animais NT-TB/OVA (Figura 17AB). Pelo contrário não foram observadas diferenças significativas na produção de TGF$\beta$, IL-5 e IL-13 (Figura 17C-E). Em adição, foi observado que os animais TR-TB/OVA apresentaram menor produção de IFN- $\gamma(\mathrm{p}>0.05)$ e IL-1 $\beta$ ( $\mathrm{p}<0.05)$, se comparados com o grupo TR-TB (Figura 17A-B). Entanto que não houve diferenças significativas na produção de TGF- $\beta$, IL-5 e IL-13 entre os grupos TR-TB/OVA e TR-TB (Figura 17 CE). Por outro lado, o grupo NT-TB/OVA apresentou diminuição na produção de TGF- $\beta$ $(\mathrm{p}<0.05)$ e aumento de IFN- $\gamma(\mathrm{p}>0.05)$, se comparado com o grupo TB (Figura 17A e C). Não foram observadas diferenças significativas na produção de IL-1 $\beta$, IL-5 e IL-13 entre os grupos NT-TB/OVA e NT-TB (Figura 17A, C-E).

Esses resultados mostram que no grupo TR-TB/OVA, o tratamento com MK886 na fase de indução de asma experimental, está associado com diminuição na produção de citocinas proinflamatórias, como IFN- $\gamma$ e IL-1 $\beta$, quando comparados com o grupo NTTB/OVA. Em adição, nossos resultados mostram que a produção de TGF- $\beta$ está diminuída nos grupos que foram mais susceptíveis à infecção com $M$. tuberculosis (NTTB/OVA, TR-TB e TR-TB/OVA), se comparado com o grupo mais resistente (NT-TB). 
A)

B)
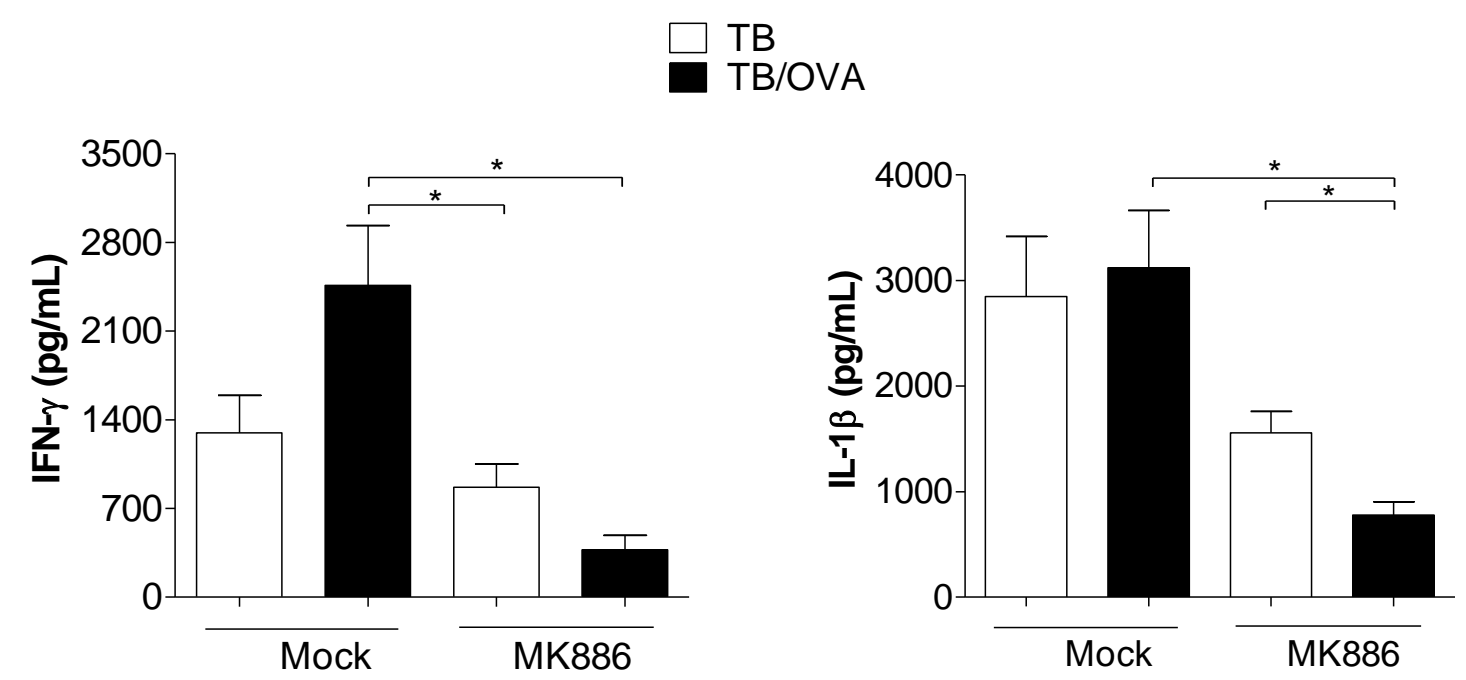

C)

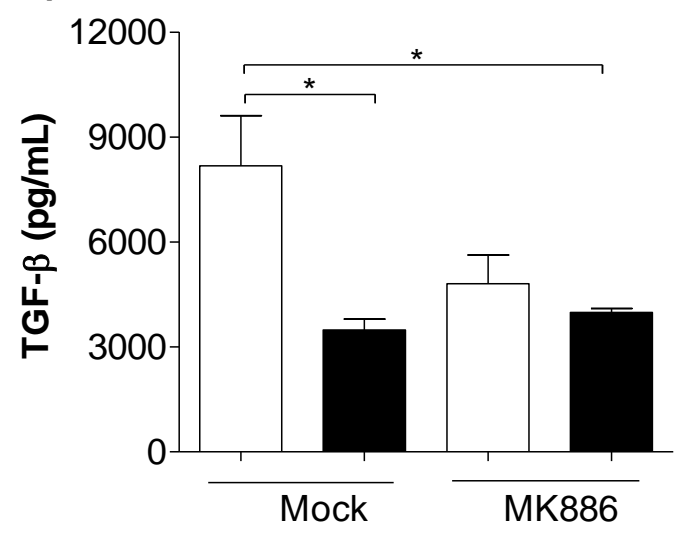

D)

E)
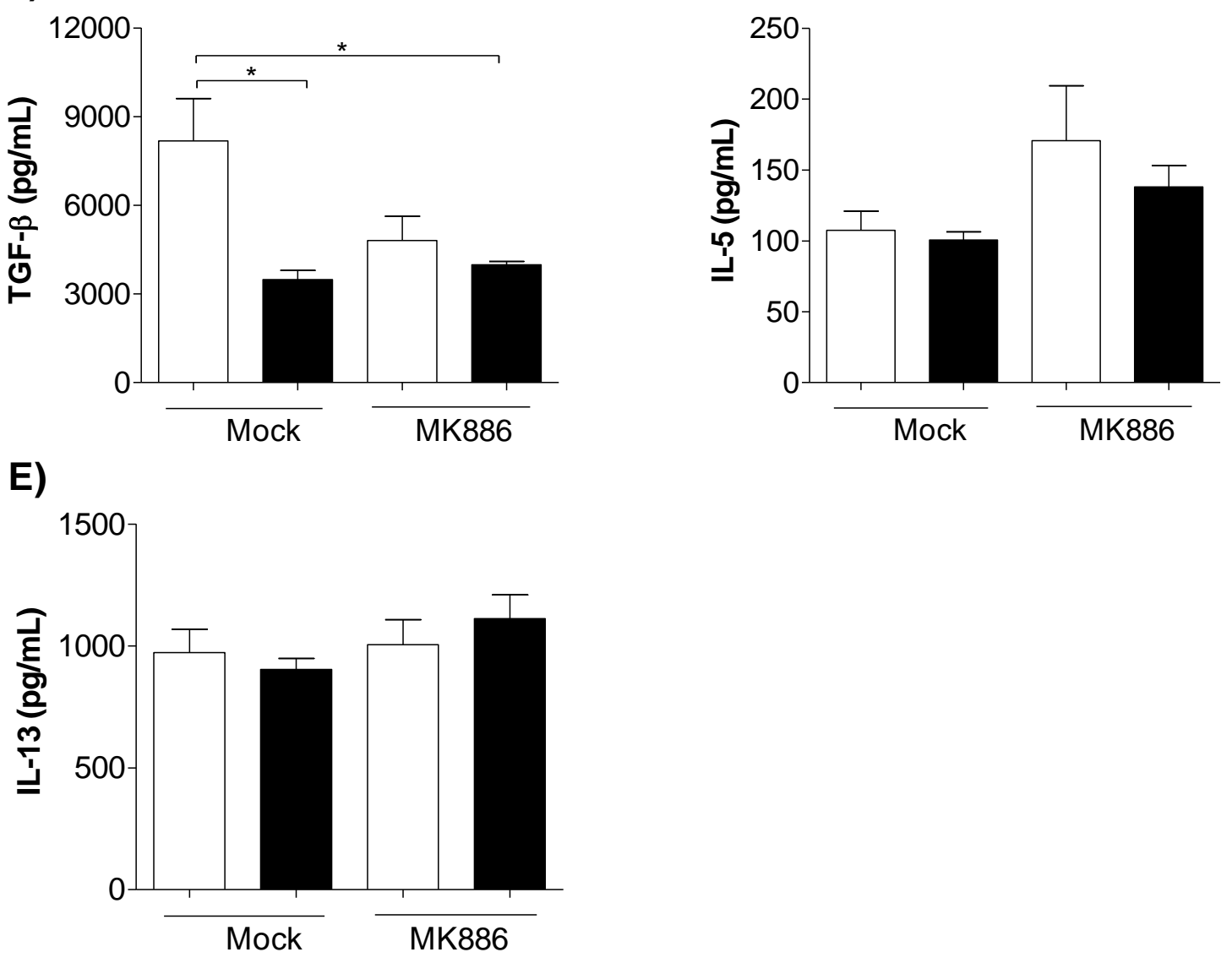

Figura 17. Detecção de citocinas em homogenato de pulmão de camundongos TB/OVA. Camundongos 129Sv foram submetidos ao protocolo de coinflamação tuberculose e alergia (Figura 16A), e 72 horas após o desafio com OVA, os pulmões foram coletados e homogeneizados para quantificação de citocinas por ELISA. Resultados representativos de um experimento ( $n=4-6$ animais), expressos como médias \pm desvio padrão. ${ }^{*} \mathrm{p}<0.05$ 


\subsubsection{3. $\quad$ Análise histológica}

Os resultados observados até o momento, utilizando como ferramenta o inibidor da síntese de leucotrienos (MK886) para avaliar o papel dos mesmos na coinflamação, mostraram que os animais NT-TB/OVA da linhagem 129Sv foram mais susceptíveis à infecção por $M$. tuberculosis quando comparados com o grupo NT-TB. Esse dado foi diferente do observado previamente para animais BALB/c. Para avaliar se houve aumento no processo inflamatório do parênquima pulmonar desses animais, foram realizados cortes do pulmão para a confecção de lâminas histológicas.

A Figura 18 mostra imagens representativas do pulmão dos grupos estudados, coradas com hematoxilina e eosina. Foi observado que, de modo geral, os quatro grupos experimentais mostraram comprometimento no parênquima pulmonar, infiltrado crônico e multifocal, com predomínio de macrófagos xantomatosos e hiperplasia no tecido linfóide associado aos brônquios (BALT) (Figura 18A-D). Os animais NTTB/OVA tiveram menos comprometimento do BALT que os animais NT-TB, com maior processo de reparo tecidual e presença de fibroblastos. (Figura 18). Esses resultados sugerem que além do aumento na susceptibilidade à infecção por $M$. tuberculosis, os animais TB/OVA da linhagem 129Sv apresentaram aumento da inflamação no parênquima pulmonar. 

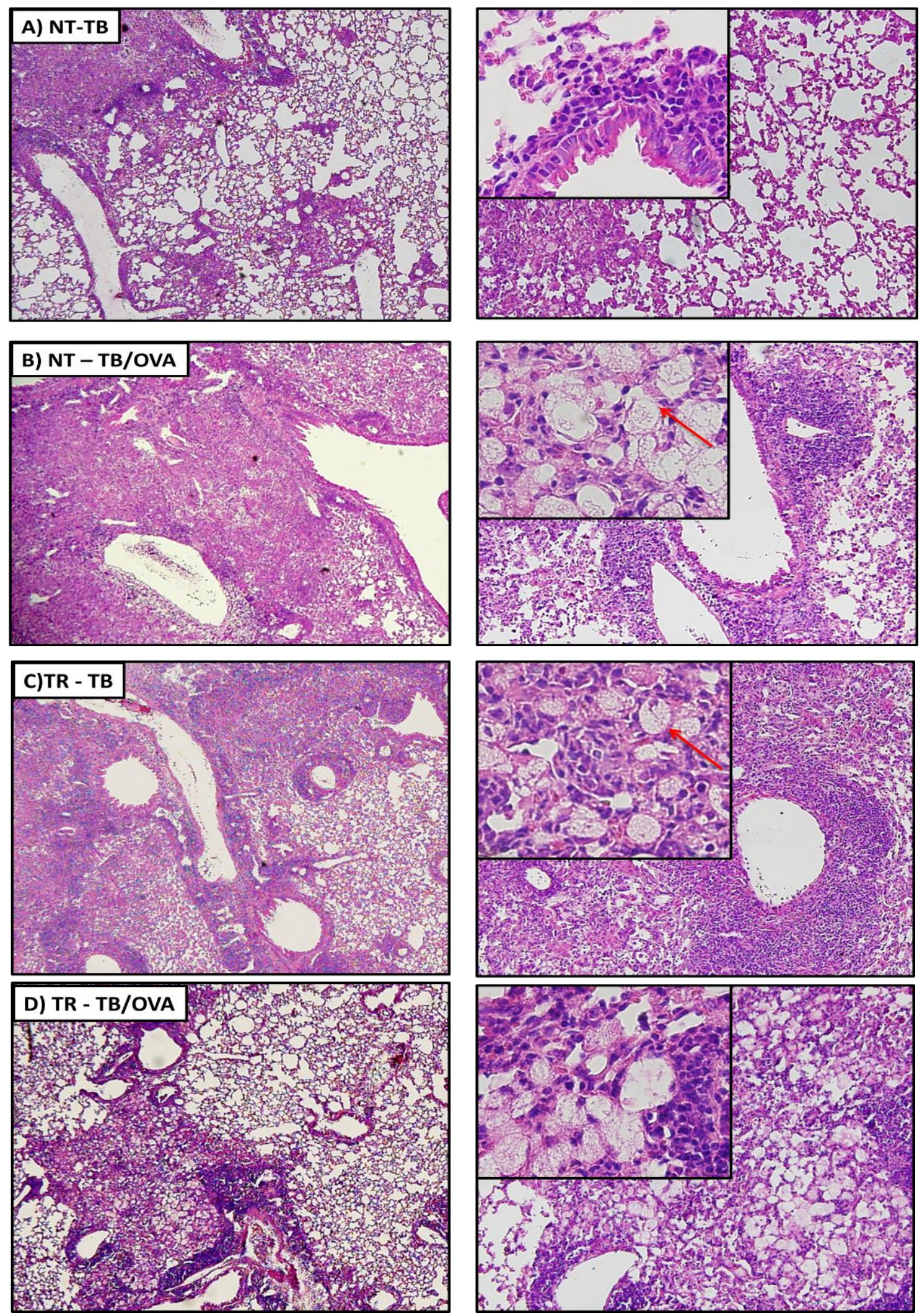

Figura 18. Avaliação histológica do pulmão de animais coinflamados tratados com MK886. Camundongos 129Sv foram infectados com M. tuberculosis, e 30 dias após a infecção, foram submetidos ao protocolo de indução de alergia, descrito anteriormente, e tratados com MK886, como descrito na Figura 16A. Após 72 horas do desafio com OVA, os pulmões foram processados para a confecção de lâminas histológicas. As 
fotomicrografias dos cortes corados com Hematoxilina e Eosina são mostradas em aumento de 40X (esquerda) e 100X (direita), além de detalhes em aumento de 400X na direita. As setas vermelhas indicam macrófagos xantomatosos. Resultados representativos de um experimento ( $n=4-5$ animais por grupo). 
4.3.3. DELINEAMENTO EXPERIMENTAL II. Avaliação do papel da enzima 5-LO na coinflamação utilizando animais $5 \mathrm{LOKO}$

\subsubsection{Quantificação do número de UFC em camundongos 5 LOKO}

Paralelamente, para avaliar o papel dos leucotrienos na modulação da resposta imune contra $M$. tuberculosis, foram utilizados camundongos deficientes para a expressão da enzima 5 lipoxigenase (5LOKO), que participa da via de síntese dos leucotrienos. Considerando que os leucotrienos são mediadores importantes no recrutamento de leucócitos tanto na tuberculose quanto na alergia, inicialmente, foi avaliado se os animais 5LOKO, submetidos ao protocolo de indução de asma experimental, descrito no apêndice 3 , desenvolviam resposta imune característica das respostas alérgicas. Como observado no apêndice 3, os animais 5LOKO apresentaram aumento significativo na frequência $(\mathrm{p}<0.05)$ e número de eosinófilos $(\mathrm{p}<0.05)$ no LBA, quando submetidos ao protocolo de indução de asma, comparados aos animais do grupo controle, que receberam apenas solução fosfato tamponado (PBS). Esses resultados confirmam que os camundongos 5LOKO submetidos ao protocolo de indução de alergia apresentam parâmetros característicos de alergia, embora em menor magnitude que os animais WT alérgicos.

Ao estabelecer o protocolo de coinflamação nos animais 5LOKO, verificamos que não houve diferença no número de bacilos recuperados do pulmão dos animais do grupo 5LOKO coinflamado (5LOKO-TB/OVA) e do grupo 5LOKO infectado (5LOKO-TB) (Figura 19). Contudo, os animais do grupo 5LOKO-TB/OVA foram menos susceptíveis à infecção por M. tuberculosis comparados aos animais do grupo WT-TB/OVA (Figura 19).

Esses resultados mostram que o animal do background genético 129Sv não é uma ferramenta adequada para avaliar o papel dos leucotrienos na restrição ao crescimento dos bacilos. Em adição, os resultados mostram que a deficiência na produção de mediadores lipídicos, nos animais 5LOKO foi associada com proteção frente à infecção por $M$. tuberculosis, tanto nos animais 5LOKO-TB/OVA quanto no grupo 5LOKO-TB (Figura 19). Entretanto, a deficiência na produção de mediadores lipídicos somente na fase de indução de alergia (animais 129Sv tratados com MK886), não afetou o crescimento do bacilo no pulmão dos animais TR-TB/OVA nem dos animais TR-TB (Figura 16B). 
Em resumo, os resultados mostrados até o momento relacionados com a avaliação dos mediadores lipídicos na coinflamação, mostram que os leucotrienos parecem exercer efeito deletério se presentes no início da coinflamação. No entanto, sua ausência durante o desenvolvimento da resposta alérgica (tratamento com MK-886 dos animais do grupo TB/OVA) não exerce efeito no crescimento dos bacilos. Em adição, os resultados apresentados mostram que o menor crescimento de $M$. tuberculosis no pulmão de animais TB/OVA depende do background genético do hospedeiro.

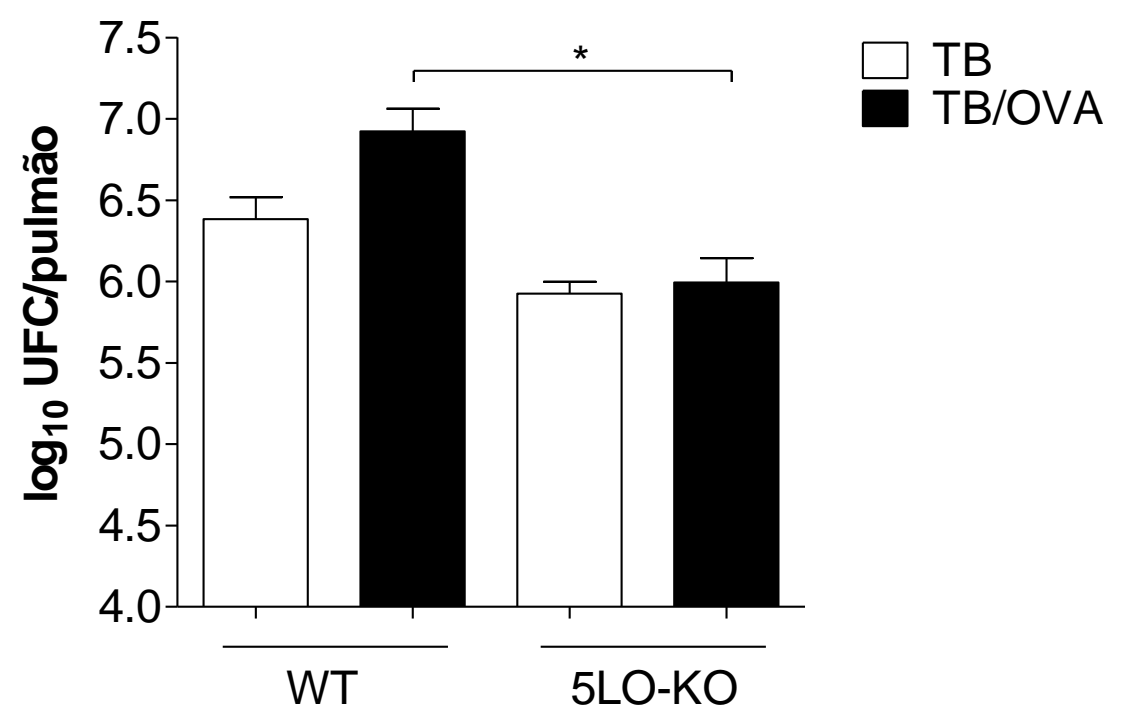

Figura 19. Avaliação do número de UFC no pulmão de animais 5LOKO coinflamados. Camundongos $129 \mathrm{~Sv}$ (WT) e $5 \mathrm{LOKO}$ foram submetidos ao delineamento experimental TB/OVA, conforme descrito previamente (Figura 2). Ao final do protocolo de indução da alergia, os pulmões foram coletados, digeridos e processados para realização do ensaio de Unidades Formadoras de Colônia (UFC) Resultados representativos de um único experimento ( $n=3-5$ animais), expressos como médias dos valores individuais \pm erro padrão. $* \mathrm{p}<0,05$. 


\section{$\underline{T B / O V A}$}

Paralelamente, foi observado que não houve diferença significativa na expressão de genes característicos de macrófagos M1 e M2 entre os grupos avaliados. No entanto, foi observado que os camundongos 5LOKO-TB/OVA e 5LOKO-TB, que foram menos susceptíveis à infecção com $M$. tuberculosis, apresentaram aumento na expressão do gene para $i N O S$ em relação aos respectivos grupos de animais WT ( $\mathrm{p}>0.05)$ (Figura 20).

A)

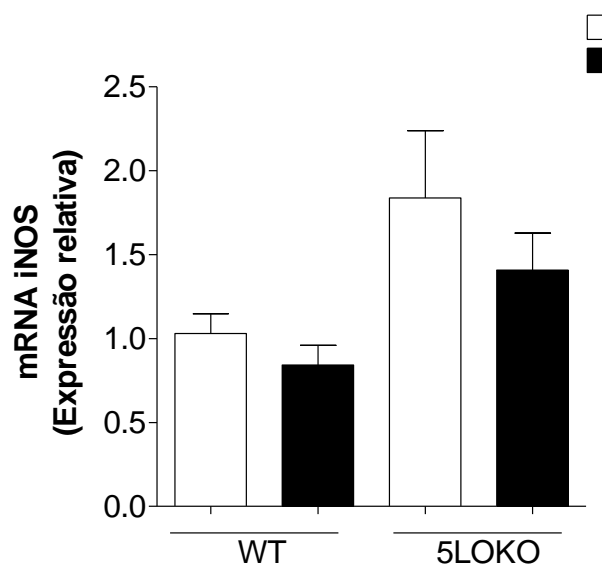

C)

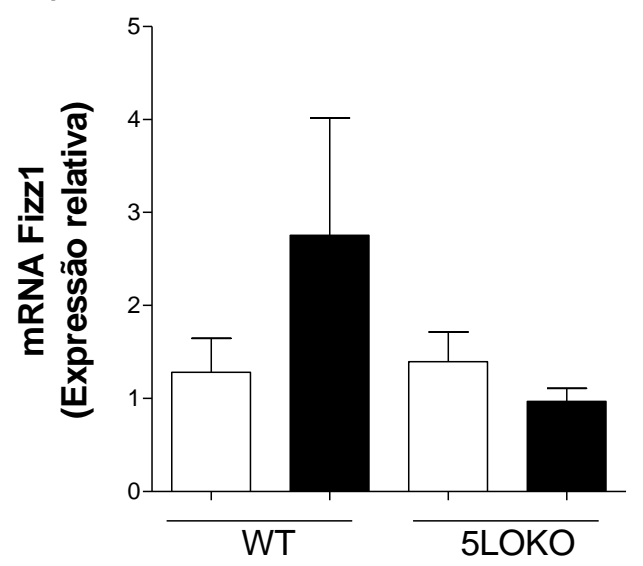

B)

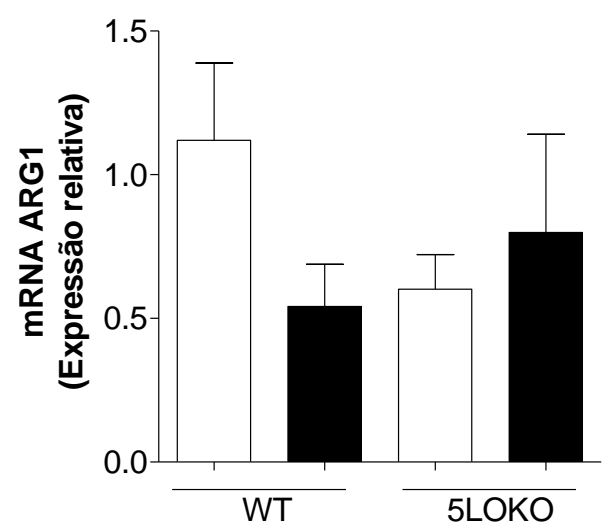

D)

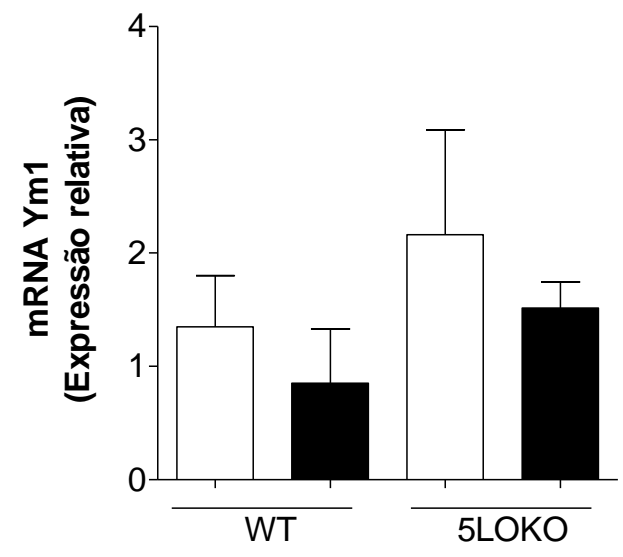

Figura 20. Expressão de genes associados com macrófagos M1 e M2 no pulmão de camundongos 5LOKO coinflamados. Camundongos $129 \mathrm{~Sv}$ (WT) e 5LOKO foram submetidos ao delineamento experimental TB/OVA, conforme descrito previamente (Figura 2). Após 72 horas do desafio com OVA, o RNA total dos pulmões foi obtido e quantificado para avaliação da expressão de RNAm para iNOS2 (A), Arg1 (B), Fizzl (C) e $Y m l$ (D) por RT-PCR. Resultados representativos de um experimento $(\mathrm{n}=3-6$ animais por grupo), expressos como médias dos valores individuais \pm desvio padrão. *p $<0.05$. 


\subsubsection{3. $\quad$ Análise histológica}

A Erro! Fonte de referência não encontrada. mostra imagens representativas do pulmão dos grupos estudados, coradas com hematoxilina e eosina. De modo geral, os quatro grupos experimentais mostraram comprometimento no parênquima pulmonar, infiltrado crônico e multifocal, com predomínio de macrófagos xantomatosos e hiperplasia no tecido linfóide associado aos brônquios (BALT) (Erro! Fonte de referência não encontrada.A-D). Em adição, foi observado que o pulmão dos animais do grupo WT-TB/OVA apresentou maior processo inflamatório e hiperplasia do BALT em relação aos animais do grupo WT-TB (Erro! Fonte de referência não encontrada. A-B). Entretanto, animais dos grupos 5LOKO-TB/OVA e 5LOKO-TB apresentaram comprometimento do parênquima pulmonar similar e comparável àquele observado nos animais do grupo WT-TB/OVA. 

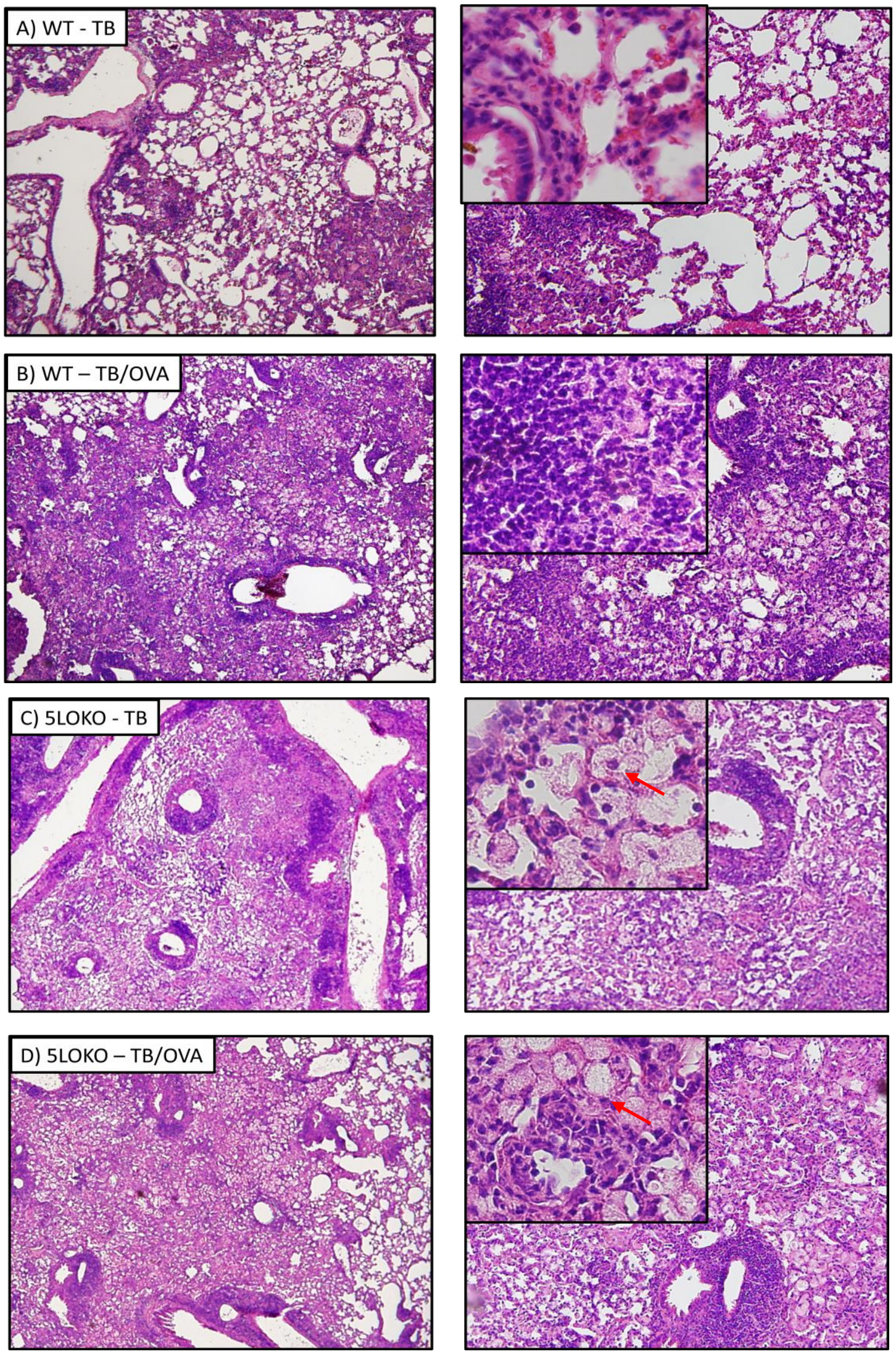

Figura 21. Avaliação histológica do pulmão de animais 5LOKO coinflamados. Camundongos 129Sv (WT) e 5LOKO foram submetidos ao delineamento experimental TB/OVA, conforme descrito previamente (Figura 2). Após 72 horas do desafio, os pulmões foram processados para a confecção de lâminas histológicas. As 
fotomicrografias dos cortes corados com Hematoxilina e Eosina são mostradas em aumento de 40X (esquerda) e 100X (direita) além de detalhes em aumento de 400X na direita. As setas vermelhas indicam macrófagos xantomatosos. Resultados representativos de dois experimentos ( $n=3-6$ animais por grupo). 


\section{DISCUSSÃO}

Os resultados apresentados neste trabalho mostram que animais coinflamados (TB/OVA), em decorrência da alergia, apresentaram aumento de macrófagos M2 que parecem modular a resposta imune frente ao bacilo M. tuberculosis, induzindo menor crescimento da bactéria no pulmão, em relação aos animais apenas infectados (TB). Esse aumento na proteção também parece associado com aumento no recrutamento de células dendríticas plasmocitóides, na produção de IL-1 $\beta$ assim como aumento de células com corpúsculos lipídicos no pulmão dos animais TB/OVA. Em adição, nossos resultados mostram que a diminuição no crescimento de bacilos nos animais coinflamados depende da linhagem do camundongo e da ausência de mediadores lipídicos durante o desenvolvimento do processo coinflamatório.

Resultados prévios no nosso grupo mostraram que camundongos TB/OVA apresentaram menor carga bacilar, associada com aumento no número de linfócitos $\mathrm{T}$ $\mathrm{CD}^{+}$e com a produção de $\mathrm{LTB}_{4}$, assim como diminuição no infiltrado granulomatoso. No presente trabalho foram avaliados cada um desses parâmetros a fim de determinar qual ou quais deles estariam envolvidos na restrição ao crescimento da bactéria no pulmão desses animais.

Os linfócitos $\mathrm{T} \mathrm{CD}^{+}$são células conhecidas por seu papel no controle do crescimento dos bacilos em animais infectados com M. tuberculosis. Estudos mostram que na ausência de linfócitos $\mathrm{T} \mathrm{CD}^{+}$, os camundongos foram mais susceptíveis à infecção por M. tuberculosis (Müller, Cobbold et al. 1987; Flynn, Goldstein et al. 1992) ou por outras espécies de micobactérias (Ladel, Daugelat et al. 1995).

Durante a infecção por $M$. tuberculosis, as células $\mathrm{T} \mathrm{CD}^{+}$são ativadas no linfonodo e migram para o pulmão, local onde exercem sua função efetora: produção de IFN- $\gamma$ (Feng, Bean et al. 1999; Serbina and Flynn 1999; Fulton, Martin et al. 2000; Hope, Kwong et al. 2000) e a geração da resposta citotóxica (Serbina, Liu et al. 2000; Kamath, Woodworth et al. 2004; Quintero-Macias, Santos-Mendoza et al. 2010). Ambas as respostas favorecem o controle no crescimento da bactéria. Em adição, um estudo realizado por van Pinxteren e colaboradores mostrou que os linfócitos T CD8 ${ }^{+}$ são mais importantes durante a fase latente que durante a fase aguda da infecção por $M$. tuberculosis, representando a maior fonte de IFN- $\gamma$ durante a latência (van Pinxteren, Cassidy et al. 2000). 


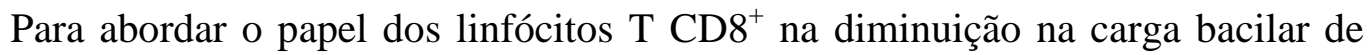
animais TB/OVA, no presente estudo foram utilizados camundongos CD8KO (linhagem C57BL/6). Inesperadamente, o grupo WT-TB/OVA foi mais susceptível à infecção pelo bacilo que o grupo WT-TB, impossibilitando-nos a utilizar os camundongos CD8KO (linhagem C57BL/6) para análise do papel dos linfócitos $\mathrm{T}$ $\mathrm{CD}^{+}$na coinflamação. Uma ferramenta alternativa para avaliarmos o papel dos linfócitos $\mathrm{T} \mathrm{CD}^{+}$seria a utilização de camundongos $\mathrm{BALB} / \mathrm{c}$ tratados com anticorpo contra CD8. Em adição, estudos posteriores poderiam avaliar a capacidade citotóxica dessas células, pois como observado nos resultados preliminares, o aumento do infiltrado de linfócitos $\mathrm{T} \mathrm{CD}^{+}$, nos animais TB/OVA, não estava associado com aumento na produção de IFN- $\gamma$. Além disso, é importante ressaltar que pacientes com tuberculose ativa tem menor expressão de granzima e perforina, moléculas associadas com capacidade citotóxica, nos linfócitos $\mathrm{T} \mathrm{CD}^{+}$que estão presentes no local da infecção (Andersson, Samarina et al. 2007). O papel dos linfócitos T CD8 ${ }^{+}$na asma é menos explorado, não havendo ainda consenso sobre a função dessas células nessa doença. Estudos sugerem que linfócitos $\mathrm{T} C D 8^{+}$são necessários para o desenvolvimento da inflamação alérgica das vias aéreas (Tsuchiya, Isogai et al. 2009) e para a indução de hiper-reatividade brônquica (Taube, Miyahara et al. 2006; Koya, Matsuda et al. 2009), enquanto outros estudos sugerem que as células $\mathrm{T} \mathrm{CD}^{+}$inibem a sensibilização ao alérgeno e a inflamação alérgica (Stock, Kallinich et al. 2004; Isogai, Athiviraham et al. 2007; Wells, Cowled et al. 2007; Takeda, Dow et al. 2009). Também foi descrito que células $\mathrm{CD}^{+}$específicas para alérgeno foram ativadas nos linfonodos após desafio com alérgeno e rapidamente migraram para o pulmão (Wells, Cowled et al. 2007). Portanto, parece que células $\mathrm{CD} 8^{+}$sofrem diferenciação durante a indução da resposta alérgica, sendo o aumento dessa população um parâmetro que pudesse estar associado com proteção na tuberculose.

Em suma, ao usar animais CD8KO, não conseguimos inferir sobre o papel desses linfócitos na coinflamação tuberculose e asma. Porém, nossos resultados mostraram que a diminuição na carga bacilar nos animais TB/OVA depende da linhagem de camundongo. Portanto, os camundongos TB/OVA (linhagem BALB/c) e TB/OVA (linhagem C57BL/6), apresentaram padrões de resposta diferentes contra $M$. tuberculosis durante o processo de coinflamação.

Estudos reportados na literatura mostram a variabilidade na resposta frente à infecção por M. tuberculosis em camundongos das linhagens C57BL/6 e BALB/c. Em 
particular, os camundongos da linhagem BALB/c geram menor resposta Th1 frente à infecção por $M$. tuberculosis se comparados aos camundongos da linhagem C57BL/6 (Wakeham, Wang et al. 2000; Jung, Ryan et al. 2009). Em adição, em um estudo prévio de nosso grupo, foi descrito que os camundongos BALB/c apresentam menor controle no crescimento de $M$. tuberculosis, associado com maior produção de IL-10 e células T reguladoras com maior capacidade supressora quando comparados aos animais C57BL/6 (Paula, Fonseca et al. 2011). Outros estudos mostraram que as duas linhagens de camundongos apresentaram respostas imunes diferentes quando foram infectadas com cargas bacilares maiores ou equivalentes a 1 x $10^{5}$ bacilos. Assim, os camundongos BALB/c respondiam gerando resposta mista Th1/Th2 (Hernandez-Pando, Orozcoe et al. 1996; Morais Fonseca, Rosada et al. 2010), enquanto os camundongos C57BL/6 geravam forte resposta Th1, com baixa produção de citocinas Th2 (Orme, Roberts et al. 1993; Jung, LaCourse et al. 2002). A resposta Th1 conservava-se até a fase crônica da infecção e estava associada com maior produção de IL-17 (Paula, Fonseca et al. 2011). Nossos estudos mostraram que no contexto da coinflamação e diferente dos estudos anteriores, os camundongos TB/OVA (linhagem C57BL/6) foram mais suscetíveis à infecção com $M$. tuberculosis que os animais TB/OVA (linhagem BALB/c). Como reportado na literatura, os camundongos C57BL/6 infectados apresentam resposta Th1 mais prolongada que os animais BALB/c (Teixeira, Munk et al. 1995; Wakeham, Wang et al. 2000; Paula, Fonseca et al. 2011) e isso pode levar ao aumento na resposta inflamatória e no dano tecidual. Como visto na análise histopatológica, nossos resultados mostram que houve maior comprometimento do BALT e aumento de infiltrado difuso com predomínio de macrófagos xantomatosos nos camundongos TB/OVA (C57BL/6) quando comparados com o grupo TB (C57BL/6). O estudo de Paula e colaboradores mostrou que os camundongos C57BL/6 infectados com $M$. tuberculosis apresentavam maior produção de TGF- $\beta$ (citocina associada com reparo tecidual e fibrose) na fase crônica da infecção. Embasado nesse estudo de nosso grupo e em nossos resultados aqui descritos, é interessante para estudos futuros avaliar a fibrose nos animais TB/OVA (C57BL/6), pois em decorrência de forte resposta Th1 e em presença da resposta Th2, possivelmente, haveria aumento do reparo tecidual gerado no pulmão desses animais.

Associado com a menor carga bacilar e o aumento de linfócitos $\mathrm{T} \mathrm{CD} 8^{+}$, os camundongos BALB/c TB/OVA também apresentaram aumento na produção de $\mathrm{LTB}_{4}$. 
Nossa hipótese inicial foi então que $\mathrm{o}^{\mathrm{LTB}_{4}}$ estava envolvido na restrição do crescimento de bacilos no pulmão dos animais TB/OVA.

Estudos reportados na literatura mostram que o $\mathrm{LTB}_{4}$ é produzido por várias células do sistema imune, como neutrófilos, mastócitos, eosinófilos e macrófagos (Sampson, Thomas et al. 1992; Serezani, Aronoff et al. 2005; Triggiani, Giannattasio et al. 2009; Gulliksson, Carvalho et al. 2010). Em adição, estudos posteriores mostraram que células como eosinófilos e macrófagos tem organelas especializadas no metabolismo de lipídeos, conhecidas como corpúsculos lipídicos. Essas organelas são especializadas na síntese de mediadores lipídicos, como o $\mathrm{LTB}_{4}$ (Weller and Dvorak 1994; Bozza, Yu et al. 1997; Weller, Bozza et al. 1999; Bandeira-Melo, Phoofolo et al. 2001) e são induzidas frente a vários estímulos, incluindo as infecções micobacterianas (D’Avila, Melo et al. 2006; Melo, Sabban et al. 2006; D'Ávila, Almeida et al. 2007; D'Avila, Roque et al. 2008). Considerando que os resultados prévios em nosso grupo mostram que animais TB/OVA apresentam maior produção de $\mathrm{LTB}_{4}$, se comparados com os animais $\mathrm{TB}$, nos avaliamos se houve diferença na quantidade de corpúsculos lipídicos observada em ambos os grupos. O grupo TB/OVA apresentou maior frequência e porcentagem de células com corpúsculos lipídicos no LBA comparados aos animais do grupo TB. Esse resultado sugere possível associação entre a formação de corpúsculos lipídicos e a produção de $\mathrm{LTB}_{4}$ nos animais TB/OVA. No entanto, estudos adicionais devem ser realizados para determinar se a formação desses corpúsculos lipídicos está correlacionada com maior produção de $\mathrm{LTB}_{4}$, assim como avaliar quais são as células que estão sendo estimuladas a formar essas organelas e se esse aumento na formação de corpúsculos lipídicos também está acontecendo nas células do tecido pulmonar.

O $\mathrm{LTB}_{4}$ é um mediador lipídico que exerce papel importante durante o controle de infecções bacterianas (Bailie, Standiford et al. 1996; Coffey, Phare et al. 2004; Serezani, Aronoff et al. 2005) e fúngicas (Medeiros, Sa-Nunes et al. 2004; Secatto, Rodrigues et al. 2012), induzindo aumento na fagocitose e na atividade microbicida, associada com aumento de produção de NO. No entanto, o papel dos leucotrienos na infecção com $M$. tuberculosis ainda não está bem esclarecido, pois estudo realizado por Bafica e colaboradores mostrou que camundongos deficientes na expressão da enzima 5LO foram mais resistentes à infecção por M. tuberculosis quando comparados aos animais WT (Bafica, Scanga et al. 2005). Do contrário, Peres e colaboradores, utilizando o composto MK886, inibidor da síntese dos leucotrienos, mostraram que os 
camundongos infectados e tratados com MK886 eram mais susceptíveis à infecção (Peres, Aronoff et al. 2007).

Para avaliarmos o papel do $\mathrm{LTB}_{4}$ na diminuição da carga bacilar nos animais coinflamados foram utilizadas duas ferramentas: tratamento com MK886 e animais 5LOKO. É importante ressaltar que a partir das duas ferramentas podem se inferir duas conclusões: 1- Os camundongos TB/OVA (129Sv) foram mais susceptíveis à infecção com M. tuberculosis se comparados aos animais do grupo TB (129Sv), e isso diferia do resultado prévio com animais BALB/c. 2- Os mediadores lipídicos parecem exercer efeito deletério durante a indução de coinflamação, pois a ausência de mediadores lipídicos desde o início da coinflamação (animais 5LOKO-TB/OVA) mostrou diminuição na susceptibilidade dos animais do grupo 5LOKO-TB/OVA frente à $M$. tuberculosis, se comparados com os animais WT-TB/OVA. No entanto, a inibição da produção de mediadores lipídicos durante a fase de indução da alergia, não gerou um efeito deletério no controle da infecção por M. tuberculosis nos animais TR-TB/OVA, quando comparados com NT-TB/OVA.

Nossos resultados mostraram que os animais TB/OVA (linhagem 129Sv) foram mais susceptíveis à infecção com $M$. tuberculosis que os camundongos apenas infectados (linhagem 129Sv - grupo TB), sendo esse resultado diferente daquele observado em animais do grupo TB/OVA (linhagem BALB/c). Esses dados sugerem que os camundongos 129Sv não representaram uma estratégia ideal para avaliar o papel dos leucotrienos na coinflamação, devido ao background genético das espécies de camundongos estudadas. Uma estratégia alternativa seria utilizar o tratamento com o inibidor da síntese de leucotrienos, MK886, nos animais BALB/c.

Uma vez mais, nossos resultados mostravam que a diminuição na carga bacilar no pulmão dos animais TB/OVA dependia da linhagem do camundongo, e consequentemente do background genético. Estudo realizado por Tobin e colaboradores mostrou que a susceptibilidade à infecção por $M$. tuberculosis está associada com polimorfismos no locus que codifica a enzima leucotrieno- $\mathrm{A}_{4}$ hidrolase $\left(\mathrm{LTA}_{4} \mathrm{H}\right)$, que metaboliza o $\mathrm{LTA}_{4}$ para formar o $\mathrm{LTB}_{4}$. Assim, pacientes que são portadores homozigotos do locus LTAH4 são mais susceptíveis à infecção com M. tuberculosis que aqueles que são heterozigotos (Tobin, Vary et al. 2010). Esses resultados foram confirmados utilizando o modelo experimental peixe zebra. Foi observado que os animais que tinham baixa expressão de LTA4H, quando infectados com M. marinum (micobactéria geneticamente mais próxima de M. tuberculosis), apresentavam aumento 
na produção de lipoxina $\mathrm{A}_{4}$ ( $\mathrm{LXA}_{4}$, mediador lipídico com atividade anti-inflamatória) e não conseguiam conter a infecção. Surpreendentemente, os animais que tinham aumento na expressão da enzima LTA4H, produziam mais $\mathrm{LTB}_{4}$, porém, também não controlavam a infecção, enquanto os animais com expressão normal de LTA4H conseguiam controlar o crescimento dos bacilos (Tobin, Roca et al. 2012). Esse aumento na suscetibilidade dos animais que expressavam mais ou menos LTA4H estava associado com aumento e diminuição na produção de TNF, respectivamente (Tobin, Roca et al. 2012). Esse estudo é particularmente importante para o entendimento da resposta imune na tuberculose porque prova o que tem sido amplamente discutido: a resposta inflamatória é essencial para o controle da infecção. Entretanto, o excesso de resposta inflamatória pode ser igualmente deletério para o hospedeiro. Sendo assim, o background genético do hospedeiro é um dos fatores determinantes para a geração da resposta imune adequada e o controle da infecção. Portanto a busca por estratégias terapêuticas adicionais deve considerar seriamente essa questão.

Em vista dos estudos de Tobin e colaboradores e considerando que a suscetibilidade à infecção por $M$. tuberculosis em animais coinflamados varia de acordo com a linhagem do camundongo, estudos posteriores podem ser realizados, direcionados a avaliar a expressão da LTA4H, especificamente determinando as diferenças genéticas associadas com este locus, em diferentes linhagens de camundongos (C57BL/6, BALB/c e 129Sv).

Outra conclusão interessante obtida durante a avaliação do papel dos leucotrienos na coinflamação é que os mediadores lipídicos podem exercer um efeito deletério se presentes durante o desenvolvimento desse processo. Os resultados obtidos no presente estudo mostram que os mediadores lipídicos exercem papel prejudicial se estão presentes desde o início da coinflamação, já que camundongos 5LOKO-TB/OVA foram mais resistentes à infecção por $M$. tuberculosis que os camundongos WTTB/OVA. Esses resultados foram similares aos descritos por Bafica e colaboradores (Bafica, Scanga et al. 2005). Como a enzima 5LO também participa da produção de mediadores anti-inflamatórios, como a lipoxina $\mathrm{A}_{4}\left(\mathrm{LXA}_{4}\right)$, nossos resultados podem ser interpretados de duas maneiras: 1- os leucotrienos exerceriam papel prejudicial frente à infecção com M. tuberculosis; 2- os leucotrienos teriam papel protetor, porém, as lipoxinas teriam efeito prejudicial no controle da infecção como já foi reportado (Bafica, Scanga et al. 2005; Chen, Divangahi et al. 2008; Divangahi, Chen et al. 2009; Behr, Schurr et al. 2010). 
Em adição, foi observado nos animais 5LOKO-TB/OVA que a proteção não estava associada com menor processo inflamatório no pulmão, já que a análise histológica mostrou aumento no influxo de leucócitos, com predomínio de macrófagos xantomatosos. É possível que o aumento no comprometimento do tecido pulmonar e no infiltrado celular no pulmão esteja acontecendo porque na ausência de mediadores antiinflamatórios, como as lipoxinas, haveria resposta inflamatória exacerbada (Machado and Aliberti 2006; Machado, Johndrow et al. 2006). Em concordância com isso, foi observado aumento de macrófagos com fenótipo M1, mas não na população de macrófagos M2.

Entretanto, a inibição na produção de leucotrienos durante o processo de indução da asma experimental, por meio do tratamento com MK886, não afetou a replicação dos bacilos, pois como observado, não houve diferença significativa no número de UFC no pulmão dos animais TB/OVA tratados comparando-se com o grupo TB/OVA não tratado. Como mencionado anteriormente, uma estratégia alternativa seria utilizar o tratamento com o inibidor MK886 nos animais BALB/c, assim como o uso de um antagonista específico de $\mathrm{LTB}_{4}$ nesses animais.

Finalmente, quando avaliamos as populações de macrófagos M1 e M2 no pulmão dos animais coinflamados, observamos que houve aumento no infiltrado de macrófagos M2 no pulmão dos animais TB/OVA comparando-se ao grupo TB. As infecções com micobactérias, que estão caracterizadas por gerar resposta Th1, induzem a polarização de macrófagos para o fenótipo M1, com um pequeno aumento de M2 na fase aguda da doença (28 dias após infecção) (Hesse, Modolell et al. 2001).

Os macrófagos M1 caracterizam-se pela produção de iNOS e por conseguinte, aumento na produção de NO. A expressão de iNOS e subsequente produção de NO, são mecanismos celulares fundamentais no controle do crescimento de Mycobacterium spp (Chan, Xing et al. 1992; MacMicking, North et al. 1997; El Kasmi, Qualls et al. 2008). Em adição, os macrófagos M1 são importantes no controle bacteriano, porque apresentam maior expressão de moléculas de MHC-II, de moléculas coestimuladoras, como CD86, além de produzirem citocinas proinflamatórias (Mosser 2003). Ressaltamos que embora os camundongos do grupo TB/OVA apresentassem maior infiltrado de macrófagos M2, a população de macrófagos M1 nesses animais continuava sendo maior quando comparada com a detectada em animais não infectados e, além disso, similar à detectada no grupo TB. Portanto, provavelmente outro fator presente 
nos animais TB/OVA estava induzindo diminuição na susceptibilidade desses animais frente à infecção com $M$. tuberculosis.

Os marcadores clássicos da população de macrófagos M2 são expressão de Arg1, Fizzl e Ym1 (Martínez, 2008). Estes macrófagos diferenciam-se em microambientes nos quais ocorrem respostas de padrão Th2 (Stein, Keshav et al. 1992). Além disso, as citocinas IL-4 e IL-13, produzidas durante a resposta Th2, estão envolvidas na diminuição da atividade microbicida de macrófagos infectados com $M$. tuberculosis (Harris, De Haro et al. 2007). A ativação na expressão de Argl em animais que são infectados com micobactérias, como BCG e M. tuberculosis, já foi reportada na literatura (Hesse, Modolell et al. 2001; El Kasmi, Qualls et al. 2008; Qualls, Neale et al. 2010; Rajaram, Brooks et al. 2010). Porém sua produção está associada com maior susceptibilidade à infecção micobacteriana (Qualls, Neale et al. 2010; Rajaram, Brooks et al. 2010). A ativação de macrófagos com fenótipo M2 é também associada com reparo tecidual e homeostase do tecido (Gordon 2003; Martinez, Helming et al. 2009). Assim, provavelmente a ativação de macrófagos M2 nos animais TB/OVA pode favorecer a manutenção da homeostase do tecido pulmonar, evitando assim o efeito prejudicial de uma resposta inflamatória exacerbada pela presença de ambas as respostas (Th1 e Th2).

Para avaliar o papel do aumento de macrófagos M2 no controle da carga bacilar de animais TB/OVA, foram usados camundongos ST2KO (deficientes na expressão dos receptores citoplasmáticos e de membrana da IL-33). A IL-33 é uma citocina produzida durante a resposta imune alérgica (Schmitz, Owyang et al. 2005; Cherry, Yoon et al. 2008; Pushparaj, Tay et al. 2009) e a via de sinalização IL-33/ST2 está descrita na literatura como indutora da polarização de macrófagos para o fenótipo M2 (KurowskaStolarska, Stolarski et al. 2009; Joshi, Oak et al. 2010; Jiang, Milovanović et al. 2012). Assim macrófagos deficientes de ST2, apresentam diminuição na polarização de macrófagos M2 (Kurowska-Stolarska, Stolarski et al. 2009).

Nesse contexto, para avaliar o papel dos macrófagos M2, animais ST2KO foram utilizados. Os resultados apresentados no presente trabalho mostram que a diminuição nos macrófagos M2 nos animais ST2KO-TB/OVA, aumentou a susceptibilidade desses camundongos à infecção por M. tuberculosis quando comparados com os animais WTTB/OVA. Nossa hipótese é que a presença de macrófagos M2 permite maior controle na inflamação exacerbada gerada durante a infecção crônica por M. tuberculosis. Para reforçar nossa hipótese, foi descrito que a infecção com o cestóide Taenia crassiceps 
induz um padrão de resposta misto Th1/Th2 (Martinez, Helming et al. 2009), sendo a resposta Th1 importante nas fases iniciais para a remoção do patógeno (Rodríguez-Sosa, Satoskar et al. 2002). No entanto, durante a infecção crônica, macrófagos M2 são recrutados, a fim de controlar a proliferação de células CD4 ${ }^{+}$(Rodríguez-Sosa, Satoskar et al. 2002) e a resposta inflamatória excessiva (Martinez, Helming et al. 2009). Portanto, possivelmente, o aumento no infiltrado de macrófagos M2 poderia equilibrar a resposta inflamatória decorrente da ativação excessiva de macrófagos M1 e de linfócitos Th1.

A fim de determinar se outras populações de células com funções antiinflamatórias estavam envolvidas no controle do crescimento do bacilo nos animais TB/OVA, foram avaliadas as células dendríticas plasmocitóides (pDC), do inglês plasmacytoid Dendritic Cells). Nossos resultados mostram que houve aumento significativo nessa população de células nos animais do grupo TB/OVA em relação aos animais do grupo TB. As pDCs são células importantes na homeostase e tolerância no trato respiratório (Lambrecht and Hammad 2009). Estudos em doenças alérgicas mostram que as pDC suprimem a geração de células $\mathrm{T}$ efetoras, modulam negativamente os sintomas associados à asma (de Heer, Hammad et al. 2004) e tem baixa expressão de moléculas coestimuladoras. Além disso, as pDC estão em maior número no pulmão de camundongos tolerizados com OVA (Oriss, Ostroukhova et al. 2005). Portanto, esses estudos sugerem um papel regulador para as pDCs. Entretanto, um artigo publicado recentemente mostrou que camundongos deficientes de pDCs, quando infectados com $M$. bovis $(B C G)$, foram caracterizados por menor recrutamento de macrófagos e células NK para o local da inflamação (Guillerey, Mouriès et al. 2012). Esse estudo atribuiu o papel proinflamatório às pDC, e nesse contexto, o aumento no número de pDC poderia estar envolvido no recrutamento de macrófagos e células NK, células importantes no controle da infecção por M. tuberculosis (Rook, Steele et al. 1986; Flynn and Chan 2001; Feng, Kaviratne et al. 2006). Contudo, não descartamos a possibilidade de que as pDCs também estejam induzindo exercendo função antiinflamatória e desse modo, também possam contribuir na homeotasia do tecido nos animais TB/OVA. É interessante ressaltar que embora a via de sinalização IL-33/ST2 seja primordial para a diferenciação de macrófagos M2, ela não afetou a população de pDC. Como os animais ST2KO TB/OVA foram mais susceptíveis à infecção por $M$. tuberculosis, e esse fato parece ser dependente de M2, é possível que essa população de 
macrófagos, mas não as pDC, sejam essenciais para controlar a inflamação dos animais TB/OVA, e consequentemente, a expansão dos bacilos.

Em resumo, nossos resultados sugerem que há modulação da resposta imunológica na infecção por $M$. tuberculosis em animais coinflamados devido à resposta imune alérgica. Essa modulação envolve a ativação de macrófagos com fenótipo M2, aumento no recrutamento de pDC, assim como o aumento na formação de corpúsculos lipídicos nas células presentes no LBA. Ao mesmo tempo, os corpúsculos lipídicos poderiam contribuir para a geração de $\mathrm{LTB}_{4}$, que sabidamente exerce papel microbicida. A presença de macrófagos M2 e de pDC poderia equilibrar a magnitude da resposta inflamatória, levando à diminuição do infiltrado granulomatoso, menor dano tecidual, evitando a disseminação de bacilos. Dessa forma, a resposta Th2 da asma contribuiria para reduzir a inflamação enquanto também desempenharia papel indireto no controle da infecção por meio da diminuição das condições favoráveis à replicação dos bacilos no pulmão. 


\section{CONCLUSÕES}

6.1. Os resultados obtidos neste trabalho mostram que, em decorrência da resposta alérgica, houve aumento de macrófagos M2 no pulmão dos camundongos coinflamados TB/OVA, que favoreceram o controle do crescimento de bacilos;

6.2. A restrição ao crescimento de bacilos no pulmão dos animais coinflamados TB/OVA depende da linhagem do camundongo, acontecendo em animais da linhagem BALB/c, e não em camundongos das linhagens C57BL/6 e $129 \mathrm{~Sv}$.

6.3. A ausência de mediadores lipídicos durante a indução de coinflamação favorece o controle no crescimento do bacilo nos animais TB/OVA. 


\section{REFERENCIAS BIBLIOGRÁFICAS}

Allakhverdi, Z., M. R. Comeau, et al. (2007). "Thymic stromal lymphopoietin is released by human epithelial cells in response to microbes, trauma, or inflammation and potently activates mast cells." The Journal of Experimental Medicine 204(2): 253-258.

Andersson, J., A. Samarina, et al. (2007). "Impaired Expression of Perforin and Granulysin in CD8+ T Cells at the Site of Infection in Human Chronic Pulmonary Tuberculosis." Infection and Immunity 75(11): 5210-5222.

Angkasekwinai, P., H. Park, et al. (2007). "Interleukin 25 promotes the initiation of proallergic type 2 responses." The Journal of Experimental Medicine 204(7): 1509-1517.

Armstrong, J. A. and P. D. Hart (1975). "Phagosome-lysosome interactions in cultured macrophages infected with virulent tubercle bacilli. Reversal of the usual nonfusion pattern and observations on bacterial survival." The Journal of Experimental Medicine 142(1): 1-16.

Bafica, A., C. A. Scanga, et al. (2005). "TLR9 regulates Th1 responses and cooperates with TLR2 in mediating optimal resistance to Mycobacterium tuberculosis." J Exp Med 202(12): $1715-1724$.

Bafica, A., C. A. Scanga, et al. (2005). "Host control of Mycobacterium tuberculosis is regulated by 5-lipoxygenase-dependent lipoxin production." The Journal of Clinical Investigation 115(6): 1601-1606.

Bailie, M., T. Standiford, et al. (1996). "Leukotriene-deficient mice manifest enhanced lethality from Klebsiella pneumonia in association with decreased alveolar macrophage phagocytic and bactericidal activities." The Journal of Immunology 157(12): 5221-5224.

Bandeira-Melo, C., M. Phoofolo, et al. (2001). "Extranuclear lipid bodies, elicited by CCR3mediated signaling pathways, are the sites of chemokine-enhanced leukotriene C4 production in eosinophils and basophils." J Biol Chem 276(25): 22779-22787.

Behr, M., E. Schurr, et al. (2010). "TB: screening for responses to a vile visitor." Cell 140(5): 615-618.

Bekker, L.-G., S. Freeman, et al. (2001). "TNF- $\alpha$ Controls Intracellular Mycobacterial Growth by Both Inducible Nitric Oxide Synthase-Dependent and Inducible Nitric Oxide SynthaseIndependent Pathways." The Journal of Immunology 166(11): 6728-6734.

Beller, T. C., D. S. Friend, et al. (2004). "Cysteinyl leukotriene 1 receptor controls the severity of chronic pulmonary inflammation and fibrosis." Proceedings of the National Academy of Sciences of the United States of America 101(9): 3047-3052.

Bhavsar, P. K., B. D. Levy, et al. (2010). "Corticosteroid suppression of lipoxin A4 and leukotriene B4 from alveolar macrophages in severe asthma." Respir Res 11: 71.

Bilenki, L., X. Gao, et al. (2010). "Dendritic cells from mycobacteria-infected mice inhibits established allergic airway inflammatory responses to ragweed via IL-10- and IL-12secreting mechanisms." J Immunol 184(12): 7288-7296.

Bischoff, S. C. (2007). "Role of mast cells in allergic and non-allergic immune responses: comparison of human and murine data." Nat Rev Immunol 7(2): 93-104.

Biswas, S. K. and A. Mantovani (2010). "Macrophage plasticity and interaction with lymphocyte subsets: cancer as a paradigm." Nat Immunol 11(10): 889-896.

Bonato, V. L. D., E. D. C. Gonçalves, et al. (2004). "Immune regulatory effect of pHSP65 DNA therapy in pulmonary tuberculosis: activation of CD8+ cells, interferon- $\gamma$ recovery and reduction of lung injury." Immunology 113(1): 130-138.

Boussiotis, V. A., E. Y. Tsai, et al. (2000). "IL-10-producing T cells suppress immune responses in anergic tuberculosis patients." The Journal of Clinical Investigation 105(9): 13171325.

Bozza, P. T., P. Pacheco, et al. (2002). "NS-398: cyclooxygenase-2 independent inhibition of leukocyte priming for lipid body formation and enhanced leukotriene generation." Prostaglandins, Leukotrienes and Essential Fatty Acids 67(4): 237-244. 
Bozza, P. T., J. L. Payne, et al. (1996). "Mechanisms of platelet-activating factor-induced lipid body formation: requisite roles for 5 -lipoxygenase and de novo protein synthesis in the compartmentalization of neutrophil lipids." The Journal of Experimental Medicine 183(4): 1515-1525.

Bozza, P. T., W. Yu, et al. (1997). "Eosinophil lipid bodies: specific, inducible intracellular sites for enhanced eicosanoid formation." J Exp Med 186(6): 909-920.

Buccheri, S., R. Reljic, et al. (2007). "IL-4 depletion enhances host resistance and passive IgA protection against tuberculosis infection in BALB/c mice." Eur J Immunol 37(3): 729737.

Bullens, D. M., E. Truyen, et al. (2006). "IL-17 mRNA in sputum of asthmatic patients: linking T cell driven inflammation and granulocytic influx?" Respir Res 7: 135.

Canetti, C., B. Hu, et al. (2003). "Syk activation is a leukotriene B4-regulated event involved in macrophage phagocytosis of IgG-coated targets but not apoptotic cells." Blood 102(5): 1877-1883.

Chan, J., Y. Xing, et al. (1992). "Killing of virulent Mycobacterium tuberculosis by reactive nitrogen intermediates produced by activated murine macrophages." J Exp Med 175(4): 1111-1122.

Chen, M., M. Divangahi, et al. (2008). "Lipid mediators in innate immunity against tuberculosis: opposing roles of PGE2 and LXA4 in the induction of macrophage death." The Journal of Experimental Medicine 205(12): 2791-2801.

Chen, Y. and M. J. Blaser (2007). "Inverse associations of Helicobacter pylori with asthma and allergy." Arch Intern Med 167(8): 821-827.

Chen, Y. and M. J. Blaser (2008). "Helicobacter pylori colonization is inversely associated with childhood asthma." J Infect Dis 198(4): 553-560.

Cherry, W. B., J. Yoon, et al. (2008). "A novel IL-1 family cytokine, IL-33, potently activates human eosinophils." The Journal of allergy and clinical immunology 121(6): 1484-1490.

Cho, J. Y., M. Miller, et al. (2004). "Inhibition of airway remodeling in IL-5-deficient mice." The Journal of Clinical Investigation 113(4): 551-560.

Coffey, M. J., S. M. Phare, et al. (2004). "Role of leukotrienes in killing of Mycobacterium bovis by neutrophils." Prostaglandins, Leukotrienes and Essential Fatty Acids 71(3): 185-190.

Cooper, A. M. (2009). "Cell-mediated immune responses in tuberculosis." Annu Rev Immunol 27: 393-422.

Cooper, A. M., D. K. Dalton, et al. (1993). "Disseminated tuberculosis in interferon gamma gene-disrupted mice." J Exp Med 178(6): 2243-2247.

Cooper, A. M., A. Kipnis, et al. (2002). "Mice Lacking Bioactive IL-12 Can Generate Protective, Antigen-Specific Cellular Responses to Mycobacterial Infection Only if the IL-12 p40 Subunit Is Present." The Journal of Immunology 168(3): 1322-1327.

Cooper, A. M., J. Magram, et al. (1997). "Interleukin 12 (IL-12) is crucial to the development of protective immunity in mice intravenously infected with mycobacterium tuberculosis." J Exp Med 186(1): 39-45.

Cooper, A. M., K. D. Mayer-Barber, et al. (2011). "Role of innate cytokines in mycobacterial infection." Mucosal Immunol 4(3): 252-260.

Court, N., V. Vasseur, et al. (2010). "Partial Redundancy of the Pattern Recognition Receptors, Scavenger Receptors, and C-Type Lectins for the Long-Term Control of Mycobacterium tuberculosis Infection." The Journal of Immunology 184(12): 7057-7070.

Cruz, A., A. G. Fraga, et al. (2010). "Pathological role of interleukin 17 in mice subjected to repeated BCG vaccination after infection with Mycobacterium tuberculosis." $\underline{\text { J Exp Med }}$ 207(8): 1609-1616.

Cywes, C., H. C. Hoppe, et al. (1997). "Nonopsonic binding of Mycobacterium tuberculosis to complement receptor type 3 is mediated by capsular polysaccharides and is strain dependent." Infect Immun 65(10): 4258-4266. 
D'Ávila, H., P. E. Almeida, et al. (2007). "Toll-Like Receptor-2-Mediated C-C Chemokine Receptor 3 and Eotaxin-Driven Eosinophil Influx Induced by Mycobacterium bovis BCG Pleurisy." Infection and Immunity 75(3): 1507-1511.

D'Avila, H., N. R. Roque, et al. (2008). "Neutrophils recruited to the site of Mycobacterium bovis BCG infection undergo apoptosis and modulate lipid body biogenesis and prostaglandin E2 production by macrophages." Cellular Microbiology 10(12): 25892604.

D'Avila, H., R. C. N. Melo, et al. (2006). "Mycobacterium bovis Bacillus Calmette-Guérin Induces TLR2-Mediated Formation of Lipid Bodies: Intracellular Domains for Eicosanoid Synthesis In Vivo." The Journal of Immunology 176(5): 3087-3097.

da Fonseca, D. M., C. L. Silva, et al. (2009). "Mycobacterium tuberculosis culture filtrate proteins plus CpG Oligodeoxynucleotides confer protection to Mycobacterium bovis BCG-primed mice by inhibiting interleukin-4 secretion." Infect Immun 77(12): 53115321.

Dahlén, S. E., J. Björk, et al. (1981). "Leukotrienes promote plasma leakage and leukocyte adhesion in postcapillary venules: in vivo effects with relevance to the acute inflammatory response." Proceedings of the National Academy of Sciences 78(6): 3887-3891.

Dahlén, S. E., G. Hansson, et al. (1983). "Allergen challenge of lung tissue from asthmatics elicits bronchial contraction that correlates with the release of leukotrienes C4, D4, and E4." Proceedings of the National Academy of Sciences 80(6): 1712-1716.

de Heer, H. J., H. Hammad, et al. (2004). "Essential Role of Lung Plasmacytoid Dendritic Cells in Preventing Asthmatic Reactions to Harmless Inhaled Antigen." The Journal of Experimental Medicine 200(1): 89-98.

Devereux, G. (2006). "The increase in the prevalence of asthma and allergy: food for thought." Nat Rev Immunol 6(11): 869-874.

Devillier, P., N. Baccard, et al. (1999). "Leukotrienes, leukotriene receptor antagonists and leukotriene synthesis inhibitors in asthma: an update. Part I: synthesis, receptors and role of leukotrienes in asthma." Pharmacol Res 40(1): 3-13.

Dheda, K., S. K. Schwander, et al. (2010). "The immunology of tuberculosis: From bench to bedside." Respirology 15(3): 433-450.

Divangahi, M., M. Chen, et al. (2009). "Mycobacterium tuberculosis evades macrophage defenses by inhibiting plasma membrane repair." Nat Immunol 10(8): 899-906.

Divangahi, M., D. Desjardins, et al. (2010). "Eicosanoid pathways regulate adaptive immunity to Mycobacterium tuberculosis." Nat Immunol 11(8): 751-758.

Divangahi, M., S. Mostowy, et al. (2008). "NOD2-Deficient Mice Have Impaired Resistance to Mycobacterium tuberculosis Infection through Defective Innate and Adaptive Immunity." The Journal of Immunology 181(10): 7157-7165.

Dorhoi, A., S. T. Reece, et al. (2011). "For better or for worse: the immune response against Mycobacterium tuberculosis balances pathology and protection." Immunol Rev 240(1): 235-251.

Eder, W., W. Klimecki, et al. (2006). "Association between exposure to farming, allergies and genetic variation in CARD4/NOD1." Allergy 61(9): 1117-1124.

Ehlers, S. (2003). "Role of tumour necrosis factor (TNF) in host defence against tuberculosis: implications for immunotherapies targeting TNF." Ann Rheum Dis 62 Suppl 2: ii37-42.

El Gazzar, M., R. El Mezayen, et al. (2006). "Downregulation of leukotriene biosynthesis by thymoquinone attenuates airway inflammation in a mouse model of allergic asthma." Biochimica et Biophysica Acta (BBA) - General Subjects 1760(7): 1088-1095.

El Kasmi, K. C., J. E. Qualls, et al. (2008). "Toll-like receptor-induced arginase 1 in macrophages thwarts effective immunity against intracellular pathogens." Nat Immunol 9(12): 13991406. 
Elias, D., H. Akuffo, et al. (2005). "Schistosoma mansoni infection reduces the protective efficacy of BCG vaccination against virulent Mycobacterium tuberculosis." Vaccine 23(11): 1326-1334.

Elias, D., S. Britton, et al. (2008). "Poor immunogenicity of BCG in helminth infected population is associated with increased in vitro TGF-beta production." Vaccine 26(31): 3897-3902.

Elias, D., D. Wolday, et al. (2001). "Effect of deworming on human T cell responses to mycobacterial antigens in helminth-exposed individuals before and after bacille Calmette-Guérin (BCG) vaccination." Clinical \& Experimental Immunology 123(2): 219225.

Fairweather, D. and D. Cihakova "Alternatively activated macrophages in infection and autoimmunity." Journal of Autoimmunity 33(3-4): 222-230.

Fayyazi, A., B. Eichmeyer, et al. (2000). "Apoptosis of macrophages and T cells in tuberculosis associated caseous necrosis." The Journal of Pathology 191(4): 417-425.

Fedatto, P. F., C. A. Sérgio, et al. (2012). "Protection conferred by heterologous vaccination against tuberculosis is dependent on the ratio of CD4+/CD4+Foxp3+ cells." Immunology 137(3): 239-248.

Feng, C. G., A. G. Bean, et al. (1999). "Increase in gamma interferon-secreting CD8(+), as well as $\mathrm{CD} 4(+)$, $\mathrm{T}$ cells in lungs following aerosol infection with Mycobacterium tuberculosis." Infect Immun 67(7): 3242-3247.

Feng, C. G., M. Kaviratne, et al. (2006). "NK Cell-Derived IFN- $\gamma$ Differentially Regulates Innate Resistance and Neutrophil Response in T Cell-Deficient Hosts Infected with Mycobacterium tuberculosis." The Journal of Immunology 177(10): 7086-7093.

Finn, P. W. and T. D. Bigby (2009). "Innate immunity and asthma." Proc Am Thorac Soc 6(3): 260-265.

Flynn, J. L. and J. Chan (2001). "Immunology of tuberculosis." Annu Rev Immunol 19: 93-129.

Flynn, J. L., J. Chan, et al. (1993). "An essential role for interferon gamma in resistance to Mycobacterium tuberculosis infection." J Exp Med 178(6): 2249-2254.

Flynn, J. L., M. M. Goldstein, et al. (1995). "Tumor necrosis factor- \pm is required in the protective immune response against mycobacterium tuberculosis in mice." Immunity 2(6): 561572.

Flynn, J. L., M. M. Goldstein, et al. (1992). "Major histocompatibility complex class I-restricted T cells are required for resistance to Mycobacterium tuberculosis infection." Proceedings of the National Academy of Sciences 89(24): 12013-12017.

Fonseca, D. M., M. O. Paula, et al. (2011). "IFN-gamma-mediated efficacy of allergen-free immunotherapy using mycobacterial antigens and CpG-ODN." Immunol Cell Biol 89(7): 777-785.

Fonseca, D. M., C. L. Silva, et al. (2007). "Increased levels of interferon-gamma primed by culture filtrate proteins antigen and CpG-ODN immunization do not confer significant protection against Mycobacterium tuberculosis infection." Immunology 121(4): 508517.

Fonseca, D. M., P. F. Wowk, et al. (2012). "Recombinant DNA immunotherapy ameliorate established airway allergy in a IL-10 dependent pathway." Clinical \& Experimental Allergy 42(1): 131-143.

Ford-Hutchinson, A. W., M. Gresser, et al. (1994). "5-Lipoxygenase." Annu Rev Biochem 63: 383-417.

Franco, L. H., M. O. e. Paula, et al. (2010). "Leukotrienes are not essential for the efficacy of a heterologous vaccine against Mycobacterium tuberculosis infection." Brazilian Journal of Medical and Biological Research 43: 645-650.

Fulton, S. A., T. D. Martin, et al. (2000). "Pulmonary Immune Responses during Primary Mycobacterium bovis- Calmette-Guerin Bacillus Infection in C57BI/6 Mice." American Journal of Respiratory Cell and Molecular Biology 22(3): 333-343. 
Gaudreault, É. and J. Gosselin (2008). "Leukotriene B4 Induces Release of Antimicrobial Peptides in Lungs of Virally Infected Mice." The Journal of Immunology 180(9): 62116221.

Gaynor, C. D., F. X. McCormack, et al. (1995). "Pulmonary surfactant protein A mediates enhanced phagocytosis of Mycobacterium tuberculosis by a direct interaction with human macrophages." The Journal of Immunology 155(11): 5343-5351.

Goodarzi, K., M. Goodarzi, et al. (2003). "Leukotriene B4 and BLT1 control cytotoxic effector T cell recruitment to inflamed tissues." Nat Immunol 4(10): 965-973.

Gordon, S. (2003). "Alternative activation of macrophages." Nat Rev Immunol 3(1): 23-35.

Grünig, G., M. Warnock, et al. (1998). "Requirement for IL-13 Independently of IL-4 in Experimental Asthma." Science 282(5397): 2261-2263.

Guillerey, C., J. Mouriès, et al. (2012). "Pivotal role of plasmacytoid dendritic cells in inflammation and NK-cell responses after TLR9 triggering in mice." Blood 120(1): 9099.

Gulliksson, M., R. F. S. Carvalho, et al. (2010). "Mast Cell Survival and Mediator Secretion in Response to Hypoxia." PLoS One 5(8): e12360.

Guyot-Revol, V., J. A. Innes, et al. (2006). "Regulatory T cells are expanded in blood and disease sites in patients with tuberculosis." Am J Respir Crit Care Med 173(7): 803-810.

Hammad, H. and B. N. Lambrecht (2008). "Dendritic cells and epithelial cells: linking innate and adaptive immunity in asthma." Nat Rev Immunol 8(3): 193-204.

Harris, J., S. A. De Haro, et al. (2007). "T helper 2 cytokines inhibit autophagic control of intracellular Mycobacterium tuberculosis." Immunity 27(3): 505-517.

Hernandez-Pando, R., H. Orozco, et al. (2009). "Factors that deregulate the protective immune response in tuberculosis." Archivum Immunologiae et Therapiae Experimentalis 57(5): 355-367.

Hernandez-Pando, R., H. Orozcoe, et al. (1996). "Correlation between the kinetics of Th1, Th2 cells and pathology in a murine model of experimental pulmonary tuberculosis." Immunology 89(1): 26-33.

Hesse, M., M. Modolell, et al. (2001). "Differential Regulation of Nitric Oxide Synthase-2 and Arginase-1 by Type 1/Type 2 Cytokines In Vivo: Granulomatous Pathology Is Shaped by the Pattern of I-Arginine Metabolism." The Journal of Immunology 167(11): 6533-6544.

Hope, Kwong, et al. (2000). "Dendritic Cells Induce CD4+ and CD8+ T-Cell Responses to Mycobacterium bovis and M. avium Antigens in Bacille Calmette Guérin Vaccinated and Nonvaccinated Cattle." Scandinavian Journal of Immunology 52(3): 285-291.

Isogai, S., A. Athiviraham, et al. (2007). "Interferon- $\gamma$-dependent inhibition of late allergic airway responses and eosinophilia by CD8+ $\delta$ T cells." Immunology 122(2): 230-238.

Jiang, H.-R., M. Milovanović, et al. (2012). "IL-33 attenuates EAE by suppressing IL-17 and IFN- $\gamma$ production and inducing alternatively activated macrophages." European Journal of Immunology 42(7): 1804-1814.

Joshi, A. D., S. R. Oak, et al. (2010). "Interleukin-33 contributes to both M1 and M2 chemokine marker expression in human macrophages." BMC Immunol 11: 52.

Jung, Y.-J., R. LaCourse, et al. (2002). "Evidence Inconsistent with a Negative Influence of T Helper 2 Cells on Protection Afforded by a Dominant T Helper 1 Response against Mycobacterium tuberculosis Lung Infection in Mice." Infection and Immunity 70(11): 6436-6443.

Jung, Y. J., L. Ryan, et al. (2009). "Differences in the Ability to Generate Type 1 T Helper Cells Need Not Determine Differences in the Ability to Resist Mycobacterium tuberculosis Infection among Mouse Strains." Journal of Infectious Diseases 199(12): 1790-1796.

Kamath, A. B., J. Woodworth, et al. (2004). "Cytolytic CD8+ T cells recognizing CFP10 are recruited to the lung after Mycobacterium tuberculosis infection." J Exp Med 200(11): 1479-1489. 
Kang, P. B., A. K. Azad, et al. (2005). "The human macrophage mannose receptor directs Mycobacterium tuberculosis lipoarabinomannan-mediated phagosome biogenesis." The Journal of Experimental Medicine 202(7): 987-999.

Kearley, J., K. F. Buckland, et al. (2009). "Resolution of Allergic Inflammation and Airway Hyperreactivity Is Dependent upon Disruption of the T1/ST2-IL-33 Pathway." American Journal of Respiratory and Critical Care Medicine 179(9): 772-781.

Khader, S. A., G. K. Bell, et al. (2007). "IL-23 and IL-17 in the establishment of protective pulmonary CD4+ $T$ cell responses after vaccination and during Mycobacterium tuberculosis challenge." Nat Immunol 8(4): 369-377.

Khader, S. A., J. E. Pearl, et al. (2005). "IL-23 Compensates for the Absence of IL-12p70 and Is Essential for the IL-17 Response during Tuberculosis but Is Dispensable for Protection and Antigen-Specific IFN- $\gamma$ Responses if IL-12p70 Is Available." The Journal of Immunology 175(2): 788-795.

Kim, H. Y., R. H. DeKruyff, et al. (2010). "The many paths to asthma: phenotype shaped by innate and adaptive immunity." Nat Immunol 11(7): 577-584.

Kim, H. Y., R. H. DeKruyff, et al. (2010). "The many paths to asthma: phenotype shaped by innate and adaptive immunity." Nat Immunol 11(7): 577-584.

Kool, M., T. Soullié, et al. (2008). "Alum adjuvant boosts adaptive immunity by inducing uric acid and activating inflammatory dendritic cells." The Journal of Experimental Medicine 205(4): 869-882.

Koya, T., H. Matsuda, et al. (2009). "Differential Effects of Dendritic Cell Transfer on Airway Hyperresponsiveness and Inflammation." American Journal of Respiratory Cell and Molecular Biology 41(3): 271-280.

Kudo, M., A. C. Melton, et al. (2012). "IL-17A produced by alphabeta T cells drives airway hyper-responsiveness in mice and enhances mouse and human airway smooth muscle contraction." Nat Med 18(4): 547-554.

Kurowska-Stolarska, M., B. Stolarski, et al. (2009). "IL-33 amplifies the polarization of alternatively activated macrophages that contribute to airway inflammation." $\underline{\mathrm{J}}$ Immunol 183(10): 6469-6477.

Ladel, C. H., C. Blum, et al. (1997). "Lethal tuberculosis in interleukin-6-deficient mutant mice." Infection and Immunity 65(11): 4843-4849.

Ladel, C. H., S. Daugelat, et al. (1995). "Immune response to Mycobacterium bovis bacille Calmette Guérin infection in major histocompatibility complex class I- and II-deficient knock-out mice: contribution of CD4 and CD8 T cells to acquired resistance." European Journal of Immunology 25(2): 377-384.

Laidlaw, T. M. and J. A. Boyce (2012). "Cysteinyl leukotriene receptors, old and new; implications for asthma." Clinical \& Experimental Allergy 42(9): 1313-1320.

Lala, S., K. Dheda, et al. (2007). "The pathogen recognition sensor, NOD2, is variably expressed in patients with pulmonary tuberculosis." BMC Infect Dis 7: 96.

Lambrecht, B. N. and H. Hammad (2009). "Biology of lung dendritic cells at the origin of asthma." Immunity 31(3): 412-424.

Lambrecht, B. N., B. t. Salomon, et al. (1998). "Dendritic Cells Are Required for the Development of Chronic Eosinophilic Airway Inflammation in Response to Inhaled Antigen in Sensitized Mice." The Journal of Immunology 160(8): 4090-4097.

Larche, M., C. A. Akdis, et al. (2006). "Immunological mechanisms of allergen-specific immunotherapy." Nat Rev Immunol 6(10): 761-771.

Law, K., M. Weiden, et al. (1996). "Increased release of interleukin-1 beta, interleukin-6, and tumor necrosis factor-alpha by bronchoalveolar cells lavaged from involved sites in pulmonary tuberculosis." American Journal of Respiratory and Critical Care Medicine 153(2): 799-804.

Locksley, R. M. (2010). "Asthma and Allergic Inflammation." Cell 140(6): 777-783. 
Luster, A. D. and A. M. Tager (2004). "T-cell trafficking in asthma: lipid mediators grease the way." Nat Rev Immunol 4(9): 711-724.

Machado, F. S. and J. Aliberti (2006). "Impact of lipoxin-mediated regulation on immune response to infectious disease." Immunol Res 35(3): 209-218.

Machado, F. S., J. E. Johndrow, et al. (2006). "Anti-inflammatory actions of lipoxin A4 and aspirin-triggered lipoxin are SOCS-2 dependent." Nat Med 12(3): 330-334.

MacMicking, J. D., R. J. North, et al. (1997). "Identification of nitric oxide synthase as a protective locus against tuberculosis." Proceedings of the National Academy of Sciences 94(10): 5243-5248.

Maeda, N., J. Nigou, et al. (2003). "The cell surface receptor DC-SIGN discriminates between Mycobacterium species through selective recognition of the mannose caps on lipoarabinomannan." J Biol Chem 278(8): 5513-5516.

Maglione, P. J., J. Xu, et al. (2008). "Fc gamma receptors regulate immune activation and susceptibility during Mycobacterium tuberculosis infection." J Immunol 180(5): 33293338.

Makker, H. K., L. C. Lau, et al. (1993). "The Protective Effect of Inhaled Leukotriene D4 Receptor Antagonist ICl 204,219 against Exercise-induced Asthma." American Journal of Respiratory and Critical Care Medicine 147(6 Pt 1): 1413-1418.

Mantovani, A., M. Muzio, et al. (2001). "Macrophage control of inflammation: negative pathways of regulation of inflammatory cytokines." Novartis Found Symp 234: 120131; discussion 131-125.

Mantovani, A., A. Sica, et al. (2004). "The chemokine system in diverse forms of macrophage activation and polarization." Trends in Immunology 25(12): 677-686.

Marino, S., S. Pawar, et al. (2004). "Dendritic cell trafficking and antigen presentation in the human immune response to Mycobacterium tuberculosis." J Immunol 173(1): 494-506.

Martinez, F. O., L. Helming, et al. (2009). "Alternative activation of macrophages: an immunologic functional perspective." Annu Rev Immunol 27: 451-483.

Means, T. K., S. Wang, et al. (1999). "Human toll-like receptors mediate cellular activation by Mycobacterium tuberculosis." J Immunol 163(7): 3920-3927.

Medeiros, A. I., A. Sa-Nunes, et al. (2004). "Blockade of Endogenous Leukotrienes Exacerbates Pulmonary Histoplasmosis." Infect. Immun. 72(3): 1637-1644.

Meena, L. S. and Rajni (2010). "Survival mechanisms of pathogenic Mycobacterium tuberculosis H37Rv." FEBS J 277(11): 2416-2427.

Melo, R. C., A. Sabban, et al. (2006). "Leukocyte lipid bodies: inflammation-related organelles are rapidly detected by wet scanning electron microscopy." J Lipid Res 47(11): 25892594.

Mogues, T., M. E. Goodrich, et al. (2001). "The relative importance of T cell subsets in immunity and immunopathology of airborne Mycobacterium tuberculosis infection in mice." J Exp Med 193(3): 271-280.

Morais da Fonseca, D., C. Lopes Silva, et al. (2007). "Increased levels of interferon- $\gamma$ primed by culture filtrate proteins antigen and CpG-ODN immunization do not confer significant protection against Mycobacterium tuberculosis infection." Immunology 121(4): 508517.

Morais Fonseca, D., R. S. Rosada, et al. (2010). "Experimental tuberculosis: designing a better model to test vaccines against tuberculosis." Tuberculosis (Edinb) 90(2): 135-142.

Mosser, D. M. (2003). "The many faces of macrophage activation." Journal of Leukocyte Biology 73(2): 209-212.

Müller, I., S. P. Cobbold, et al. (1987). "Impaired resistance to Mycobacterium tuberculosis infection after selective in vivo depletion of L3T4+ and Lyt-2+ T cells." Infection and Immunity 55(9): 2037-2041.

Munder, M., K. Eichmann, et al. (1998). "Alternative Metabolic States in Murine Macrophages Reflected by the Nitric Oxide Synthase/Arginase Balance: Competitive Regulation by 
CD4+ T Cells Correlates with Th1/Th2 Phenotype." The Journal of Immunology 160(11): 5347-5354.

Munitz, A., E. B. Brandt, et al. (2008). "Distinct roles for IL-13 and IL-4 via IL-13 receptor $\alpha 1$ and the type II IL-4 receptor in asthma pathogenesis." Proceedings of the National Academy of Sciences 105(20): 7240-7245.

Muñoz, S., R. Hernández-Pando, et al. (2003). "Mast Cell Activation by Mycobacterium tuberculosis: Mediator Release and Role of CD48." The Journal of Immunology 170(11): 5590-5596.

Murray, P. J. and T. A. Wynn (2011). "Protective and pathogenic functions of macrophage subsets." Nat Rev Immunol 11(11): 723-737.

Nakanishi, Y., M. Nakatsuji, et al. (2011). "COX-2 inhibition alters the phenotype of tumorassociated macrophages from M2 to M1 in ApcMin/+ mouse polyps." Carcinogenesis.

Ngoc, L. P., D. R. Gold, et al. (2005). "Cytokines, allergy, and asthma." Current Opinion in Allergy and Clinical Immunology 5(2): 161-166.

Nicolle, D., C. Fremond, et al. (2004). "Long-term control of Mycobacterium bovis BCG infection in the absence of Toll-like receptors (TLRs): investigation of TLR2-, TLR6-, or TLR2-TLR4-deficient mice." Infect Immun 72(12): 6994-7004.

Obihara, C. C., N. Beyers, et al. (2005). "Inverse association between Mycobacterium tuberculosis infection and atopic rhinitis in children." Allergy 60(9): 1121-1125.

Oriss, T. B., M. Ostroukhova, et al. (2005). "Dynamics of Dendritic Cell Phenotype and Interactions with CD4+ T Cells in Airway Inflammation and Tolerance." The Journal of Immunology 174(2): 854-863.

Orme, I. M., A. D. Roberts, et al. (1993). "Cytokine secretion by CD4 T lymphocytes acquired in response to Mycobacterium tuberculosis infection." J Immunol 151(1): 518-525.

Oshikawa, K., K. Kuroiwa, et al. (2001). "Elevated soluble ST2 protein levels in sera of patients with asthma with an acute exacerbation." Am J Respir Crit Care Med 164(2): 277-281.

Palecanda, A., J. Paulauskis, et al. (1999). "Role of the Scavenger Receptor MARCO in Alveolar Macrophage Binding of Unopsonized Environmental Particles." The Journal of Experimental Medicine 189(9): 1497-1506.

Paul, W. E. and J. Zhu (2010). "How are TH2-type immune responses initiated and amplified?" Nat Rev Immunol 10(4): 225-235.

Paula, M. O., D. M. Fonseca, et al. (2011). "Host genetic background affects regulatory T-cell activity that influences the magnitude of cellular immune response against Mycobacterium tuberculosis." Immunol Cell Biol 89(4): 526-534.

Paula, M. O., D. M. Fonseca, et al. (2011). "Host genetic background affects regulatory T-cell activity that influences the magnitude of cellular immune response against Mycobacterium tuberculosis." Immunol Cell Biol 89(4): 526-534.

Peres, C. M., D. M. Aronoff, et al. (2007). "Specific Leukotriene Receptors Couple to Distinct G Proteins to Effect Stimulation of Alveolar Macrophage Host Defense Functions." The Journal of Immunology 179(8): 5454-5461.

Peres, C. M., L. de Paula, et al. (2007). "Inhibition of leukotriene biosynthesis abrogates the host control of Mycobacterium tuberculosis." Microbes and Infection 9(4): 483-489.

Peyron, P., J. Vaubourgeix, et al. (2008). "Foamy Macrophages from Tuberculous Patients' Granulomas Constitute a Nutrient-Rich Reservoir for <italic>M. tuberculosis</italic> Persistence." PLoS Pathog 4(11): e1000204.

Philips, J. A. and J. D. Ernst (2012). "Tuberculosis pathogenesis and immunity." Annu Rev Pathol 7: 353-384.

Potian, J. A., W. Rafi, et al. (2011). "Preexisting helminth infection induces inhibition of innate pulmonary anti-tuberculosis defense by engaging the IL-4 receptor pathway." The Journal of Experimental Medicine 208(9): 1863-1874.

Pushparaj, P. N., H. K. Tay, et al. (2009). "The cytokine interleukin-33 mediates anaphylactic shock." Proceedings of the National Academy of Sciences 106(24): 9773-9778. 
Qiu, H., R. KuoLee, et al. (2011). "<italic>Acinetobacter baumannii</italic> Infection Inhibits Airway Eosinophilia and Lung Pathology in a Mouse Model of Allergic Asthma." PLoS One 6(7): e22004.

Qualls, J. E., G. Neale, et al. (2010). "Arginine Usage in Mycobacteria-Infected Macrophages Depends on Autocrine-Paracrine Cytokine Signaling." Sci. Signal. 3(135): ra62-.

Quintero-Macias, L., T. Santos-Mendoza, et al. (2010). "T-Cell Responses and In Vivo Cytotoxicity in the Target Organ and the Regional Lymphoid Tissue During Airborne Infection with the Virulent Mycobacterium tuberculosis MT103 and its Lipid Mutant fadD26." Scandinavian Journal of Immunology 71(1): 20-28.

Rajaram, M. V., M. N. Brooks, et al. (2010). "Mycobacterium tuberculosis activates human macrophage peroxisome proliferator-activated receptor gamma linking mannose receptor recognition to regulation of immune responses." J Immunol 185(2): 929-942.

Redente, E. F., D. M. Higgins, et al. (2010). "Differential polarization of alveolar macrophages and bone marrow-derived monocytes following chemically and pathogen-induced chronic lung inflammation." J Leukoc Biol 88(1): 159-168.

Reibman, J., M. Marmor, et al. (2008). "Asthma is inversely associated with Helicobacter pylori status in an urban population." PLoS One 3(12): e4060.

Ribeiro-Rodrigues, R., T. Resende Co, et al. (2006). "A role for CD4+CD25+ T cells in regulation of the immune response during human tuberculosis." Clinical \& Experimental Immunology 144(1): 25-34.

Rodríguez-Sosa, M., A. R. Satoskar, et al. (2002). "Chronic Helminth Infection Induces Alternatively Activated Macrophages Expressing High Levels of CCR5 with Low Interleukin-12 Production and Th2-Biasing Ability." Infection and Immunity 70(7): 3656-3664.

Rook, G. A. (2007). "Th2 cytokines in susceptibility to tuberculosis." Curr Mol Med 7(3): 327337.

Rook, G. A., J. Steele, et al. (1986). "Activation of macrophages to inhibit proliferation of Mycobacterium tuberculosis: comparison of the effects of recombinant gammainterferon on human monocytes and murine peritoneal macrophages." Immunology 59(3): 333-338.

Sada-Ovalle, I., A. Chiba, et al. (2008). "Innate invariant NKT cells recognize Mycobacterium tuberculosis-infected macrophages, produce interferon-gamma, and kill intracellular bacteria." PLoS Pathog 4(12): e1000239.

Saenz, S. A., M. Noti, et al. (2010). "Innate immune cell populations function as initiators and effectors in Th2 cytokine responses." Trends Immunol 31(11): 407-413.

Sampson, A. P., R. U. Thomas, et al. (1992). "Enhanced leukotriene synthesis in leukocytes of atopic and asthmatic subjects." Br J Clin Pharmacol 33(4): 423-430.

Schmitz, J., A. Owyang, et al. (2005). "IL-33, an Interleukin-1-like Cytokine that Signals via the IL-1 Receptor-Related Protein ST2 and Induces T Helper Type 2-Associated Cytokines." Immunity 23(5): 479-490.

Scott-Browne, J. P., S. Shafiani, et al. (2007). "Expansion and function of Foxp3-expressing T regulatory cells during tuberculosis." The Journal of Experimental Medicine 204(9): 2159-2169.

Scriba, T. J., B. Kalsdorf, et al. (2008). "Distinct, Specific IL-17- and IL-22-Producing CD4+ T Cell Subsets Contribute to the Human Anti-Mycobacterial Immune Response." The Journal of Immunology 180(3): 1962-1970.

Secatto, A., L. C. Rodrigues, et al. (2012). "5-Lipoxygenase deficiency impairs innate and adaptive immune responses during fungal infection." PLoS One 7(3): e31701.

Serbina, N. V. and J. L. Flynn (1999). "Early emergence of CD8(+) T cells primed for production of type 1 cytokines in the lungs of Mycobacterium tuberculosis-infected mice." Infect Immun 67(8): 3980-3988. 
Serbina, N. V., C.-C. Liu, et al. (2000). "CD8+ CTL from Lungs of Mycobacterium tuberculosisInfected Mice Express Perforin In Vivo and Lyse Infected Macrophages." The Journal of Immunology 165(1): 353-363.

Serezani, C. H. C., D. M. Aronoff, et al. (2005). "Leukotrienes enhance the bactericidal activity of alveolar macrophages against Klebsiella pneumoniae through the activation of NADPH oxidase." Blood 106(3): 1067-1075.

Shafiani, S., G. s. Tucker-Heard, et al. (2010). "Pathogen-specific regulatory T cells delay the arrival of effector T cells in the lung during early tuberculosis." The Journal of Experimental Medicine 207(7): 1409-1420.

Shiloh, M. U. and C. F. Nathan (2000). "Reactive nitrogen intermediates and the pathogenesis of Salmonella and mycobacteria." Current Opinion in Microbiology 3(1): 35-42.

Silva, R. C., M. A. Landgraf, et al. (2010). "Leukotrienes produced in allergic lung inflammation activate alveolar macrophages." Cell Physiol Biochem 26(3): 319-326.

Singh, P. P., C. LeMaire, et al. (2011). "Exosomes Released from <italic >M.tuberculosis</italic> Infected Cells Can Suppress IFN- $\gamma$ Mediated Activation of Naïve Macrophages." PLoS One 6(4): e18564.

Singh, V., S. Jamwal, et al. (2012). "Mycobacterium tuberculosis-Driven Targeted Recalibration of Macrophage Lipid Homeostasis Promotes the Foamy Phenotype." Cell host \& microbe 12(5): 669-681.

Sokol, C. L., N. Q. Chu, et al. (2009). "Basophils function as antigen-presenting cells for an allergen-induced T helper type 2 response." Nat Immunol 10(7): 713-720.

Sousa, A. O., R. J. Mazzaccaro, et al. (2000). "Relative contributions of distinct MHC class Idependent cell populations in protection to tuberculosis infection in mice." Proceedings of the National Academy of Sciences 97(8): 4204-4208.

Stein, M., S. Keshav, et al. (1992). "Interleukin 4 potently enhances murine macrophage mannose receptor activity: a marker of alternative immunologic macrophage activation." The Journal of Experimental Medicine 176(1): 287-292.

Stewart, G. R., M. Boussinesq, et al. (1999). "Onchocerciasis modulates the immune response to mycobacterial antigens." Clin Exp Immunol 117(3): 517-523.

Stock, P., T. Kallinich, et al. (2004). "CD8+ T cells regulate immune responses in a murine model of allergen-induced sensitization and airway inflammation." European Journal of Immunology 34(7): 1817-1827.

Strachan, D. P. (2000). "Family size, infection and atopy: the first decade of the "hygiene hypothesis"." Thorax 55 Suppl 1: S2-10.

Surcel, H. M., M. Troye-Blomberg, et al. (1994). "Th1/Th2 profiles in tuberculosis, based on the proliferation and cytokine response of blood lymphocytes to mycobacterial antigens." Immunology 81(2): 171-176.

Tai, H. Y., M. F. Tam, et al. (2006). "Pen ch 13 allergen induces secretion of mediators and degradation of occludin protein of human lung epithelial cells." Allergy 61(3): 382-388.

Takeda, K., S. W. Dow, et al. (2009). "Vaccine-Induced CD8+ T Cell-Dependent Suppression of Airway Hyperresponsiveness and Inflammation." The Journal of Immunology 183(1): 181-190.

Tamachi, T., Y. Maezawa, et al. (2006). "IL-25 enhances allergic airway inflammation by amplifying a TH2 cell-dependent pathway in mice." The Journal of allergy and clinical immunology 118(3): 606-614.

Taube, C., N. Miyahara, et al. (2006). "The Leukotriene B4 Receptor (BLT1) Is Required for Effector CD8+ T Cell-Mediated, Mast Cell-Dependent Airway Hyperresponsiveness." The Journal of Immunology 176(5): 3157-3164.

Teixeira, H. C., M. E. Munk, et al. (1995). "Frequencies of IFN gamma- and IL-4-producing cells during Mycobacterium bovis BCG infection in two genetically susceptible mouse strains: role of alpha/beta T cells and NK1.1 cells." Immunol Lett 46(1-2): 15-19. 
Tobin, D. M., F. J. Roca, et al. (2012). "Host genotype-specific therapies can optimize the inflammatory response to mycobacterial infections." Cell 148(3): 434-446.

Tobin, D. M., J. C. Vary, Jr., et al. (2010). "The Ita4h locus modulates susceptibility to mycobacterial infection in zebrafish and humans." Cell 140(5): 717-730.

Torrelles, J. B., A. K. Azad, et al. (2006). "Fine discrimination in the recognition of individual species of phosphatidyl-myo-inositol mannosides from Mycobacterium tuberculosis by C-type lectin pattern recognition receptors." J Immunol 177(3): 1805-1816.

Triggiani, M., G. Giannattasio, et al. (2009). "Lung mast cells are a source of secreted phospholipases A2." Journal of Allergy and Clinical Immunology 124(3): 558-565.e553.

Tsuchiya, K., S. Isogai, et al. (2009). "Depletion of CD8+ T cells enhances airway remodelling in a rodent model of asthma." Immunology 126(1): 45-54.

Tyagi, A. K., P. Nangpal, et al. (2011). "Development of vaccines against tuberculosis." Tuberculosis (Edinb).

van Crevel, R., T. H. Ottenhoff, et al. (2002). "Innate immunity to Mycobacterium tuberculosis." Clin Microbiol Rev 15(2): 294-309.

van der Wel, N., D. Hava, et al. (2007). "M. tuberculosis and M. leprae Translocate from the Phagolysosome to the Cytosol in Myeloid Cells." Cell 129(7): 1287-1298.

van Pinxteren, L. A., J. P. Cassidy, et al. (2000). "Control of latent Mycobacterium tuberculosis infection is dependent on CD8 T cells." Eur J Immunol 30(12): 3689-3698.

Wakeham, J., J. Wang, et al. (2000). "Genetically determined disparate innate and adaptive cell-mediated immune responses to pulmonary Mycobacterium bovis BCG infection in C57BL/6 and BALB/c mice." Infect Immun 68(12): 6946-6953.

Weller, P. F., P. T. Bozza, et al. (1999). "Cytoplasmic lipid bodies in eosinophils: central roles in eicosanoid generation." Int Arch Allergy Immunol 118(2-4): 450-452.

Weller, P. F. and A. M. Dvorak (1994). "Lipid bodies: intracellular sites for eicosanoid formation." J Allergy Clin Immunol 94(6 Pt 2): 1151-1156.

Wells, J. W., C. J. Cowled, et al. (2007). "Regulation of allergic airway inflammation by class Irestricted allergen presentation and CD8 T-cell infiltration." Journal of Allergy and Clinical Immunology 119(1): 226-234.

WHO (2007). Global surveillance, prevention and control of chronic respiratory diseases : a comprehensive approach J. B. a. N. Khaltaev. Geneva: 155.

WHO (2012). Global tuberculosis report 2012. Geneva, Switzerland, World Health Organization

Wolf, A. J., B. Linas, et al. (2007). "Mycobacterium tuberculosis Infects Dendritic Cells with High Frequency and Impairs Their Function In Vivo." The Journal of Immunology 179(4): 2509-2519.

Xu, W., Q. Lan, et al. (2012). "Adoptive Transfer of Induced-Treg Cells Effectively Attenuates Murine Airway Allergic Inflammation." PLoS One 7(7): e40314.

Ying, S., B. O'Connor, et al. (2005). "Thymic Stromal Lymphopoietin Expression Is Increased in Asthmatic Airways and Correlates with Expression of Th2-Attracting Chemokines and Disease Severity." The Journal of Immunology 174(12): 8183-8190.

Zhang, M., J. Gong, et al. (1994). "T cell cytokine responses in persons with tuberculosis and human immunodeficiency virus infection." The Journal of Clinical Investigation 94(6): 2435-2442.

Zhou, B., M. R. Comeau, et al. (2005). "Thymic stromal lymphopoietin as a key initiator of allergic airway inflammation in mice." Nat Immunol 6(10): 1047-1053. 


\section{APÊNDICES}

\section{Apêndice 1}

A)

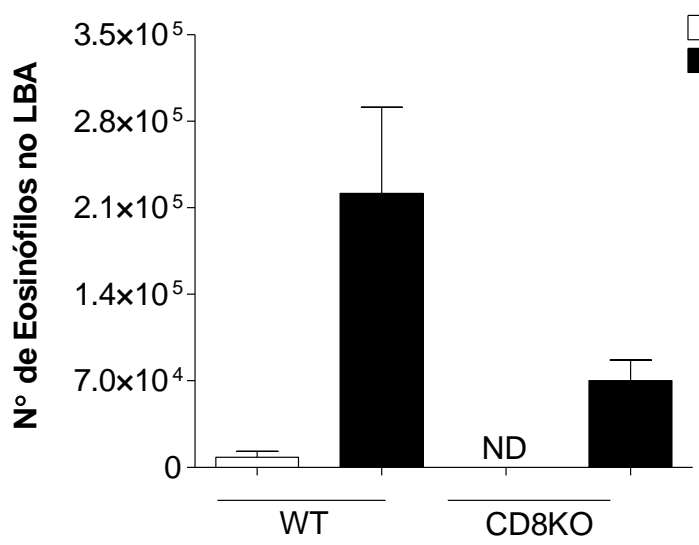

B)

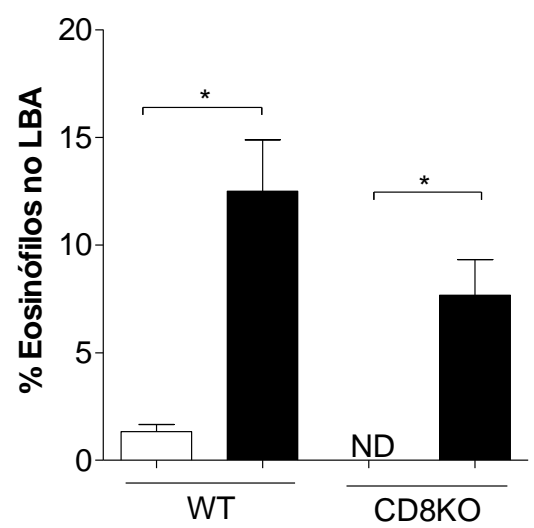

Contagem e frequência de eosinófilos no pulmão de animais CD8KO-TB/OVA. Camundongos CD8KO e C57BL/6 (WT) foram submetidos ao protocolo de coinflamação, tuberculose e alergia. Após 72 horas do desafio com alérgeno, as células do LBA foram obtidas para avaliar número $(\mathbf{A})$ e frequência $(\mathbf{B})$ eosinófilos presentes no LBA. Resultados representativos de um único experimento $(\mathrm{n}=3-5$ animais por grupo), expressos como médias dos valores individuais \pm erro padrão. $* \mathrm{p}<0,05$. 


\section{Apêndice 2}

A)

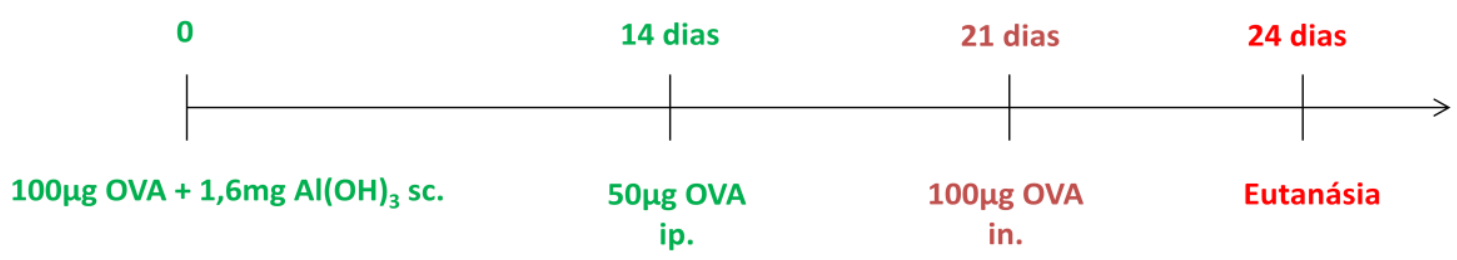

B)

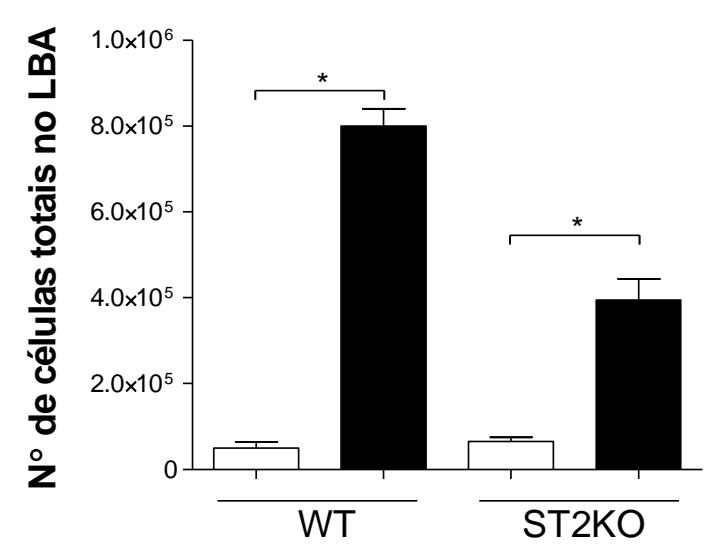

C)

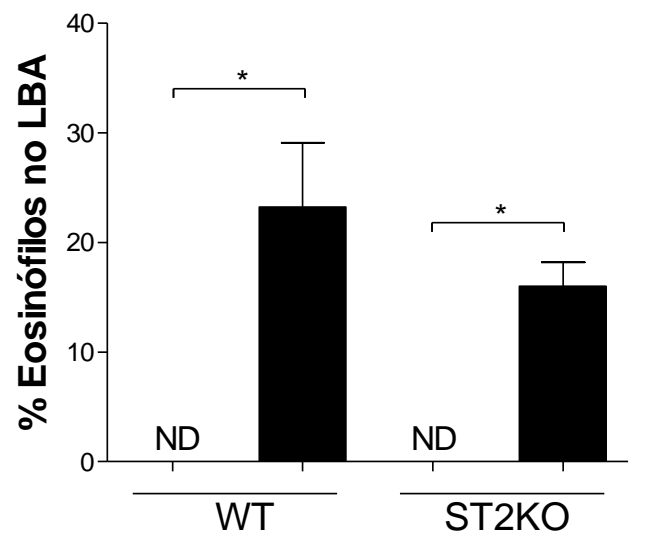

Frequência e número de eosinófilos no pulmão de animais ST2KO. (A) Camundongos ST2KO e BALB/c (WT) foram sensibilizados com OVA em presença do adjuvante $\mathrm{Al}(\mathrm{OH})_{3}$ pela via subcutânea (sc). Após 14 dias da primeira sensibilização, os animais foram sensibilizados novamente com OVA, pela via intraperitoneal (ip). Sete dias após a segunda sensibilização, os animais foram desafiados com OVA pela via intranasal (in). As células do LBA, coletadas três dias após o desafio com OVA, foram analisadas quanto ao número de células totais $(\mathbf{B})$ e a frequência de eosinófilos $(\mathbf{C})$. Resultado representativo de um único experimento ( $\mathrm{n}=6-8$ animais por grupo), expressos como médias dos valores individuais \pm erro padrão. ${ }^{*} \mathrm{p}<0,05$. 


\section{Apêndice 3}

A)

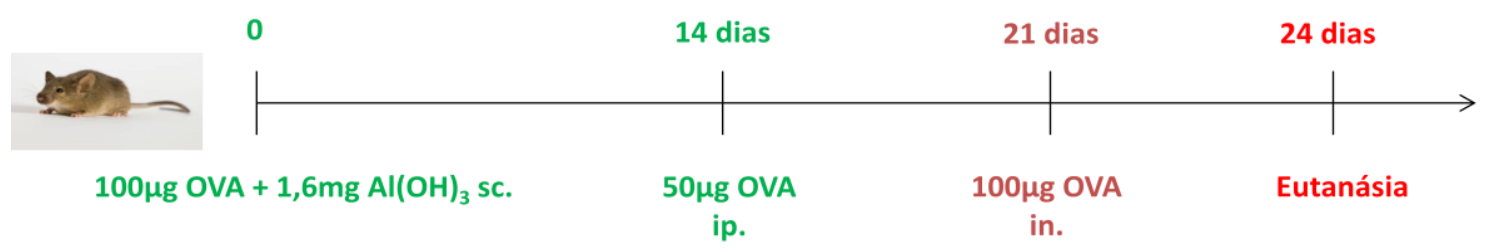

B)

C)

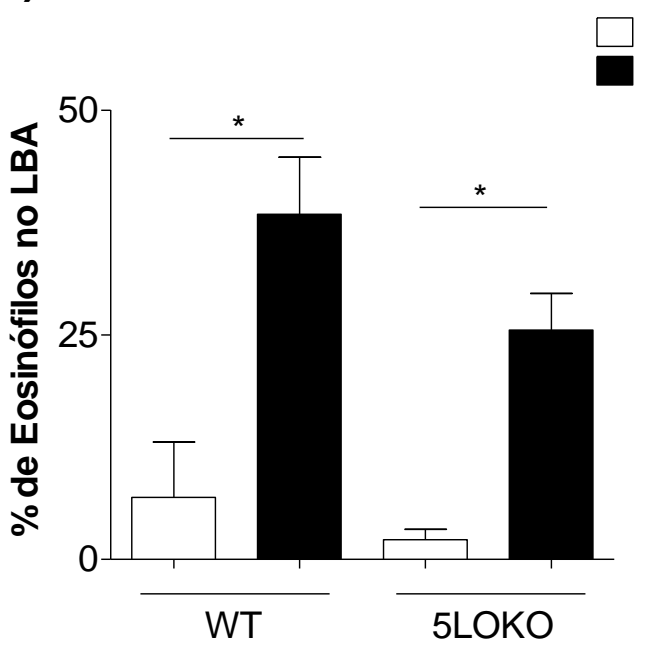

CT
OVA

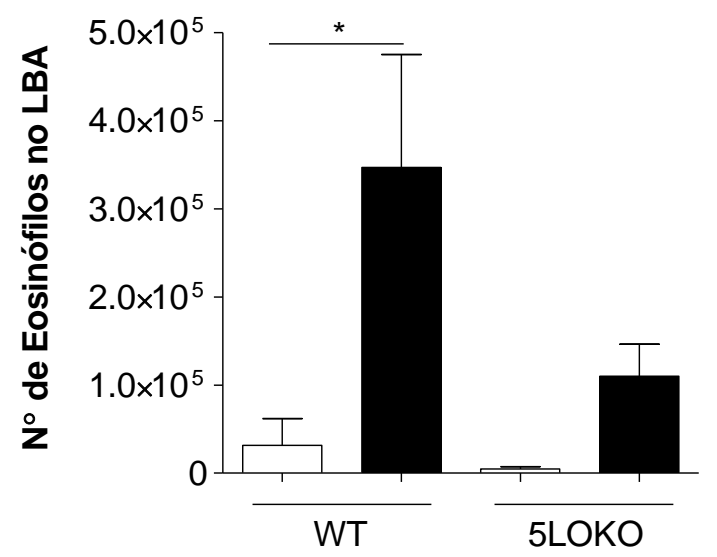

Frequência e número de eosinófilos no pulmão de animais 5LOKO. (A) Camundongos 5LOKO e 129Sv (WT) foram sensibilizados com OVA em presença do adjuvante $\mathrm{Al}(\mathrm{OH})_{3}$ pela via subcutânea (sc). Após 14 dias da primeira sensibilização, os animais foram sensibilizados novamente com OVA, pela via intraperitoneal (ip). Sete dias após a segunda sensibilização, os animais foram desafiados com OVA pela via intranasal (in). As células do LBA, coletadas três dias após o desafio com OVA, foram analisadas quanto à frequência (B) e número (C) de eosinófilos. Resultado representativo de um único experimento ( $\mathrm{n}=8-12$ animais por grupo), expressos como médias dos valores individuais \pm erro padrão. $* \mathrm{p}<0,05$. 